\title{
Manufacturing Metrology for c-Si Module Reliability and Durability Part II: Cell Manufacturing
}

Kristopher O. Davis ${ }^{1,2,3}$, Marianne P. Rodgers ${ }^{2}$, Giuseppe Scardera ${ }^{4}$, R. Paul Brooker $^{2}$, Hubert Seigneur ${ }^{1,2}$, Nahid Mohajeri ${ }^{2}$, Neelkanth G. Dhere ${ }^{2}$, John Wohlgemuth $^{5}$, Eric Schneller ${ }^{1,2}$, Narendra Shiradkar ${ }^{2}$, Andrew C. Rudack ${ }^{1,6}$, Winston V. Schoenfeld ${ }^{1,2,3}$

1. c-Si Division, U.S. Photovoltaic Manufacturing Consortium, 12354 Research Parkway - Suite 210, Orlando, FL 32826, USA

2. Florida Solar Energy Center, University of Central Florida, 1679 Clearlake Road, Cocoa, FL 32922, USA

3. CREOL, The College of Optics and Photonics, 4000 Central Florida Boulevard, Orlando, FL 32826, USA

4. DuPont Silicon Valley Technology Center, 965 East Arques Avenue, Sunnyvale, CA 94085, USA

5. National Renewable Energy Laboratory, 1617 Cole Boulevard, Golden, Co 80401, USA

6. SEMATECH, 257 Fuller Road, Albany, NY 12203 USA

Corresponding Author: Kristopher O. Davis, Kris.Davis@uspvmc.org

\section{Abstract}

This article is the second article in a three-part series dedicated to reviewing each process step in crystalline silicon (c-Si) photovoltaic (PV) module manufacturing process: feedstock and wafering, cell fabrication, and module manufacturing. The goal of these papers is to identify relevant metrology techniques that can be utilized to improve the quality and durability of the final product. The focus of this article is on the cell fabrication process. In this review, the fabrication of $\mathrm{C}-\mathrm{Si}$ PV cells is divided into four steps: (1) wet chemical processes; (2) emitter formation; (3) anti-reflection coating (ARC) and passivation deposition; and (4) metallization. Each of these processing steps can impact the final reliability and durability of PV modules deployed in the field, and here the failure modes and degradation mechanisms induced during cell manufacturing are explored. Additionally, a literature review of relevant measurement techniques aimed at reducing or eliminating the probability of such failures occurring is presented along with an assessment of potential gaps wherein the PV community could benefit from new research and demonstration efforts.

Keywords: silicon solar cells, photovoltaic module, manufacturing, reliability, durability, metrology

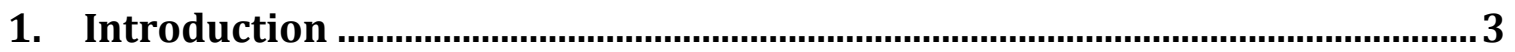

2. Wet chemical processes ..................................................................................

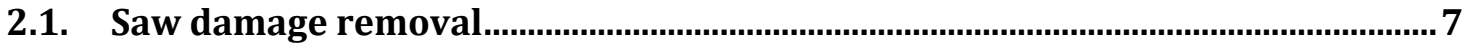


2.1.1. Background ......................................................................................................................

2.1.2. Failure modes related to saw damage removal ...........................................................

2.1.3. Metrology techniques relevant to saw damage removal.............................................

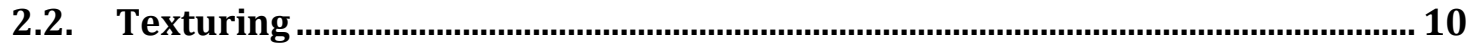

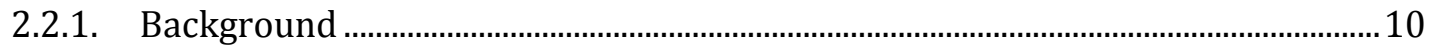

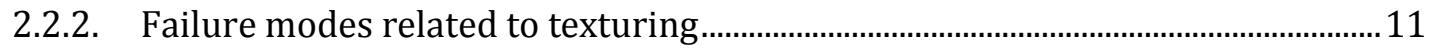

2.2.3. Metrology techniques relevant to texturing ............................................................. 11

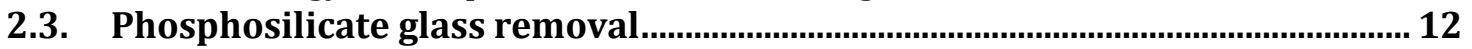

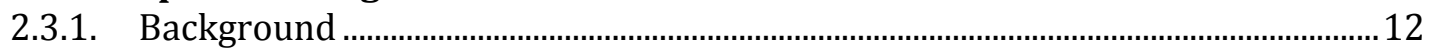

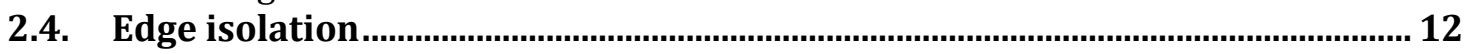

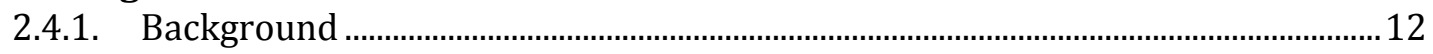

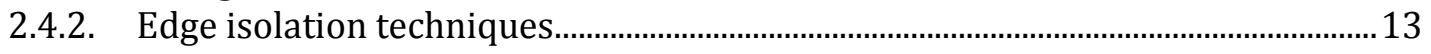

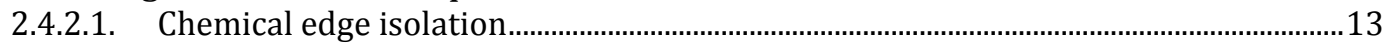

2.4.2.2. Plasma edge isolation.........................................................................................................

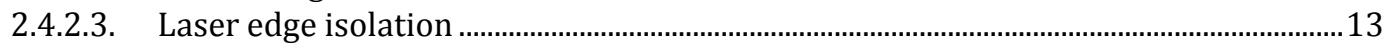

2.4.3. Failure modes related to edge isolation .................................................................... 14

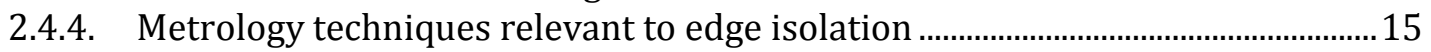

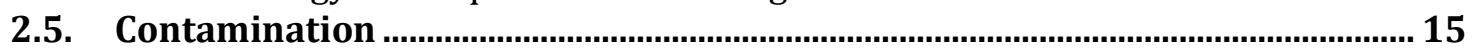

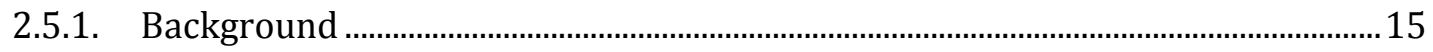

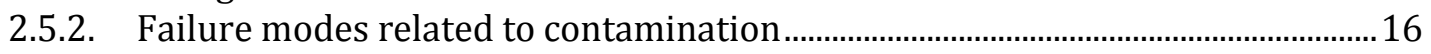

2.5.3. Metrology related to contamination ......................................................................... 16

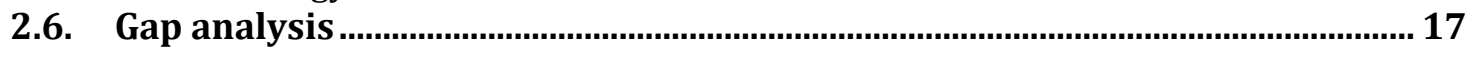

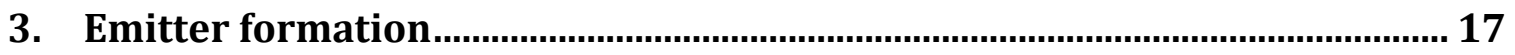

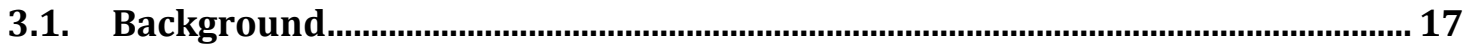

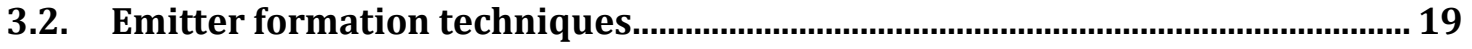

3.2.1. $\mathrm{POCl}_{3}$ diffusion ................................................................................................... 19

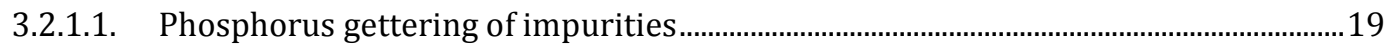

3.2.1.2. Recent advances in $\mathrm{POCl}_{3}$ emitter processing ............................................................20

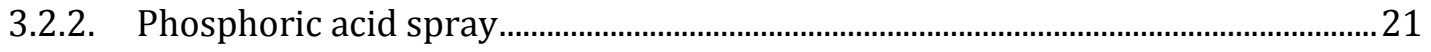

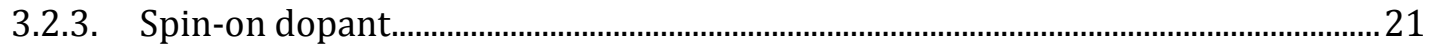

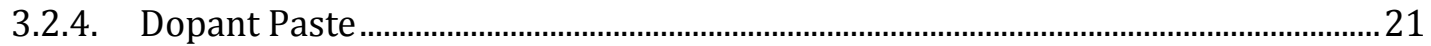

3.2.5. Plasma enhanced chemical vapor deposition .......................................................22

3.2.6. Atmospheric pressure chemical vapor deposition ....................................................... 22

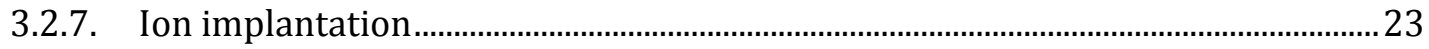

3.2.7.1. Recent advances in ion implanted emitter processing .................................................2

3.2.7.2. Outlook for ion implantation .......................................................................................... 24

3.3. Failure modes and degradation mechanisms related to emitter formation.. 25

3.3.1. Shunts, junction pre-breakdown and hot-spots......................................................... 25

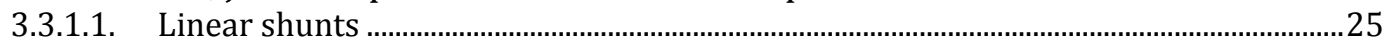

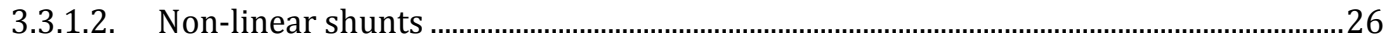

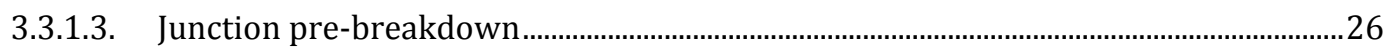

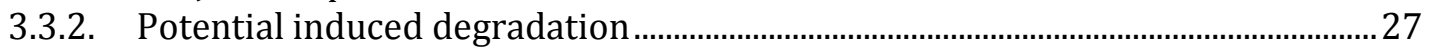

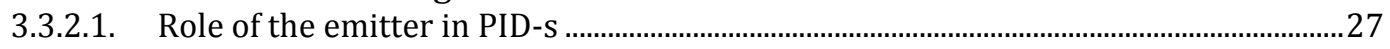

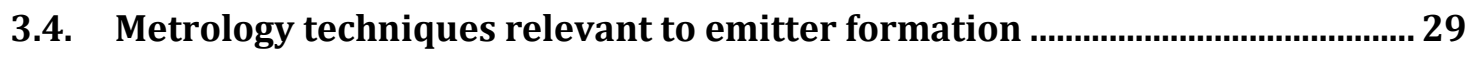

3.4.1. Shunts and junction pre-breakdown metrology.......................................................29

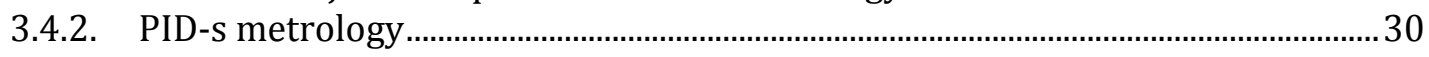

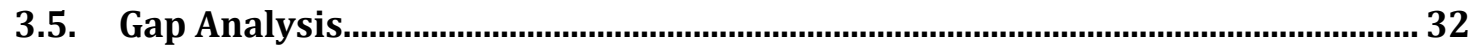

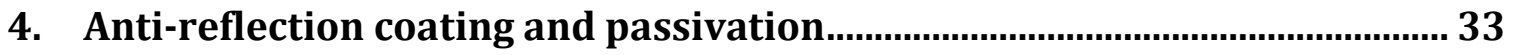

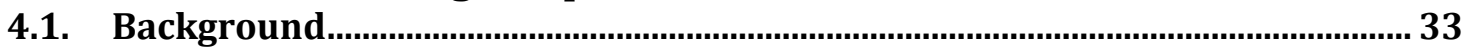

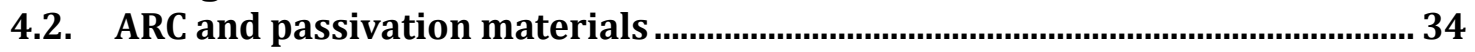




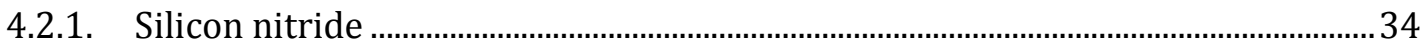

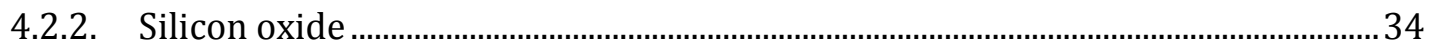

4.2.3. Titanium oxide ............................................................................................................

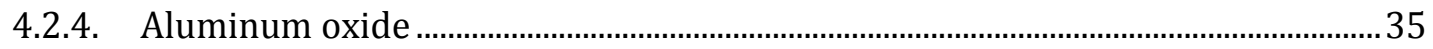

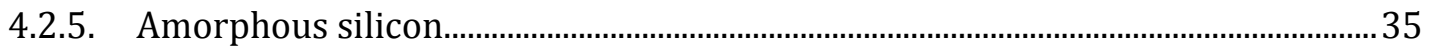

4.2.6. Hafnium oxide........................................................................................................... 36

4.3. Failure modes and degradation mechanisms related to ARC and passivation 36

4.3.1. Potential induced degradation ......................................................................................36

4.3.2. Induced mechanical stress..........................................................................................36

4.3.3. Blistering ...........................................................................................................

4.3.4. Background plating and pinhole formation..................................................................37

4.4. Metrology techniques relevant to ARC and passivation ....................................... 37

4.5. Gap Analysis............................................................................................ 40

5. Metallization....................................................................................... 40

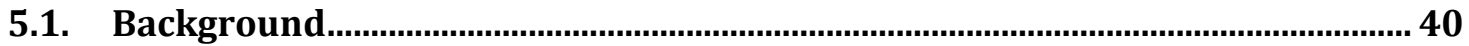

5.1.1. Back contact metallization ..........................................................................................4 41

5.1.2. Front side metallization ............................................................................................. 42

5.1.3. Alternative metallization technologies ...................................................................4 43

5.2. Failure modes related to metallization ................................................................ 43

5.2.1. Screen-printing irregularities......................................................................................4

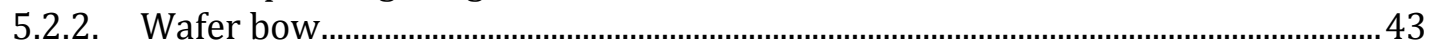

5.2.3. Micro-crack failure mode ............................................................................................. 44

5.2.4. Over firing (emitter/junction damage) ......................................................................4 44

5.3. Metrology techniques relevant to metallization .................................................... 44

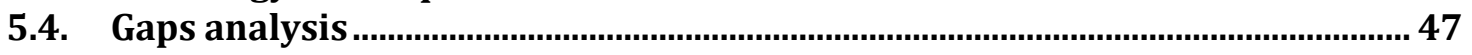

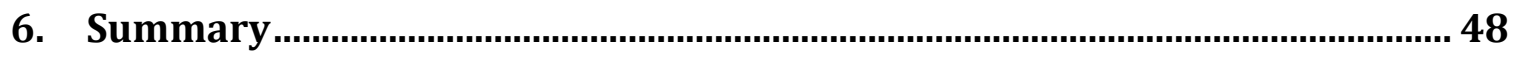

6.1. Wet chemical processes ............................................................................ 48

6.2. Emitter formation........................................................................................... 48

6.3. Anti-reflection coating and passivation …….....................................................48

6.4. Metallization.................................................................................................. 49

7. Conclusion ......................................................................................... 49

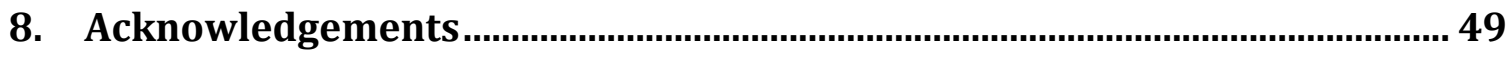

\section{Introduction}

With an increased attention to the environment and the limited supply of fossil fuels, production of electricity through harnessing of renewable energy sources is critical to meeting future energy demands. Although energy needs will likely be met through a variety of renewable sources, electricity produced through solar photovoltaics (PV) will be a significant contributor. In order to make this technology cost effective, PV module output must maintain high performance for long periods of time (i.e., over 25 years). By increasing the lifetime of the PV module, the levelized cost of electricity (LCOE) will decrease.

It has been well documented that the production of a PV module will decrease over time, due to several degradation modes. These modes exist at various 
points within the module, including the impurities within the silicon of the solar wafer, or the flexibility of the encapsulant around the cells, or the solder bond adhesion between the cell and the ribbon, to name a few.

This is the second article in a three-part series regarding identifying degradation modes during PV module production. The three broad steps covered by this paper series are shown schematically in Figure 1. In this paper, potential failure modes and degradation mechanisms induced during $\mathrm{c}-\mathrm{Si} \mathrm{PV}$ cell manufacturing will be overviewed, along with relevant measurement techniques aimed at reducing or eliminating the probability of such failures occurring. The goals of this work are to:

1. Identify known failure modes and degradation mechanisms induced during manufacturing

2. Provide a review of the current state of manufacturing metrology for improved PV reliability and durability

3. Perform a gap analysis and identify where improvements can be made

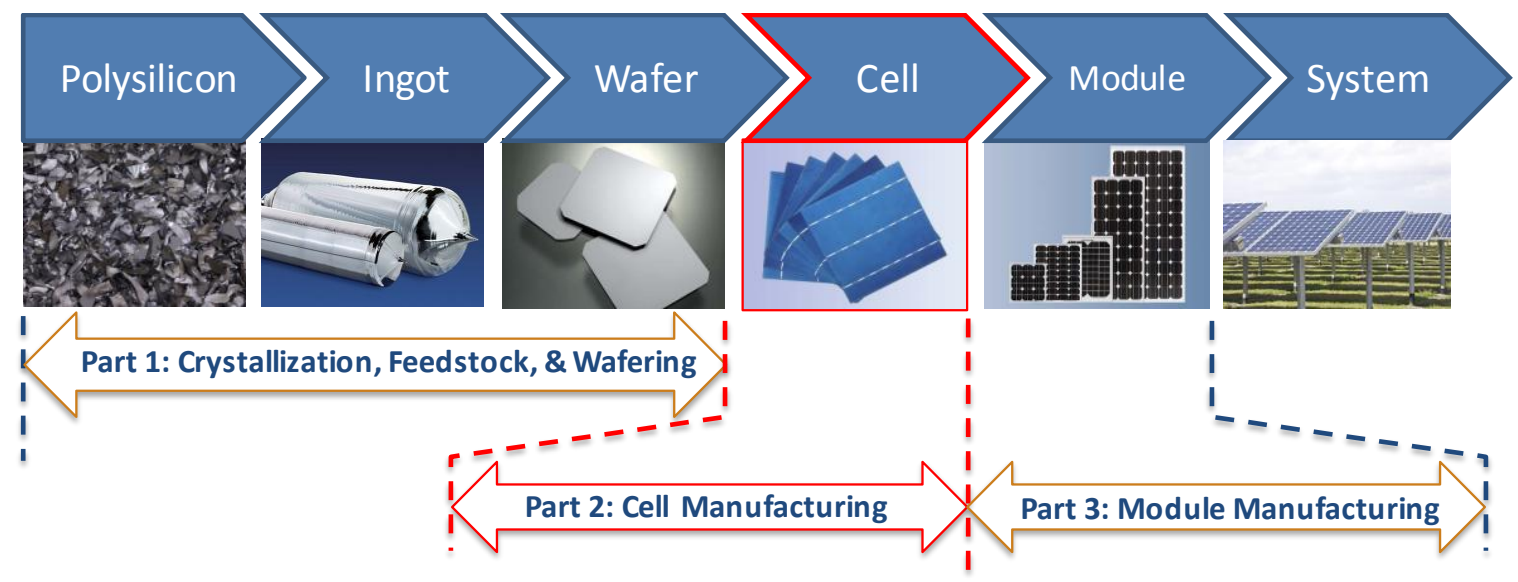

Figure 1. Schematic depiction of c-Si PV manufacturing production areas across the supply chain and highlighting cell manufacturing as the focus of this article.

In this review, the focus is on $156 \mathrm{~mm} \times 156 \mathrm{~mm}$ Al-BSF cells with screenprinted contacts and $\mathrm{SiN}_{\mathrm{x}} \mathrm{ARC}$ and passivation layer deposited by plasmaenhanced chemical vapor deposition (PECVD). The conversion of incoming $p$ type crystalline silicon (c-Si) wafers into Al back surface field (Al-BSF) photovoltaic (PV) cells can be divided into four primary process areas: (1) wet chemical processes; (2) emitter formation (e.g., P diffusion); (3) anti-reflection coating (ARC) and passivation deposition (e.g., PECVD $\mathrm{SiN}_{\mathrm{x}}$ ); and (4) metallization (e.g., screen-printing and co-firing of the $\mathrm{Ag}$ front and $\mathrm{Al}$ rear contacts). The process flow for cell manufacturing is depicted in Figure 2. Several wet chemical processes are carried out after wafer production, including post-wafering cleaning (i.e., saw damage removal), texturing, edge isolation, and phosphosilicate glass (PSG) removal. The emitter, or $p$ - $n$ junction, is the heart of c-Si solar cells. For industrial Al-BSF cells, the emitter is typically created by high 
temperature diffusion of phosphorus into the crystal lattice. Dielectric films act as ARCs and passivation layers in $\mathrm{C}-\mathrm{Si}$ cells. ARCs reduce the front surface reflectance of $\mathrm{c}$-Si cells, while passivation layers reduce recombination losses, improving cell efficiency. Often, a material that can both provide passivation and act as an ARC is used. To ensure efficient extraction of photogenerated carriers, metallization must provide good electrical contact with low interfacial recombination velocity between the silicon wafer and metal contacts. Metallization is performed on both the front and rear sides of the cell, with each side having different requirements. For example, the front of the cell must remain as open to light as possible, while the rear of the cell may be completely covered.

This paper will describe each of the foregoing steps in detail, as well as provide potential degradation modes that could be introduced during each step. Techniques for measuring these "degradation enhancers" will also be presented. For readers interested more in trends in c-Si cell manufacturing and different cell architectures, the following references are recommended [1-16].. 
Wafer Inspection

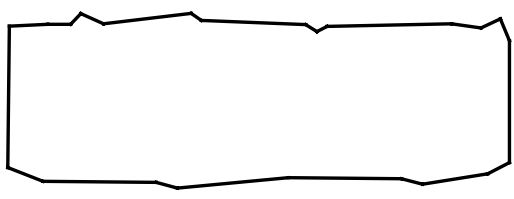

Saw Damage Removal

$\mathrm{p}-\mathrm{Si}$

Texturing



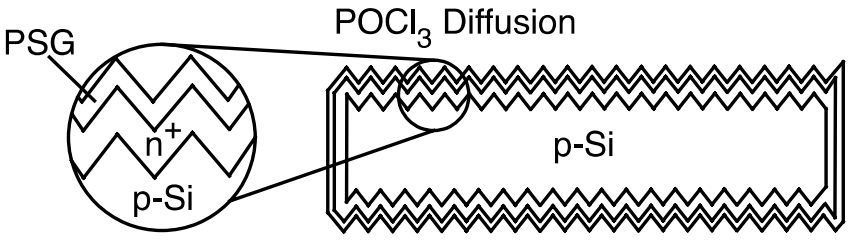

$\mathrm{n}^{+} \quad$ PSG Removal \& Edge Isolation

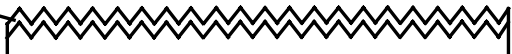

$\mathrm{p}-\mathrm{Si}$
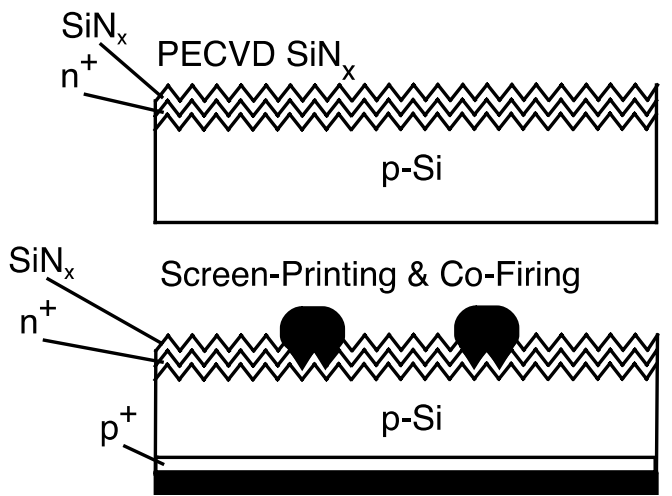

Figure 2. Typical cell manufacturing process flow for industrial Al-BSF solar cells.

\section{Wet chemical processes}

Following wafer production, several wet chemical processes are performed on the wafers and are commonly the first steps taken during cell manufacturing. The key steps that currently use wet chemistry processing in C-Si solar cells include: post-wafering cleaning (i.e., saw damage removal), texturing, PSG removal and edge isolation. Several of these steps can impact the reliability and durability of the finished PV module in various ways, a summary of which can be found in Table 1. 


\subsection{Saw damage removal}

\subsubsection{Background}

After the sawing process is performed to create Si wafers, the wafer surface is damaged and can include organic and inorganic contaminants, particularly when free abrasive slurry-based wire sawing is used [17]. Wafer breakage is believed to often be related to micro-cracks ( $\mu$-cracks) created in the sawing operation [18]. Therefore, an etching and cleaning process is used to remove saw damage and contaminants before proceeding with cell fabrication.

After the free abrasive wafering step, the silicon carbide ( $\mathrm{SiC}$ ) slurry must be removed from the sliced ingot (e.g., via a spraying process), followed by the use of a solvent (or heat [19]) to release the wafers from the adhesive on the mounting plate [20]. A wide array of different chemistries (e.g., water, surfactants, solvents, acids, alkalis) are used to remove the contamination introduced during wafering, examples of which include excessive dried SiC slurry and residual metals and metal oxides from the wire during wafering [20].

While free abrasive slurry-based wire sawing has been the dominant wafering technology for the c-Si PV industry [18, 21], fixed abrasive diamond wire sawing is expected to increase market share significantly, particularly for monocrystalline $\mathrm{Si}$, due to its potential for high productivity and improved materials utilization [1, 22]. These two types of sawing operations result in different types of wafer damage that can be observed using multiple metrology techniques. With transmission electron microscopy (TEM) images, Holt et al. [23] observed the presence of $\mu$-cracks distributed inward from the wafer surface as deep as $4 \mu \mathrm{m}$ after slurry-based wire sawing. In the fixed abrasive sawing cut wafer, $\mu$-cracks were not present, but a defective region up to $2 \mu \mathrm{m}$ deep was observed [23]. Using optical microscopy, Wu et al. found that fixed abrasive diamond wire cut wafers featured a higher crack density than free abrasive slurry cut wafers, although the crack length was smaller for the diamond wire cut wafers. For slurry cut wafers, cracks were found to be longer in wafers cut by larger grits [24]. Atomic force microscopy (AFM) and scanning electron microscopy (SEM) images showed a lower surface roughness for the fixed abrasively sawn wafers compared to the wafers cut through free abrasive sawing [23]. This lower surface roughness was maintained throughout the entire etch process [25].

Not only is the type of wafer damage dependent on the sawing procedure used, as indicated above, but also on the process conditions (i.e., the ratio of feed speed to wire speed, wire type, diamond grit sizes, and the effects of different vibration modes during the cutting process) [26]). Increasing the feed speed proportionally with respect to the wire speed allows for an increase in productivity without inducing more roughness damage [26].

The temperature variation from the start of the saw run until the maximum temperature is reached has been estimated at about $50^{\circ} \mathrm{C}$, while the temperature difference from wire entrance to wire exit after reaching stable sawing conditions is about $20^{\circ} \mathrm{C}$. During block sawing, the produced heat can lead to thermallyinduced stresses which, in addition to the sawing forces, can contribute to the initiation and propagation of cracks [27]. Additionally, it is claimed that wafer warp 
and bow can be caused by undesirable temperature variation during slicing [28, 29]. However, to avoid this large temperature difference, water or coolant is typically sprayed over the silicon ingot during cutting, which eliminates these issues.

Saw damage is commonly removed by wet chemical etching. Two types of chemical solutions are used for this purpose:

- Acidic etching: using a mixture of nitric acid $\left(\mathrm{HNO}_{3}\right)$, hydrofluoric acid (HF), and acetic acid $\left(\mathrm{CH}_{3} \mathrm{COOH}\right)[30]$

- Alkaline etching: using mixture of potassium hydroxide $(\mathrm{KOH})$ or sodium hydroxide $(\mathrm{NaOH})$ with water [30].

Etching of Si involves oxidation of the silicon followed by the dissolution of the oxidant product. Normally, acidic etching is carried out below room temperature. For commercial applications, alkaline etching is mainly used for both saw damage removal and surface texturing of monocrystalline wafers [30].

In acidic etching, the $\mathrm{HNO}_{3}$ is the oxidant and $\mathrm{HF}$ acid dissolves the oxidized product. The acetic acid is used to prevent $\mathrm{HNO}_{3}$ dissociation and facilitate wetting of the Si wafer surface, thereby improving etch quality [31]. The overall etching reaction can be given by the following reaction [30]:

$$
3 \mathrm{Si}+4 \mathrm{HNO}_{3}+18 \mathrm{HF} \rightarrow 3 \mathrm{H}_{2} \mathrm{SiF}_{6}+4 \mathrm{NO}+8 \mathrm{H}_{2} \mathrm{O}
$$

Alkaline etching takes place in about $25 \mathrm{wt} \%$ to $45 \mathrm{wt} \% \mathrm{KOH}$ (or $\mathrm{NaOH}$ ) and the balance of $\mathrm{H}_{2} \mathrm{O}$ solution at temperatures between $70^{\circ} \mathrm{C}$ and $90^{\circ} \mathrm{C}$. The overall etching reaction can be given by the following reaction [30,32]:

$$
2 \mathrm{KOH}+\mathrm{Si}+\mathrm{H}_{2} \mathrm{O} \rightarrow \mathrm{K}_{2} \mathrm{SiO}_{3}+\mathrm{H}_{2}
$$

Rather than using large quantities of wet chemicals, it is also possible to use a fast dry etching method: plasma etching with dry process gases, such as $\mathrm{SF}_{6}$ or $\mathrm{CF}_{4}$ [33]. Saw damage removal by plasma etching can be carried out, theoretically, through adapting a system that has been designed for use in edge isolation by adjusting the combination of process gases. The highly reactive radicals produced by the microwave plasma source during plasma saw damage removal results in greatly increased mechanical stability of the wafer. The radicals are much smaller than water-immersed ions and can, therefore, penetrate into the smallest $\mu$-cracks [33]. However, due to the complexity of the plasma reaction with the silicon surface, it is challenging to carry out this technique in mass production.

\subsubsection{Failure modes related to saw damage removal}

Saw marks are very harmful to cell performance [34] and could potentially lead to reliability issues if the damage isn't completely removed during cell manufacturing. Obvious manifestations of this include the formation of $\mu$-cracks, propagation of surface cracks or high levels of mechanical stress, all of which could result in macroscopic cracks within the cell. Additionally, latent stresses around saw marks can facilitate the formation of crystallographic defects (e.g., 
stacking faults, dislocations) during subsequent thermal treatments [35]. As reported by Dekkers et al. [36], small defects can result in blistering at the $\mathrm{Si}$ surface. The small blisters result from $\mathrm{H}$ aggregation, which is induced by the interaction of $\mathrm{H}$ and the defects. Blisters typically only form on saw-damaged material, especially on multicrystalline $\mathrm{Si}[35,36]$ and, in the worst case, can cause the $\mathrm{SiN}_{\mathrm{x}}$ layer to peel off.

\subsubsection{Metrology techniques relevant to saw damage removal}

TEM [23], resonance ultrasonic vibrations (RUV) [37, 38], and scanning acoustic microscopy (SAM) $[37,38]$ can be used to observe $\mu$-cracks. AFM, SEM, confocal microscopy, and optical profilometry can be used to observe surface roughness after sawing [23]. Wafers with $\mu$-cracks can also be detected and removed from the production lines using a wafer screening furnace [39]. Optical microscopy can identify surface cracks. Mechanical strength and stress can be determined using Raman Spectroscopy, IR polariscopy [40], and a twist or four-point bending method. Optical methods can be used to measure the amount of bowing present in a wafer.

\begin{tabular}{|c|c|c|c|}
\hline $\begin{array}{l}\text { Process } \\
\text { Step }\end{array}$ & $\begin{array}{c}\text { Failure Mode } \\
\text { or Degradation } \\
\text { Type }\end{array}$ & Mechanism(s) & Metrology Method(s) \\
\hline \multirow{5}{*}{$\begin{array}{l}\text { Saw damage } \\
\text { removal }\end{array}$} & \multirow{4}{*}{ Cracking } & $\begin{array}{l}\mu \text {-cracks formed during } \\
\text { wafering }\end{array}$ & $\begin{array}{l}\text { Resonance ultrasonic vibration (RUV) } \\
{[37,38]} \\
\text { Scanning acoustic microscopy (SAM) } \\
{[37,38]} \\
\text { Transmission electron microscopy [23, } \\
41] \\
\text { Angle polishing followed by defect } \\
\text { etching [42] }\end{array}$ \\
\hline & & $\begin{array}{l}\text { Insufficient saw damage } \\
\text { removal }\end{array}$ & $\begin{array}{l}\text { Atomic force microscopy (AFM) [23, } \\
43] \\
\text { Scanning electron microscopy (SEM) } \\
{[23,41,44,45]} \\
\text { Confocal microscopy [46-48] } \\
\text { Optical profilometry [18] }\end{array}$ \\
\hline & & $\begin{array}{l}\text { Compromised } \\
\text { mechanical strength or } \\
\text { excessive stress }\end{array}$ & $\begin{array}{l}\text { Infrared polariscopy [40] } \\
\text { Raman spectroscopy }[48] \\
\text { Four-point bend testing }[46,48,49] \\
\text { Wafer bow measurement }\end{array}$ \\
\hline & & $\begin{array}{l}\text { Propagation of surface } \\
\text { cracks }\end{array}$ & $\begin{array}{l}\text { RUV }[37,38] \\
\text { SAM }[23] \\
\text { Optical microscopy }[24,34,49]\end{array}$ \\
\hline & Blistering & $\begin{array}{l}\mathrm{H} \text { aggregation } \\
\text { interaction with } \\
\text { damage defects }\end{array}$ & $\begin{array}{l}\text { SEM } \\
\text { Optical microscopy }\end{array}$ \\
\hline Texturing & $\begin{array}{l}\text { Pre-breakdown } \\
\text { [50] }\end{array}$ & $\begin{array}{l}\text { Trench structure or etch } \\
\text { pit formation [43] }\end{array}$ & $\begin{array}{l}\text { AFM }[23,43] \\
\text { SEM }[23,41,44,45] \\
\text { Confocal microscopy [46-48] } \\
\text { Color vision system [43] } \\
\text { Dark lock-in thermography (DLIT) [41, } \\
50] \\
\text { Electroluminescence (EL) imaging [41, }\end{array}$ \\
\hline
\end{tabular}




\begin{tabular}{|c|c|c|c|}
\hline & & & $\begin{array}{l}48,50] \\
\text { Light or dark current-voltage }(I-V)[49] \\
\text { Electron beam-induced current (EBIC) } \\
{[41]}\end{array}$ \\
\hline \multirow{3}{*}{$\begin{array}{l}\text { Edge } \\
\text { Isolation }\end{array}$} & \multirow{3}{*}{ Shunting } & $\begin{array}{l}\text { Incomplete electrical } \\
\text { isolation of the } n^{+} \text {emitter } \\
\text { from the rear Al contact } \\
\text { during chemical, plasma- } \\
\text { based or laser edge } \\
\text { isolation }\end{array}$ & $\begin{array}{l}\text { DLIT } \\
\text { Photoluminescence }(\mathrm{PL}) \text { imaging } \\
\text { Light or dark } I-V\end{array}$ \\
\hline & & $\begin{array}{l}\text { Scratching of the wafer } \\
\text { surface during stacking }\end{array}$ & $\begin{array}{l}\text { SEM } \\
\text { Optical microscopy }\end{array}$ \\
\hline & & $\begin{array}{l}\text { Emitter drive-in as a } \\
\text { byproduct of laser edge } \\
\text { isolation }[44,51]\end{array}$ & $\begin{array}{l}\text { Electron backscatter diffraction (EBSD) } \\
\text { [44] } \\
\text { Scanning conductive microscopy [44] } \\
\text { Conductive AFM (C-AFM) [44] }\end{array}$ \\
\hline
\end{tabular}

Table 1. Failure modes, mechanisms and relevant metrology methods related to wet chemical processes.

\subsection{Texturing}

\subsubsection{Background}

The next step after cleaning is wafer texturing, which is primarily used to reduce the front surface reflectance and improve light trapping, but also removes any residual saw damage [20]. For monocrystalline wafers, a blend of an alkaline etchant, like $\mathrm{KOH}, \mathrm{NaOH}$, or tetramethylammonium hydroxide $(\mathrm{TMAH})$, and isopropanol (IPA) are typically used by industry to form random upright pyramids. The alkaline etchant provides the anisotropic etching along the $\{100\}$ plane of the silicon crystal, which exposes the $\{111\}$ plane. The etch rate in the $\langle 100\rangle$ direction is much faster than $<111>$ direction as the $<111>$ plane shows a very high atomic packing density. Therefore, when the slow etching planes, (111) orientation, are exposed, they intersect at the surface to form square based upright pyramids of random size, which are distributed randomly on the surface. The role of the IPA is to aid in controlling the alkaline etch rate and selectivity to the $\{111\}$ crystal plane, which also helps in the formation of the random pyramid structure [52]. Balancing the etch rate with pyramid formation is important to ensure that enough silicon is removed to optimize saw damage removal (typically $>6 \mu \mathrm{m}$ per side), while maintaining the appropriate height, base width and period of the pyramids to minimize front surface reflectance without increasing surface recombination [20]. The characteristic size of these textures is typically 3-10 $\mu \mathrm{m}$ and it has been shown that decreasing pyramid height and a uniform distribution of the size of the pyramids is advantageous in decreasing reflectance [53].

Texturing of multicrystalline $\mathrm{Si}$ wafers requires an etching solution that provides an isotropic etch, since many different Si crystal orientations are present on a single wafer [54,55]. A nitric acid $\left(\mathrm{HNO}_{3}\right)$ and hydrofluoric acid (HF) mixture are commonly used to carry out this "isotexture" process [55]. $\mathrm{HNO}_{3}$ oxidizes the Si surface while HF dissolves the silicon oxide and performs the bulk etching of the wafer [20]. In both the alkaline and acidic ("isotexture") processes, a final hydrochloric $(\mathrm{HCl})$ rinse is performed to remove potential metal ion contamination prior to emitter formation [20]. 
Different surface structures created during each sawing process (i.e., fixed abrasive diamond wire sawing and free abrasive SiC slurry-based sawing) can behave like masks during chemical etching, impacting the sites where the chemical etching preferentially occurs. Moreover, it has been shown that the specific features of these mask-like surface structures introduced by the wafer sawing process may not be changed during etching [25]. Etch mixtures and parameters (e.g., etch time, temperature) optimized for the etching of slurry wire sawn wafers are not suitable for a successful texturing of diamond wire sawn wafers. Modification of traditional etch mixtures and process parameters used for slurry cut wafers to accommodate diamond wire sawn wafers may impact other parameters, which could impact reliability [25].

Reactive-ion-etching (RIE) is an alternative method of texturing both monocrystalline and multicrystalline Si wafers [56]. Due to the use of plasma source generated by high power, the wafer surface is physically damaged during this texturing process, which can result in the need to perform an additional damage removal step [56]. However, a self-masking RIE process has demonstrated the ability to remove surface damage induced during RIE in situ, eliminating the need for additional wet chemical damage removal step [56].

\subsubsection{Failure modes related to texturing}

Rough surfaces with strong etch attacks (trench structures or etch pits) can be formed during acidic texturing of multicrystalline Si wafers, particularly at locations featuring crystallographic defects [43]. Trench structures present on the wafer surface have been demonstrated to be harmful to cell performance.

It has been suggested that etch pits cause pre-breakdown, which is an important phenomenon in partially shaded PV modules [50]. Shaded cells in a module become reverse biased. Reverse bias operation can not only decrease module output power and increase the cell operating temperature, but can also concentrate the reverse current within a small area in the cell wherein the power dissipation can result in local destruction of the $p-n$ junction. Conventional encapsulation materials can be destroyed by excessive heat, so the reverse breakdown voltage is particularly important for cells encapsulated within a module operating in the field [43]. Etch pits are known to be the primary cause of these hot spots and should be avoided by adjusting the etching parameters [41]. Trench structures can also influence the reverse breakdown voltage because of an electric field effect caused by their tapering morphology [43]. By comparing cells textured using both alkaline and acidic processes, Lausch et al. have shown that proper surface preparation does not lead to pre-breakdown sites, and that they are instead determined by the bulk (multicrystalline) structure itself [50]. However, acidic texturized cells exhibit pre-breakdown at lower voltages compared to alkaline texturized cells. Therefore, the texturing process does influence the voltage at which pre-breakdown occurs through field enhancement at etch pits [50].

\subsubsection{Metrology techniques relevant to texturing}

Several methods have been used to examine the wafer surface for trench structures. SEM and TEM have been used to view trench structures [41]. While 
electron microscopy methods are off-line and destructive, in-line non-destructive methods have also been used to view trench structures. In one method, the wafer is scanned through a diffusion foil that lies on a flatbed scanner [43]. Another method used to examine trench structures is based on an in-line color vision system [43].

Researchers at NREL $[57,58]$ have developed an online high-speed reflectance mapping system for monitoring many different wafer and cell parameters using spectral reflectance. Parameters monitored include surface roughness, cutting irregularities, texture quality and uniformity, ARC thickness and uniformity, and metallization parameters.

Once samples have been made into complete cells with contacts, breakdown voltage can be measured using dark current-voltage (I-V) [50] and several methods have been used to observe the locations of the pre-breakdown sites. Locations of pre-breakdown sites can be viewed as bright spots using dark lock in thermography (DLIT) and, with higher spatial resolution, using reversebiased electroluminescence (EL) [41, 50]. However, conventional reverse-bias EL investigations cannot distinguish between different types of breakdown sites, so electron beam-induced current (EBIC) measurements at various reverse voltages have been used for a microscopic investigation of areas showing carrier multiplication [41].

\subsection{Phosphosilicate glass removal}

\subsubsection{Background}

Diffusion of $\mathrm{P}$ into the $\mathrm{Si}$ lattice is the most common technique to make a $p-n$ junction [30]. PSG is formed on the surface of the wafer during the diffusion process. This PSG can act as a recombination center for charge carriers and can negatively impact the front surface reflectance of the cell (compared to a single $\mathrm{SiN}_{\mathrm{x}} \mathrm{ARC}$ ) and is normally removed. This oxide removal step is commonly achieved using a dilute HF acid solution, which selectively removes PSG without etching the underlying emitter layer (i.e., self-limiting). Subsequent cleaning of the wafers surface may follow to ensure the surface is completely free of any residual PSG and HF, the latter of which is severely detrimental to screen printed paste [20]. Richter et al. found that PSG layers can entrap metal ion contaminants and provide a gettering function during in-line P diffusion [59]. It is unclear at this time whether or not the PSG removal step during cell manufacturing can lead to potential failure or accelerate degradation of PV modules installed in the field outside of the introduction of potential contaminants (which can be introduced in any wet chemical process).

\subsection{Edge isolation}

\subsubsection{Background}

Edge isolation of the $p-n$ junction is a critical step for the fabrication of c-Si cells to ensure the electrical isolation of the $n^{+}$emitter on the front surface from the rear Al contact layer. After diffusion, a thin $n^{+}$doped emitter layer can be present on both sides and/or on the edges of the wafer. The front and the back contacts are connected to the $n^{+}$around the edge, which results in shunts (a 
shunt is an unwanted short-circuit between the front and back surface contacts of a solar cell). The front and back contacts must be isolated to prevent shortcircuiting of the solar cell. The purpose of the edge isolation process is to remove the $\mathrm{P}$ diffused regions $\left(n^{+}\right.$layer) around the edge of the cell to provide electrical isolation of the cell's front and rear contacts. Some cell architectures, like the $p$ type passivated emitter and rear cell (pPERC) also require removal of the rear $n^{+}$ layer.

\subsubsection{Edge isolation techniques}

\subsubsection{Chemical edge isolation}

In wet chemical edge isolation process, the $\mathrm{P}$ diffused edges and rear side of the wafer are removed following diffusion via etching. An etch bath is designed such that only one side and the edges of the wafers come in contact with the etching solution. The depth and speed of the etching process can be varied by modifying the wafer transport velocity, etching bath concentration, and temperature [60]. Chemical edge isolation completely removes the rear $n^{+}$emitter and doesn't cause any reduction in the size of the active front emitter region [61]. There is no loss in active cell area because this technique removes only $5 \mu \mathrm{m}$ from the edges and rear side [60]. The front side of the wafer does not come in contact with the etching chemistry and is, therefore, not damaged [60].

\subsubsection{Plasma edge isolation}

A common way to achieve electrical isolation of the front emitter from the cell rear is to stack the wafers on top of each other, place the stack in a vacuum chamber, then plasma etch using $\mathrm{CF}_{4}$ and $\mathrm{O}_{2}$ [60]. Typically $2 \mu \mathrm{m}$ to $5 \mu \mathrm{m}$ of material is removed from the edge of the cells. Plasma edge isolation is common because the stacking method ensures high throughput and low cost per wafer [60]. This method also avoids handling of dangerous chemicals, produces less $\mathrm{Si}$ waste, and ensures larger active areas in the solar cells [60]. However, edge isolation using a plasma-based method has several drawbacks that make it a less desirable process step. Because it is a batch process and not an in-line process, the manufacturing process flow is interrupted and the wafers must be handled more frequently. The potential for cracking and wafer breakage is therefore increased due to the increased wafer handling and the mechanical stresses induced on the wafers during the actual plasma etching process [60]. This method of edge junction isolation also fails to remove the $n^{+}$emitter from the rear side of cells.

\subsubsection{Laser edge isolation}

The laser edge isolation of solar cells is a process involving melting and evaporating material to remove the edge shunt pathway by scribing the cells with a laser beam. A laser-scribed thin groove through the $n^{+}$to $p$-type layer along the edges can electrically isolate the front emitter. Typically, the groove is $\approx 10-20 \mu \mathrm{m}$ deep and less than $20 \mu \mathrm{m}$ wide [60]. The edge isolation step is typically performed after metallization to avoid losing the isolation due to the thermal treatment. However, some researchers altered the order of process steps so that $\mathrm{SiN}_{\mathrm{x}}$ deposition was carried out after the laser edge isolation so that the $\mathrm{SiN}_{\mathrm{x}}$ 
deposition passivates the laser-induced damage [62]. Kray et al. demonstrated successful edge isolation using a waterjet-guided laser, resulting in a more homogeneous groove than dry laser processes [49].

To reduce the cost of $\mathrm{Si}$ in c-Si-based solar cell manufacturing, industry is trending towards the production of thinner wafers, while still retaining the relatively large areas used today in production $(156 \mathrm{~mm} \times 156 \mathrm{~mm})$. Since thinner and larger wafers are more fragile and mechanically vulnerable, the noncontact nature of laser edge isolation processes offers profound benefits versus any contact-based alternative. In addition, the laser processing is fast, easy to align, and does not require chemicals [60]. However, similar to plasma edge isolation, laser edge isolation does not remove the $n^{+}$emitter from the rear side of cells.

\subsubsection{Failure modes related to edge isolation}

Besides the induced stress due to handling, other potential reliability and durability issues may arise from the plasma-based method for edge isolation. Scratching of surfaces during stacking can lead to shunting, for example. Plasma-based edge isolation can also remove some of the $\mathrm{SiN}_{\mathrm{X}}$ around the edge of the cell when performed after ARC deposition, which compromises surface passivation around the perimeter of the cells [60].

The laser edge isolation method offers several drawbacks that could lead to module failure in the field. Due to the thermal effect of nanosecond laser pulses, Si melting occurs during scribing. This melting causes an undesired effect known as emitter drive-in, which is a result of laser ablation stimulating $P$ atoms to go further underneath the isolation groove. This is why, although the P-doped $n^{+}$ emitter layer is only about $0.3 \mu \mathrm{m}$ deep, the grooves made by nanosecond laser ablation have to be about $30 \mu \mathrm{m}$ deep to overcome emitter drive-in effect [44, 51]. Jiang et al. [44] also observed that a portion of the ablated or molten material was redeposited or recrystallized, forming $a \approx 2-4 \mu \mathrm{m}$-wide stripe on top of the $n^{+}$ region in the groove. The stripe formed a raised fringe on the edge of the groove and was doped with $\mathrm{P}$, but featuring different doping concentrations than the original and remaining emitters. There were also some $n$-type doped particles on top of the recrystallized stripes [44]. Sedao et al. [51] used new generation ultrashort picosecond lasers with high pulse repetition rates, which can ablate material while minimizing melting, thereby minimizing the thermal impact of the process. Using these new generation lasers, the isolation grooves scribed were reduced to $4 \mu \mathrm{m}$ deep [51]. In the Saturn process, BP Solar overcame the residual shunt leftover from the scribing by breaking off the outer edge of the solar cell after scribing. However, this process is costly and has a low yield.

Photoluminescence (PL) images have indicated that laser edge junction isolation can cause substantial damage extending several millimeters inside of the ablated groove. This can reduced active emitter area along with an area of reduced voltage. On cells featuring plated contacts, regions of high series resistance and shunting were found to be caused by parasitic plating nucleating in the damaged laser grooved region [61]. 


\subsubsection{Metrology techniques relevant to edge isolation}

Several different metrology methods have been used to observe the different failure modes as a result of edge junction isolation. Time-resolved or lock in thermography (LIT) can be used to show areas of shunting due to improper edge isolation. An example of this is shown in Figure 3. Atomic force microscopy (AFM) and optical imaging show the size of the grooves [44]. Electron backscatter diffraction (EBSD) can be used to investigate the local crystalline structure in the groove area [44]. Scanning conductive microscopy and conductive atomic force microscopy (C-AFM) show localization of electrical properties of the surface [44]. Scratching of the surface and $\mathrm{SiN}_{\mathrm{x}}$ removal can be observed using optical microscopy and SEM. PL imaging can be used to observe cell damage caused by edge junction isolation.

(a)

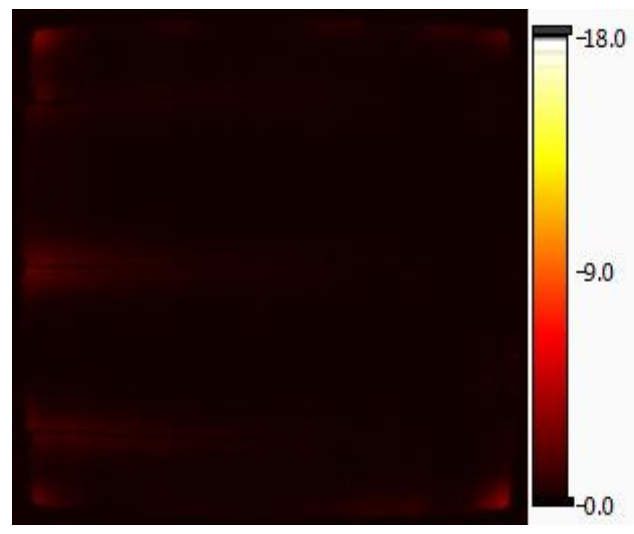

(b)

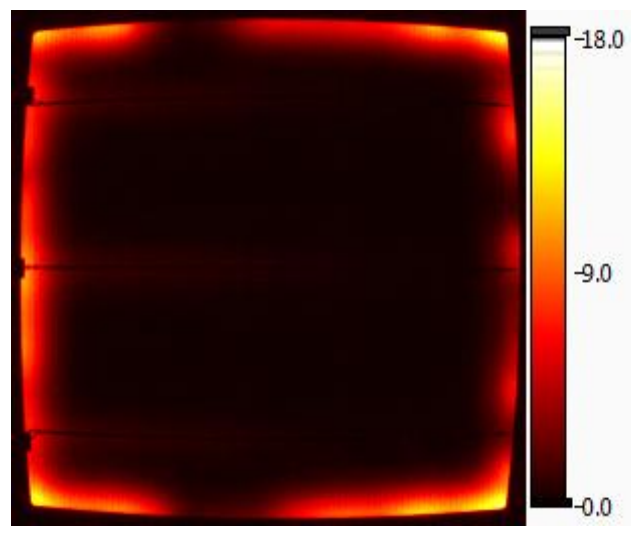

Figure 3. Time-resolved thermography images taken of a monocrystalline Si cell with good edge isolation (a) and poor edge isolation (b) with a Tau Science IRIS-210. The higher temperatures shown in (b) are due to the presence of shunt paths that were not properly eliminated during edge isolation.

\subsection{Contamination}

\subsubsection{Background}

The introduction of contaminants in silicon wafers can often be due to impurities found in the wet chemical processes [63]. High purity chemicals used in the manufacturing of $\mathrm{c}-\mathrm{Si}$ solar cells such as $\mathrm{HF}, \mathrm{HNO}_{3}$, and $\mathrm{KOH}$ are transported through valves, fittings, tubing, and containers. Contaminants leached from the wetted surfaces into the fluid stream can ultimately end up as part of the c-Si solar cell. Johnson et al. showed that impurity concentration in wet chemical baths is the biggest factor impacting the deposition of contaminants, with less influential factors being the removal speed of the wafers from the bath and properties of the liquid (e.g., surface tension, density, viscosity) [63]. Johnson also showed that the least amount of metallic contaminants to the fluid media occurs when valves, fittings, tubing, and containers are composed of perfluoroalkoxy (PFA). On the other hand, 316 stainless steel and polyvinyl chloride (PVC) contribute the greatest amount of contaminants. The data also shows that PFA has the lowest amount of anion and cation contamination of all the materials tested [64]. 
Ineffective cleaning following PSG removal and/or edge isolation is of particular importance, since the next process step is normally the deposition of PECVD SiN $x$ passivation. Impurities remaining on the surface of the wafer before passivation deposition can increase surface recombination velocity through an increase in the interface defect density $\left(D_{i t}\right)[45]$.

The detrimental effects associated with introducing contamination can sometimes be mitigated by phosphorus gettering during the emitter diffusion process. Zuschlag et al. [65] investigated the effect of processing steps on $\mathrm{Cu}$ and $\mathrm{Fe}$ concentration in solar cells. The $\mathrm{Si}$ wafers were intentionally contaminated with $\mathrm{Cu}$ and Fe prior to testing. The $\mathrm{Cu}$ concentration measured by micro-x-ray fluorescence ( $\mu$-XRF) was drastically reduced during cell processing, particularly following $\mathrm{P}$ diffusion where it falls below the detection limit. However, the Fe distribution was apparently not influenced by these processing steps. Ultimately, the applied temperature profile had the largest effect on the detectable metal precipitate distribution [65]. When Yoon et al. [66] carried out $\mathrm{POCl}_{3}$ diffusion on both the front and back sides of cells, they showed that $\mathrm{Fe}$ was sufficiently gettered and minority carrier lifetime was improved. Fenning et al. showed that Fe may be relatively higher at the start of the cool-down from diffusion temperature due to the higher solubility. This high interstitial concentration requires further defect engineering during cooling and subsequent metallization, such as slow-cooling or low temperature annealing [67].

\subsubsection{Failure modes related to contamination}

Different types of contaminants have varying effects on PV cells. Not only do metallic impurities decrease the minority carrier diffusion length, resulting in cell performance loss, but they can also have a corrosive etching effect on critical surfaces leading to over etching, which can result in pre-breakdown. Ionic contamination is another type of impurity that can lead to over etching and a reduction in cell efficiency, as well as leave a surface residue on the wafer following evaporation of the chemicals from the surface.

\subsubsection{Metrology related to contamination}

Several methods have been used to identify types and levels of contamination. The chemical identities of low levels of residue can be verified by observation of both core-level x-ray photoelectron spectroscopy (XPS) emission and $x$-ray or electron beam-stimulated Auger emission (XAES) [45]. Synchrotron radiation based measurements methods such as $\mu$-XRF are other methods of detecting metal precipitates in $\mathrm{Si}$ wafers. Secondary ion mass spectrometry (SIMS), low energy electron diffraction (LEED), surface photovoltage (SPV), and high-resolution inductively coupled plasma mass spectrometry (HR-ICP-MS) can also be used to detect metal ion contaminants. The impact of smaller precipitates or finely distributed transition metal point defects on the recombination activity of a wafer or cell can indicate the presence of certain impurities [65]. Therefore, additional measurements of the minority charge carrier lifetime via photoconductance decay (PCD), quasi-steady state photoconductance (QSSPC), microwave-PCD ( $\mu-P C D)$, and PL can be utilized. 


\subsection{Gap analysis}

With regards to contamination, it is unknown how high the purity of the chemicals used in manufacturing need to be to prevent degradation. In addition, as the solar industry evolves, the needs for purity will evolve as well. The current standard industrial $\mathrm{C}-\mathrm{Si}$ solar cell has contacts of $\mathrm{Ag}$ paste at the front and $\mathrm{Al}$ at the rear. For example, in pPERC cells, the full-area Al will be replaced by a dielectric passivation layer in contact with most of the rear side, reducing the rear surface recombination velocity, but also increasing the level of cleanliness needed to maximize the cell efficiency. Additionally, front contacts utilizing a selective $n^{++}$emitter below the fingers to improve the blue response of cells may also be adopted. These types of changes will increase the efficiency, but could also make the performance of the cell more sensitive to recombination losses due to impurities.

\section{Emitter formation}

\subsection{Background}

Emitter formation is arguably the most critical step in making an industrial cSi solar cell as it creates the $p-n$ junction, which collects photogenerated carriers. In an industrial c-Si solar cell, the front surface of a B-doped ( $p$-type) Si wafer is counter-doped with a relatively high concentration of P. This P-doped ( $n$-type) region is typically referred to as the emitter and, together with the $p$-type base, forms the $p-n$ junction. Apart from junction formation, the emitter plays several other roles in the solar cell including: providing electrical contact with metal fingers which extract current from the cell; enabling lateral transport of carriers between metal fingers; and minimizing recombination of carriers at the front surface. The optimization of the emitter profile for individual solar cell performance is dictated by the compromise between the competing requirements of minimizing carrier recombination losses and minimizing resistive losses associated with extracting carriers out of the cell. These topics have been extensively studied and reported in the literature and fall outside the scope of this review. A brief overview of how emitters are described and characterized is worthwhile in order to set a frame of reference for the subsequent topics.

Diffused regions like emitters are typically described by their sheet resistance and/or doping profile. Sheet resistance describes the resistance of the diffused layer as seen by carries moving laterally between metal fingers. The distribution of $\mathrm{P}$ dopant atoms in the emitter is described by its profile with its notable features of surface concentration, shape and depth. Diffusions are typically described as "light" or "heavy" based on their sheet resistance values (i.e., high or low, respectively). It should be noted, however, that the average sheet resistance is an integral of active dopants across the junction depth, and as such emitters with very different profiles can result in the same value. The emitter profiles, simulated using PC1D software [68], shown in Figure 4 demonstrate this point. All the emitters in Figure 4Error! Reference source not found. have a sheet resistance of $65 \Omega / \square$, but exhibit very different profiles. Great care is therefore required when discussing emitters in terms of sheet resistance. 
Metrology techniques for sheet resistance include four point probe [69-71], SPV probing [72], and sheet resistance imaging [73]. In general, diffusion engineers typically rely on two profile techniques, secondary ion mass spectrometry (SIMS) [74] to track how dopant atoms are being introduced into the substrate via processing and either spreading resistance probe (SRP) [75] or electrochemical capacitance-voltage (ECV) [76-78] to monitor the electrically active dopants. The use of two techniques allows for the monitoring of any offset between atomic and active concentrations. Two-dimensional carrier profiling techniques are able to distinguish between $n$-type and $p$-type regions and therefore can create images of the $p-n$ junction $[79,80]$. Being able to image the $p-n$ junction allows for the detection of discontinuities, which can be missed with one-dimensional profiling techniques. The EBIC method [81] and secondary electron (SE) contrast imaging [82-87], both performed in a SEM, are well suited for solar cell emitter characterization.

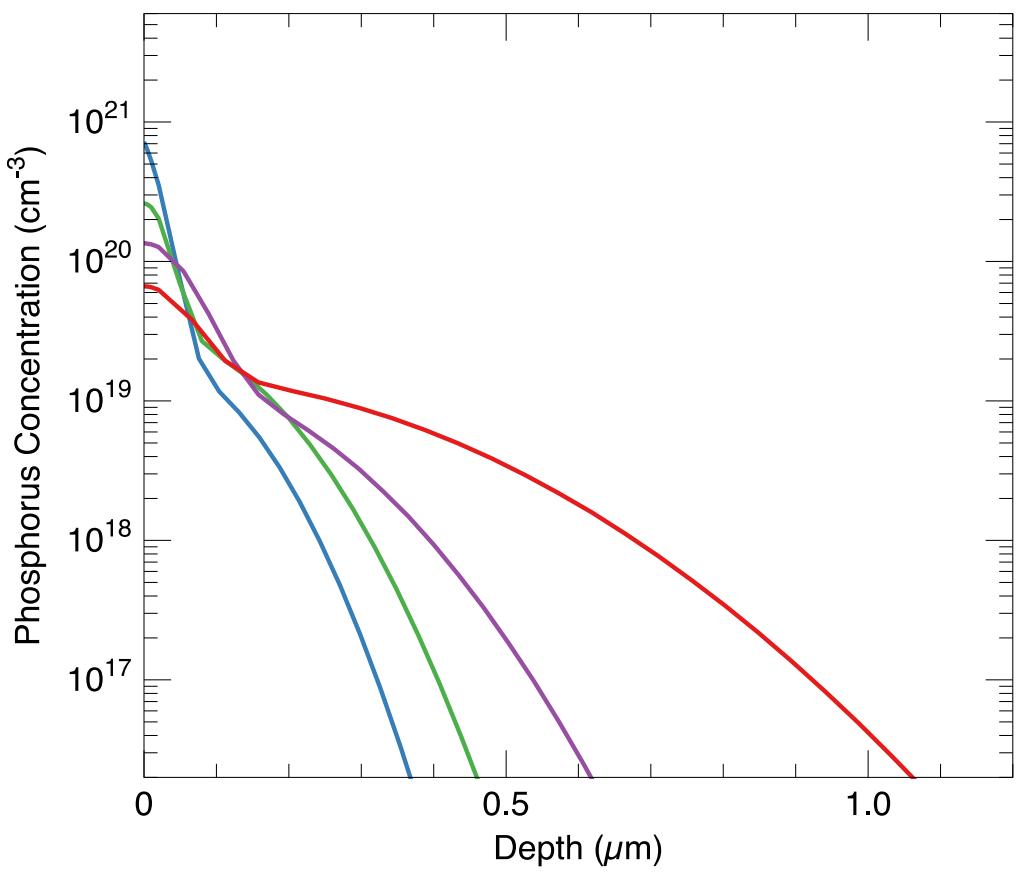

Figure 4. Simulated emitter profiles all having sheet resistance values of $65 \Omega / \square$.

The final product for the end-user is the module (as part of a PV installation), and not individual solar cells, therefore additional understanding is required to determine what role if any the emitter formation process plays in module reliability. This section begins with an overview of $\mathrm{P}$ emitter formation techniques including the industry standard, phosphorus oxychloride $\left(\mathrm{POCl}_{3}\right)$ diffusion, as well as actively researched alternative techniques. This is followed by a description of emitter related failure modes and degradation mechanisms at the module level. Relevant metrology techniques for characterizing and diagnosing these failure modes are also highlighted. This section ends with a gap analysis pertaining to the role of the emitter in these failure modes. 


\subsection{Emitter formation techniques}

This subsection describes various $P$ diffusion techniques including the industry standard $\mathrm{POCl}_{3}$ as well as alternatives like deposited liquid dopant approaches, chemical vapor deposition approaches and ion implantation. A motivation for replacing a batch $\mathrm{POCl}_{3}$ diffusion process with an inline diffusion process is based on the projected trend of thinner substrates and its inherent challenges with wafer yield. Another motivation to replace $\mathrm{POCl}_{3}$ is to find a nontoxic $\mathrm{P}$ doping solution.

\subsection{1. $\mathrm{POCl}_{3}$ diffusion}

$\mathrm{POCl}_{3}$ is the dominant $\mathrm{P}$ dopant source used for emitter formation in industrial solar cells. In a $\mathrm{POCl}_{3}$ batch diffusion process, $\mathrm{Si}$ wafers sitting vertically in a slotted quartz boat are loaded into a heated horizontal quartz tube furnace. A carrier $\mathrm{N}_{2}$ gas is flowed into a quartz vessel, often referred to as a bubbler, containing liquid $\mathrm{POCl}_{3}$ causing it to bubble and resulting in $\mathrm{POCl}_{3}$ vapor being introduced into the heated quartz tube. $\mathrm{O}_{2}$ is simultaneously introduced into the tube and reacts with the $\mathrm{POCl}_{3}$ to form phosphorus pentoxide $\left(\mathrm{P}_{2} \mathrm{O}_{5}\right)$ and $\mathrm{Cl}_{2}$ gas following the reaction:

$$
4 \mathrm{POCl}_{3}+3 \mathrm{O}_{2} \rightarrow 2 \mathrm{P}_{2} \mathrm{O}_{5}+6 \mathrm{Cl}_{2} \text {. }
$$

During this deposition step, $\mathrm{P}_{2} \mathrm{O}_{5}$ coats the $\mathrm{Si}$ wafers and acts as the $\mathrm{P}$ dopant source. The byproduct $\mathrm{Cl}_{2}$ gas reacts with most metals and therefore has the added benefit of cleaning away any metal impurities present on the wafer surface. $\mathrm{P}_{2} \mathrm{O}_{5}$ interacts with the underlying silicon wafer creating silicon dioxide $\left(\mathrm{SiO}_{2}\right)$ and free $\mathrm{P}$ atoms following the reaction:

$$
2 \mathrm{P}_{2} \mathrm{O}_{5}+5 \mathrm{Si} \rightarrow 5 \mathrm{SiO}_{2}+4 \mathrm{P}
$$

which is accompanied by the simultaneous growth of oxide and $\mathrm{P}_{2} \mathrm{O}_{5}$.

The mixed layer of $\mathrm{P}_{2} \mathrm{O}_{5}$ and $\mathrm{SiO}_{2}$ growing on the silicon wafer is the aforementioned PSG layer.

$\mathrm{POCl}_{3}$ diffusion processes are typically run at temperatures between $800^{\circ} \mathrm{C}$ and $900^{\circ} \mathrm{C}$. Process variables that influence the $\mathrm{P}$ doping include: process temperature and temperature profile, deposition time and $\mathrm{POCl}_{3}$ partial pressure (via N2 carrier flow rate), as well as process ambient. A large parameter space is available for $\mathrm{POCl}_{3}$ processing, allowing for highly tunable emitter profile design.

\subsubsection{1. $\quad$ Phosphorus gettering of impurities}

Emitter formation is the highest temperature process step for conventional industrial solar cells. As a result, diffusion is susceptible to the incorporation of unintended impurities or contaminants into the silicon wafer. The high temperatures used to drive-in phosphorus atoms into the wafer can also serve to drive-in contaminants that are present on the wafer. Contaminants like metals 
can create recombination centers, which reduce minority carrier lifetime and as a result degrade overall solar cell efficiency. Impurities can also be introduced into the starting material during ingot growth. $\mathrm{Fe}$ is the most common contaminant for c-Si PV. Multicrystalline Si wafers are prone to have significant amounts of ingrown interstitial iron, $\mathrm{Fe}_{\mathrm{i}}$, incorporated during their low cost crystal growth process [88, 89]. Si wafers, including monocrystalline wafers, are also susceptible to extrinsic $\mathrm{Fe}_{i}$ contamination during cell processing. $\mathrm{Fe}$ is a very common and prevalent element, which is very difficult to completely eliminate from a production line [90].

Reducing the concentration of impurities in Si wafers, a process referred to as gettering, can occur via several mechanisms including $P$ gettering [91-95]. The benefit of $P$ gettering on multicrystalline silicon wafers has been studied extensively [67, 96-99]. Another advantage of $\mathrm{POCl}_{3}$ diffusion is the enhanced $\mathrm{P}$ gettering provided by the double-sided $P$ doping via conformal coating of PSG on both sides of the wafer. Phosphorus gettering coupled with the $\mathrm{Cl}$ present during diffusion makes the $\mathrm{POCl}_{3}$ a very forgiving process in a manufacturing environment.

\subsubsection{Recent advances in $\mathrm{POCl}_{3}$ emitter processing}

Industrial solar cells have traditionally employed what is often referred to as heavily doped emitters whereby the profiles have surface concentrations above $5 \cdot 10^{20} \mathrm{~cm}^{-3}$. Such profiles ensured good metal contact using screenprinted Ag metal paste. Several groups have reported on superior performing emitters created using more sophisticated $\mathrm{POCl}_{3}$ processing [100-107]. The common trend among these studies is the move to lower surface concentration and deeper emitters resulting in lower emitter recombination losses while maintaining good metal contact.

Recent advancements in screen-printable Ag paste technology have enabled contacting homogeneous emitters with phosphorus surface concentrations significantly lower than those used in conventional solar cells $[108,109]$. When using these new Ag pastes, the Si-Ag contact regions exhibit ultra-thin, uniform interfacial films which result in improved conductor line contact resistivity and reduced emitter/junction damage [109]. As a result more aggressive emitter profiles with lower surface concentrations can be contacted. Excellent metal contacts and high efficiency cells have been reported for emitters with surface concentrations as low as $2.4 \cdot 10^{20} \mathrm{~cm}^{-3}$ and $1.4 \cdot 10^{20} \mathrm{~cm}^{-3}$ when implementing a deeper profile [104, 105].

Cell efficiencies well above $19 \%$ have been reported for screen-printed industrial monocrystalline Si cells employing optimized $\mathrm{POCl}_{3}$ emitters with the industry standard now pushing towards 19.5\% [107, 110]. Future Ag paste improvements will continue to target contacting to even lower surface concentrations while minimizing recombination losses at the metal contact. While $\mathrm{POCl}_{3}$ continues to dominate emitter diffusion processing, alternative doping techniques continue to be explored. 


\subsubsection{Phosphoric acid spray}

$\mathrm{P}$ doping can be achieved using a phosphoric acid $\left(\mathrm{H}_{3} \mathrm{PO}_{4}\right)$ spray combined with an inline furnace [111]. A dilute $\mathrm{H}_{3} \mathrm{PO}_{4}$ solution containing some surfactants is sprayed onto the wafer surface. The wafers are then subjected to a low temperature (less than $50^{\circ} \mathrm{C}$ ) dehydration step in order to convert the $\mathrm{H}_{3} \mathrm{PO}_{4}$ into $\mathrm{P}_{2} \mathrm{O}_{5}$ and $\mathrm{H}_{2} \mathrm{O}$. The $\mathrm{P}_{2} \mathrm{O}_{5}$ serves as the dopant source and when subjected to a high temperature creates free $\mathrm{P}$ atoms following the same reaction as that described above for a $\mathrm{POCl}_{3}$ process. To perform the $\mathrm{P}$ drive-in, wafers transition onto a conveyor belt and run through an IR heated inline furnace. The doping strength can be modulated via temperature settings and belt speed [111] although some further tuning capability has been demonstrated with lower spray flow rates [112]. Processing with phosphoric acid spray and an in-line furnace has a limited profile tuning capability compared to $\mathrm{POCl}_{3}$ diffusion.

\subsubsection{Spin-on dopant}

$\mathrm{P}$ diffusion can also be achieved using a spin-on dopant (SOD) combined with rapid thermal processing. A P SOD contains $\mathrm{SiO}_{2}$ and $\mathrm{P}_{2} \mathrm{O}_{5}$ in an organic solution. SODs are low viscosity solutions, known as a sol-gel, and are typically deposited using a fast rotating spinner. Due to their low viscosity, SODs can in principle also be deposited using spray techniques. SODs have been used in microelectronics to achieve shallow diffusions [113]. P SOD has also been implemented for solar cell emitter formation in conjunction with rapid thermal processing, quartz tube furnace, and in-line furnace drive-in steps [114-117]. As with the phosphoric acid spray approach, diffusion strength tuning is limited as compared to $\mathrm{POCl}_{3}$ diffusion. One concern regarding SODs is residual organic components, which can introduce unwanted impurities into the wafer during drive-in and requires additional processing to mitigate [116, 117]. Another concern is the highly hygroscopic nature of $\mathrm{P}_{2} \mathrm{O}_{5}$. In the presence of humidity, $\mathrm{P}_{2} \mathrm{O}_{5}$ can convert into orthophosphoric acid, which becomes very volatile at drivein temperatures possibly making diffusion stability difficult [118]. This can be an issue for atmospheric processing like in an in-line furnace drive-in step, which will contain a certain level of humidity. Other concerns include short shelf life, post diffusion residual layers, and dopant-silicide precipitates for high concentrations [118]. Recent advancements have been made with spin-on organic polymer dopants, which avoids some of the issues associated with conventional SODs [119]. During drive-in the dopants closest to the substrate surface diffuse into the wafer while the polymer film simultaneously burns off. Initial studies have targeted shallow diffusions suitable for microelectronic applications and the suitability for solar applications has yet to be tested.

\subsubsection{Dopant Paste}

Yet another deposited liquid dopant source approach is screen-printing dopant paste combined with a drive-in step, which can be performed using rapid thermal processing, tube furnace, or an in-line furnace step [120-124]. Doping strength is controlled via drive-in temperature, time and ambient. A screenprintable doping solution is desirable in a manufacturing setting as existing tools and know-how can be repurposed and leveraged for this approach. A concern 
with dopant pastes is gas phase doping of non-printed surfaces, sometimes referred to as auto-doping, which bring to question the stability of the doping process in a manufacturing setting. Another major concern is wafer contamination from impurities in the paste. Severe wafer lifetime degradation has been reported for $p$-type wafers processed with dopant pastes [124]. X-ray topography studies have also shown that screen-printed dopant pastes create more micro-defects in Si wafers than $\mathrm{POCl}_{3}$ or phosphoric acid diffusion [125]. Auto-doping and lifetime issues will need to be addressed before such a doping approach can gain any traction in the industry.

\subsubsection{Plasma enhanced chemical vapor deposition}

Uniform $\mathrm{P}$ doping has been demonstrated using a large-scale in-line microwave plasma enhanced chemical vapor deposition (PECVD) system [126]. PSG films were deposited using tetramethlycyclotetrasiloxane (TMCTS), trimethylphopshite (TMPi) and $\mathrm{O}_{2}$ as precursor gases. A capping layer was also used as protective moisture barrier for the hygroscopic PSG layer. The PSG film properties were varied by means of pressure, temperature, microwave power, and gas flows while the post-PSG deposition drive-in step was performed in an in-line furnace.

\subsubsection{Atmospheric pressure chemical vapor deposition}

Highly tunable $\mathrm{P}$ profiles have been demonstrated using a static atmospheric pressure chemical vapor deposition (APCVD) PSG deposition followed by a rapid thermal annealing (RTA) step [127]. PSG layers were deposited at $400^{\circ} \mathrm{C}$ using Ar-diluted $\mathrm{PH}_{3}$, Ar-diluted $\mathrm{SiH}_{4}$, and $\mathrm{O}_{2}$ as precursor gases. The $P$ content in the PSG layer was controlled via gas flow ratios. Dopant drive-in was performed using a $1000^{\circ} \mathrm{C}, 20$ second anneal. A wide range of surface concentrations $\left(\approx 2 \cdot 10^{19} \mathrm{~cm}^{-3}\right.$ to $\left.\approx 1 \cdot 10^{21} \mathrm{~cm}^{-3}\right)$ and depths $(\approx 0.1$ to $\approx 0.4$ $\mu \mathrm{m})$ have been demonstrated.

A high throughput multiple chamber in-line atmospheric pressure chemical vapor deposition (APCVD) system has also been developed [128]. PSG is deposited using $\mathrm{N}_{2}$ diluted $\mathrm{SiH}_{4}, \mathrm{PH}_{3}$ and $\mathrm{O}_{2}$ as precursor gases. Wafers travel horizontally through the system on ceramic rollers. The second chamber is used to deposit a $40 \mathrm{~nm} \mathrm{SiO}_{2}$ capping layer. The capping layer serves as a moisture barrier for the highly hygroscopic PSG layer. The capping layer also prevents the transfer of dopant species (referred to as auto-doping) from the PSG layer onto the rear side of the wafer and/or onto neighboring wafers during the subsequent drive-in step. The dopant drive-in step can be performed using an in-line furnace (e.g., 12 minutes at $840-910^{\circ} \mathrm{C}$ ) or can be performed in a conventional batch tube diffusion furnace. The emitter profile can be tuned via $\mathrm{PH}_{3}$ gas flow (i.e., $\mathrm{P}$ content in PSG) and drive-in condition. Surface concentrations as low as $3 \cdot 10^{20}$ $\mathrm{cm}^{-3}$ have been demonstrated approaching the high performance $\mathrm{POCl}_{3}$ emitters demonstrated by other groups. A throughput of 4,000 wafers per hour has been demonstrated with such a system. 


\subsubsection{Ion implantation}

Ion implantation is perhaps the most sophisticated doping technique. Ion implantation is a commonly used doping technique in microelectronics due to its high precision doping capabilities. An ion implanter is a particle accelerator that produces a beam of impurity ions, which is directed towards a Si substrate target. Traditional ion implantation systems, referred to as beam line systems, consist of the following components: an ion source, a mass spectrometer, a high-voltage accelerator, a scanning system, and a target chamber. The high voltage (25keV) ion source produces a plasma of impurity ions. Phosphine gas is used as the source for $\mathrm{P}$ doping. Various ions are produced in the plasma including $\mathrm{PH}_{2}{ }^{+}$, $\mathrm{PH}^{+}, \mathrm{P}^{+}, \mathrm{H}^{+}$, and $\mathrm{P}_{2} \mathrm{H}^{+}$[129]. The mass spectrometer then selects the desired impurity ions creating a high purity beam. The high voltage accelerator column accelerates the ions to the velocities required to penetrate the wafer surface. An $x-y$ scanning system is used to raster the beam across the target wafer to achieve the desired dose [130]. Apart from the traditional beam line system, other non-mass-analyzed ion implant techniques include plasma immersion implantation and continuous flux ion implantation [131].

The bombardment of high velocity ions results in lattice damage within the Si wafer. Implantation damage can be removed with an annealing step typically in the temperature range of $800-1000^{\circ} \mathrm{C}$ for approximately 30 minutes. The damage annealing also simultaneously serves as a dopant activation step and a dopant drive-in step. For high enough doses, the implanted layer will be amorphous. This amorphous layer can be annealed via solid phase epitaxy whereby the underlying crystalline substrate serves as the seed layer. Solid phase epitaxy recrystallization also allows for lower annealing temperatures.

\subsubsection{Recent advances in ion implanted emitter processing}

Early applications of ion implantation for C-Si solar cells, in the 1980's, yielded high efficiency cells on both $n$-type [132] and $p$-type wafers [133]. However, the doping technique never gained traction due to its limited throughput and high cost. More recently ion implanters have been designed specifically for solar cell manufacturing. Implanters have been redesigned with higher beam currents, relaxed ion beam energy spread specifications, and improved wafer handling to achieve throughputs of around 1,000 wafer per hour [134, 135]. More recently, a new generation of ion implanters with 3,000 wafers per hour throughput has been announced [136]. An in-line, continuous flux ion implantation tool has also been developed with a 2,400 wafer per hour throughput [129, 131].

Several groups have reported efficiencies above $19 \%$ for front contacted solar cells fabricated with ion implanted $P$ emitters $[129,135,137,138]$. Ion implanted $\mathrm{P}$ emitters have also been incorporated into selective emitter cells $[134,139]$ and into pPERC cells [140, 141]. Typical results for ion implanted $P$ emitter cells include superior doping uniformity, higher efficiency, and tighter distribution over cells made with standard $\mathrm{POCl}_{3}$ emitters. Another commonly reported advantage of ion implantation cells is the elimination of edge isolation and PSG removal steps. It should be noted, however, that it is quite common to perform edge isolation and PSG removal in one in-line wet chemistry tool, thus 
maintaining the same number of production steps as a $\mathrm{POCl}_{3}$ emitter cell, but essentially replacing the wet chemistry tool with an ion implantation tool.

Tube furnaces are typically used for the damage anneal. Fully amorphous implanted layers have been demonstrated via cross-sectional TEM for both beam line and continuous flux ion implantation [131, 137]. Damage annealing temperatures of between $800^{\circ} \mathrm{C}$ and $950^{\circ} \mathrm{C}$ have been reported by various groups [129, 131, 134, 137, 139]. Recrystallization of the amorphous implanted layer by means of such damage anneals has been demonstrated via crosssectional TEM $[131,137]$. Chun et al. have shown that beam line implanters can create defects which propagate into the Si lattice away from the original amorphous dosed layer upon annealing whereas a continuous flux ion implantation technique is defect free after recrystallization [131].

Optimization of implant dose and annealing conditions has led to low surface concentration $P$ emitters [137-139] more closely resembling those of advanced $\mathrm{POCl}_{3}$ processing [104, 105]. Oxygen is often introduced into the damage anneal ambient in order to simultaneously grow a thin oxide passivation layer with reported thicknesses in the 10-30 nm range [129, 134, 137, 139].

\subsubsection{Outlook for ion implantation}

Despite the superior doping uniformity achievable with ion implantation, convincing cell manufacturers to replace existing $\mathrm{POCl}_{3}$ lines with expensive ion implantation systems may prove to be difficult given that the industry has moved to much more sophisticated $\mathrm{POCl}_{3}$ emitters with efficiencies above $19 \%$ [107, 110]. The limited gettering from a single sided ion implantation $P$ process may also prove to be a challenge for the application to multicrystalline Si. Control of the ion penetration in multicrystalline $\mathrm{Si}$, with its varying grain sizes, orientations, grain boundaries and defect clusters, is also a concern.

While widespread adoption of ion implantation may be difficult for industry standard $P$ emitter front contact solar cells, the technology may be well suited for more advanced architectures. Perhaps the most attractive feature of ion implantation for solar cell applications is the capability for high precision $P$ and $B$ doping. Such capabilities lend themselves to high efficiency $n$-type base passivated emitter, totally rear diffused (nPERT) cell [135, 142-145]. Another attractive feature of ion implantation for solar cell applications is the capability for creating patterned $\mathrm{P}$ and $\mathrm{B}$ doped regions via shadow masking which could enable the interdigitated back contact (IBC) solar cell [146, 147].

$P$ and $B$ implantation can in principle be done sequentially followed by $a$ single furnace step simultaneously serving as the damage annealing, dopant activation and surface passivation steps. Thus far studies of $n$-base cells have shown better results when using separate annealing steps [135].

Since $B$ is a relatively light element, high doses are required to achieve the desired amorphous implanted layer. As a result, higher temperatures are required for the lattice damage annealing which raises concerns about maintaining high wafer lifetime. Co-annealing of $B$ and $P$ would therefore have the $B$ annealing condition as a processing boundary condition. B implantation has other challenges including $B$ cluster formation and incomplete amorphisation and activation [135, 144]. The ability to overcome these challenges (along with 
throughput and cost) will likely be a key factor in determining whether ion implantation will achieve widespread adoption in the solar industry.

\subsection{Failure modes and degradation mechanisms related to emitter formation}

This subsection covers module level failure modes and degradation mechanisms which relate directly to the emitters of the individual component solar cells. Thermal degradation due to hot spots and potential induced degradation appear at the module level. However, these effects can be isolated to localized emitter regions. The different types of emitter shunts (linear, nonlinear, and junction pre-breakdown), which can lead to hot spot formation, are described. Research looking into the role of the emitter in the more recent topic of potential induced degradation is reviewed and discussed. Relevant metrology techniques for detecting these failure modes and for diagnosing their degradation mechanisms are also presented.

\subsubsection{Shunts, junction pre-breakdown and hot-spots}

A shunt is referred to, here, as a local short-circuit in a solar cell whereby a small resistance path is created through the $p$ - $n$ junction (and therefore through the emitter) into the base of the cell. Shunts lower solar cell efficiency via lower fill factor and can also lead to module degradation via hot spots. Several forms of shunts have been identified in silicon solar cells [148]. Shunts typically fall into one of three categories: linear shunts, non-linear shunts, and junction prebreakdown shunts [149].

Under normal solar cell operating conditions (i.e., forward bias), shunts will negatively impact the global $I-V$ parameters of the cell and thus reduce its efficiency. However, a solar cell's behavior in reverse bias becomes critical for module performance and reliability. Shading of an individual cell in a module leads the cell into reverse bias. Bypass diodes are introduced into the module design in order to limit the reverse bias to $10-15 \mathrm{~V}$. The reverse biased cells act as electrical loads with the reverse current flowing through their shunts, dissipating heat. These localized regions of heat dissipation are referred to as hot spots. For highly localized hot spots, local temperatures can reach levels high enough to permanently damage the module [150]. Both local shunts and local sites of junction pre-breakdown can lead to hot spots.

\subsubsection{Linear shunts}

A linear shunt exhibits ohmic behavior (i.e., like a resistor) in response to negative and positive bias. A common example of a linear shunt is an edge shunt caused by poor junction isolation [148]. Linear shunts across the $p-n$ junction can also be caused by local non-homogeneities in the wafer prior to emitter diffusion. A crack in the wafer created prior to diffusion can cause an emitter layer to form across the crack creating a strong linear shunt between the emitter and the base [148]. Material-induced linear shunts caused by $\mathrm{SiC}$ filaments in multicrystalline Si solar cells have also been reported [151]. In general, linear shunts cause greater degradation of solar cell performance than non-linear shunts. [148] 


\subsubsection{Non-linear shunts}

A non-linear shunt exhibits a diode-like behavior in response to negative and positive bias. Non-linear shunts can be process induced or related to wafer quality. If the front side metal grid of a solar cell punches through the emitter and makes direct contact with the p-type base, it will form a poor quality Schottky diode. This type of non-linear shunt can also result from metal fingers directly contacting the base due to local non-uniformities in the $\mathrm{P}$ doping (e.g., nonuniform PSG coverage) [148]. Scratches on the wafer surface created either before or after emitter diffusion can create high-density recombination sites, which behave like non-linear shunts [148]. Crystal defects in Si wafers can also act as very strong recombination sites and exhibit non-linear shunting behavior [148]. Macroscopic $\mathrm{Si}_{3} \mathrm{~N}_{4}$ inclusions found in multicrystalline Si wafers, believed to be created during the crystallization process, have also been correlated with non-linear shunting [148].

\subsubsection{Junction pre-breakdown}

A conventional $p$-type base solar cell should theoretically begin to breakdown at a reverse bias of approximately $-50 \mathrm{~V}$. However, solar cells sometimes exhibit junction breakdown at lower reverse bias, referred to as junction pre-breakdown. Three categories of junction pre-breakdown have been identified: early pre-break down (type I); soft pre-break down (type II); and hard pre-break down (type III) [152].

Type I breakdown occurs at very low reverse bias (around $-5 \mathrm{~V}$ ) and is believed to be process induced [152]. Lausch et al. demonstrated that local Al surface contamination prior to $P$ diffusion led to type I breakdown [153].

Type II breakdown occurs at a reverse bias closer to $-10 \mathrm{~V}$ and appears to be related to recombination active defects. In a study employing controlled metal impurity $(\mathrm{Cr}, \mathrm{Ni}, \mathrm{Fe})$ dosing of multicrystalline $\mathrm{Si}$ wafers, Kwapil et al. reported that the decoration of crystallographic defects with metal impurities is a likely cause of type II breakdown [152, 154]. Moreover, the concentration of the metal impurity and not the type of metal played a strong role. While the purity of the starting Si wafer can play a role in type II breakdown, the introduction of extrinsic metal impurities, via processing, should also be a concern.

Hard pre-breakdown (type III) occurs at a slightly higher reverse bias, around $-13 \mathrm{~V}$. Beyond this value, type III breakdown dominates the global I-V behavior of the solar cell with the resulting reverse current leading to high heat dissipation. Type III breakdown is thus believed to be the most dangerous for module degradation [152]. The origin of type III breakdown sites is still not fully understood. Type III sites have been attributed to local field enhancement created after $\mathrm{P}$ diffusion at dislocations located at the bottom of etch pits, which are created during texturing $[41,152]$. However other studies attribute the type III sites not to etch pits, but to some bulk defects [50].

In general, junction pre-breakdown sites have been readily observed in multicrystalline Si cells and have been attributed to various effects, although the underlying mechanisms are not fully understood [50, 149, 152, 153, 155]. Prescreening of pre-breakdown sites, especially of the Type III variety, would have 
obvious implications for cell selection prior to module assembly. Shunt metrology at the cell level is critical for such selection.

\subsubsection{Potential induced degradation}

In recent years potential induced degradation (PID) has become a major reliability issue for C-Si PV modules. Solar panels in the field, subjected to high voltages and humidity, have shown strong power losses. Arrays of modules are typically connected in series in order to meet PV array power design requirements. As a result, for conventional $p$-type solar cells, this results in a large negative bias between the solar cell and the module frame. Under these conditions a leakage current may be created between the cell and the module frame, through the glass and encapsulation, possibly causing degradation of the cells and module [156-159]. At the module level, PID manifests itself as a dramatic drop in shunt resistance and therefore as a drop in module fill factor and power output. This degradation is also referred to as PID of the shunting type (PID-s) in order to distinguish it from the breakdown of the ARC or metallization [157]. PID-s can also be characterized by the shunting of individual cells within the module.

The transport of $\mathrm{Na}$ ions from the soda lime glass to the cell surface has been readily reported as playing a major role in the strength of the leakage current between the cells and the module frame [156, 160, 161]. However, other studies have suggested that positive ions of any species could play a role [159, 162]. In fact, $\mathrm{Cu}$ [161] and $\mathrm{Li}$ [163] have also been added to the list of suspects. Studies also suggest that the soda lime glass, the EVA and the ARC all play a role in PID [156, 159-162]. Solutions to mitigate PID have been proposed at the system, module and cell level [162].

The underlying mechanisms for PID-s are not yet fully understood. While the emitters in PID-prone solar cells are locally shunted, the role of the emitter itself in this failure mode is unclear. Results pertaining to PID-s in the context of emitters are presented here.

\subsubsection{Role of the emitter in PID-s}

A direct correlation between emitter strength and PID is less than clear from the literature. Pingel et al. reported increased sensitivity to PID for increasing emitter sheet resistance. However, it should be pointed out that in that study the baseline cells already had quite a high level of PID [156]. Schütze et al. were unable to verify the influence of emitter sheet resistance on PID [159]. Cells with varying emitter sheet resistance were incorporated into a module and degradation was monitored during PID testing using electroluminescence (EL). No correlation was found between emitter sheet resistance and PID. Furthermore, Koch et al. found no difference in PID losses between homogenous emitter cells and selective emitter cells, which use lighter doped emitters [160].

Industrial cells created using ion implantation may provide some insight into the emitter's role in PID-s. Researchers at Astroenergy, employing their own internal PID testing protocol, found that cells made using ion implantation showed no signs of PID-s [138]. In this study, completed panels made with conventional cells and with ion implanted cells were placed in a damp heat 
chamber $\left(85^{\circ} \mathrm{C}, 85 \%\right.$ humidity) with all cells grounded and a $1000 \mathrm{~V}$ DC voltage applied to the module frame. After 192 hours the modules with ion implanted cells showed no degradation while the conventional modules exhibited a $30 \%$ power loss. The only nominal differences between the ion implanted cells and the baseline cells were the $\mathrm{P}$ diffusion methods (ion implant vs. $\mathrm{POCl}_{3}$ ). However, the ion implanted cells also had a thin oxide layer grown during the post-implantation annealing process which the conventional cells employing a $\mathrm{POCl}_{3}$ diffused emitter did not have. A loss mechanism was not provided. The role, if any, of either the diffusion process or the thin oxide layer in ion implanted cells requires further study.

Perhaps the most detailed studies of PID-s at the emitter level have been carried out by Naumann et al. [164-166]. In an initial study, the accumulation of $\mathrm{Na}$ at the $\mathrm{Si}_{-} \mathrm{SiN}_{\mathrm{x}}$ interface was strongly correlated with localized PID-s sites. This study revealed that PID-s sites consisted of several micron-sized ohmic shunt paths through the $p-n$ junction. It was proposed that the $n^{+}$emitter is inverted to $p^{+}$in these localized regions thus creating the shunt paths. An inversion layer mechanism has also been suggested by other researchers [163]. A mechanism was proposed whereby a double charge layer is created in the $\mathrm{SiN}_{\mathrm{x}}$ layer consisting of $\mathrm{Na}^{+}$ions and negative charges [164, 166]. $\mathrm{Na}^{+}$ions migrate from the soda lime glass due to the electric field created by the applied potential. These positive charges then attract negative charges between them and the $n^{+}$ layer. The double charge layer creates an electric field within the $\operatorname{SiN}_{x}$ layer, which repels emitter electrons. With a large enough accumulation of charge the resulting electric field can cause local inversion of the $n^{+}$emitter to $p^{+}$. This proposed mechanism was brought into question with a subsequent study.

In a follow-up study, Naumann et al. investigated the localized $\mathrm{Na}$ accumulation sights associated with shunting. This study confirmed the accumulation of $\mathrm{Na}$ at the $\mathrm{Si}$ wafer interface but also found that the $\mathrm{Na}$ was accumulating at crystallographic defects. These defects were confirmed to be stacking faults. Based on these results an alternative mechanism has been proposed whereby a high density of $\mathrm{Na}$ penetrating into intrinsic stacking faults creates a band of states filling the bandgap and thus creating a conductivity shunt path between the $n^{+}$emitter and $p$-type base [165]. While this proposed mechanism contradicts that of the previous study, the proposed cause is the same, notably the accumulation of $\mathrm{Na}^{+}$ions at the wafer surface driven by the resulting electric field within the nitride layer originally caused by the bias between the cells and the module. PID-s associated stacking faults have been identified in both multicrystalline and monocrystalline Si wafers [167].

The role of the emitter in PID remains unclear. Further investigation is required in order to clarify the underlying mechanisms for the localized emitter shunts associated with PID. Furthermore the impact of emitter formation technique on PID also warrants further study. 


\subsection{Metrology techniques relevant to emitter formation}

\subsubsection{Shunts and junction pre-breakdown metrology}

Shunt metrology involves detection and diagnostic techniques. Imaging techniques like DLIT, EL and PL can be used to detect localized shunt sites on a solar cell. The type of shunt is usually determined by its response to different bias conditions. Diagnosing or determining the underlying mechanisms typically requires more sophisticated techniques, which can perform measurements at the $\mu \mathrm{m}$ or sub- $\mu \mathrm{m}$ level.

DLIT is a commonly used technique for imaging shunts in solar cells [148]. A pulsed bias is applied to the cell and an IR sensitive camera captures an image of temperature modulation across the surface [168]. Shunts, which dissipate heat, will appear as bright spots in the LIT image. Several different types of shunts have been identified using DLIT [148]. Information on the nature of the shunt (e.g., linear vs. non-linear) can be deduced based on its response to positive and negative bias [151]. An ultra-fast DLIT method, employing a reverse bias and a $10 \mathrm{~ms}$ acquisition time, has been proposed as an in-line technique for identifying hot-spots at the cell level [169].

EL and PL imaging have both been used to image strong linear (ohmic) shunts and good agreement with DLIT has been demonstrated [155]. EL involves electrically biasing a solar cell and measuring the resulting light emission with a charge coupled device (CCD) camera. The EL signal is proportional to the excess carrier density in the sample and is related to the applied voltage of the cell $[170,171]$. EL produces high spatial resolution images, which can detect metallization problem areas as well as recombination sites. EL also has the advantage of allowing for forward and reverse biasing, thus enabling the detection of linear and non-linear shunts [155]. PL imaging measures the radiative recombination of excess carriers created by means of laser excitation [172]. The PL signal is proportional to the excess carrier concentration and is related to the junction voltage. By employing a silicon CCD camera for PL signal detection, a high resolution spatially resolved lifetime image is obtained highlighting any localized regions of recombination [173]. Proof of concept work on quantitative PL shunt resistance imaging has also been reported [174]. PL has the advantage of being able to measure non-metalized samples. However, due to its use of optical excitation samples can only be measured in forward bias with PL, which limits analysis only to linear shunts.

It should be noted that junction pre-breakdown shunt detection requires reverse biasing of the solar cell, thus limits imaging options to reverse-bias EL and DLIT [50,149,152, 153, 155]. However, it has also been demonstrated that reverse-bias $E L$ is not capable of detecting all pre-breakdown sites [155].

The light (or laser) beam-induced current (LBIC) method measures shortcircuit current $\left(I_{S C}\right)$, or photocurrent, induced by a light beam, of a solar cell. High resolution 2D maps of the photocurrent allow for the detection of irregularities like defects, recombination sites and shunts on a completed solar cell [175]. LBIC has been used as a complimentary technique to DLIT to help identify locations of material-induced shunts in multicrystalline Si solar cells [151]. 
EBIC is performed in a SEM and uses a focused electron beam to generate current which is measured in an external circuit employing a current amplifier [81]. Scanning the beam across the sample creates an EBIC image which provides a complimentary technique to LBIC but at the $\mu \mathrm{m}$ level. EBIC is capable of imaging, with high spatial resolution ( $<1 \mathrm{um}$ ), local shunts caused by materialinduced defects [151], recombination active crystal defects [148] and grain boundaries [176].

Structural characterization is often combined with elemental analysis in identifying shunts. SEM is often used to image structural defects associated with shunts like crystallographic defects [148], material defects [151], precipitates [148], and etch-pits [41, 152, 154]. For non-linear shunts caused by gaps in doping, SEM can be used to monitor PSG coverage uniformity [87] and SE contrasting can be used to confirm local doping inhomogeneities [85-87]. TEM has also been used for high resolution imaging of recombination active crystal defects as well as $\mathrm{Si}_{3} \mathrm{~N}_{4}$ inclusions and $\mathrm{SiC}$ precipitates [148]. Identification of inclusions and precipitates is aided with elemental analysis using energydispersive x-ray analysis (EDX) performed in an SEM [148]. The combination of SEM and EDX has also been used to detect Al particles responsible for type I pre-breakdown shunts [153]. Very sophisticated synchrotron-based $\mu$-XRF has been used to detect metal precipitates at crystallographic defects imaged with SEM in order to diagnose type II pre-breakdown [152, 154]. A combination of SEM, EBIC and TEM imaging has been employed in order to isolate type III prebreakdown to dislocations at etch pits [41, 152].

\subsubsection{PID-s metrology}

PID-s is typically detected at the module level using EL imaging. EL images are taken of the entire module before and after subjecting it to a high voltage stress (on the order of $1000 \mathrm{~V}$ ) under various environmental conditions for time periods ranging from several hours to several months. An example of PID-s degradation as observed in EL imaging is shown in Figure 5 provided from the work in [177]. Modules suffering from PID-s will have dramatically reduced shunt resistance after testing and PID-s prone cells will appear dark in the EL image $[156,159,160]$. All other PID-s relevant metrology tools described here are offline diagnostic techniques applied at the cell level aimed at gaining insight into the underlying mechanisms. 

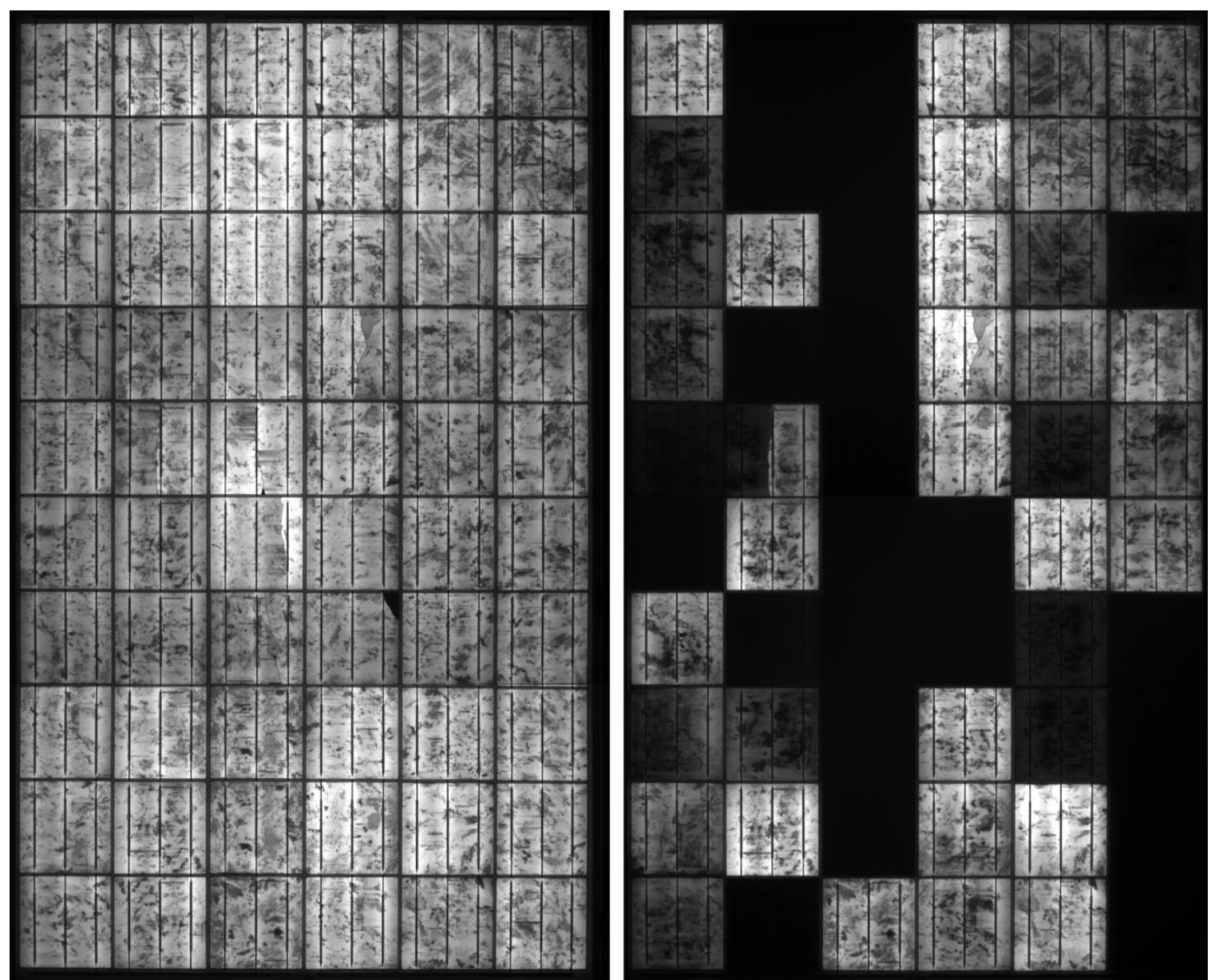

Figure 5. EL image of a standard 60-cell multicrystalline $\mathrm{Si}$ module (left) before and (right) after six months of outdoor high voltage stress testing in Florida. Severe shunting was observed in several cells after this accelerated PID testing.

Imaging techniques can be applied to PID-s prone cells in order to isolate the localized shunt points participating in the PID-s failure. Dark regions in EL images of the cell have been correlated with bright regions from DLIT images corresponding to localized shunts [164]. Performing DLIT measurements in both forward and reverse bias have also identified such shunts as ohmic (linear) [164].

Microscopic analysis at these localized shunt sites have been employed to gain further insight into the origins of PID-s failure at the cell level. SIMS as well as time of flight secondary ion spectroscopy (ToF-SIMS), a qualitative elemental depth profiling technique, have been employed at these local shunt sites and have identified the high levels of $\mathrm{Na}$ and other alkali metals in the nitride layer, peaking at the surface of the solar cell $[161,164,165]$. Na signals in ToF-SIMS measurements have also been correlated with localized shunt sites imaged with plan-view SEM and EBIC images [165].

As mentioned in the introduction of this section, EBIC can also be used to identify and image the location of a $p-n$ junction. Cross-sectional EBIC imaging of localized PID-s sites have shown the degradation of the $p-n$ junction and have also confirmed linear, local $I-V$ characteristics consistent with linear shunting [164]. TEM, which provides high resolution imaging at the sub- $\mu \mathrm{m}$ level, has 
been used to identify stacking faults in the Si wafer at PID-s sites [165]. TEM imaging has also been used in conjunction with EDX for elemental mapping of the imaged PID-s areas, revealing accumulation of $\mathrm{Na}$ within the stacking faults [165]. The nature of the stacking faults (i.e., intrinsic or not) at PID-s sites have been characterized at the atomic level using scanning transmission electron microscopy (STEM) [165].

Efforts to analyze PID-s sites at the cell level are currently still focused on diagnosing the problem and determining the underling mechanisms. As such reliable monitoring or pre-screening tests prior to module assembly are not yet available. More fundamental studies of PID-s sites are required.

\subsection{Gap Analysis}

The emitter related failure modes and degradation mechanisms covered in this review essentially all involve various forms of localized shunting associated with hot spots or PID-s. Shunt detection at the cell-level has become quite sophisticated allowing for some level of hot spot pre-screening prior to module assembly. However, not all observed shunts are fully understood. Some shunts are created during the diffusion process like linear shunts due to cracks or nonlinear shunts due to poor PSG coverage or surface scratches. However, limited shunt detection capabilities exist for diffused wafers prior to metallization.

While there appears to be consensus on the mechanism for PID at the module level, i.e., leakage current between the module and the cell, the underlying mechanism at the localized sites of emitter shunts is still not fully understood. PID symptoms are clearly observed at the emitter, but whether the emitter diffusion process plays a role in making cells PID-prone remains unclear. If localized shunts leading to PID are indeed linear shunts as in the case of stacking faults then PL imaging, which can only detect linear shunts, may provide pre-screening solutions for diffused wafers prior to metallization. In general, the underlying mechanisms for the localized shunts require further study. Further investigation is also required in order to clarify if ion implanted solar cells are less prone to PID and if so what mechanism is at play. Furthermore, the possible role of oxidation mitigating PID-s in ion implanted cells also warrants investigation. It is imperative to determine whether or not the $\mathrm{P}$ diffusion process plays a direct role in PID as this would constitute yet another boundary condition for emitter optimization along with the traditional recombination and resistive losses.

\begin{tabular}{|c|c|c|}
\hline $\begin{array}{c}\text { Failure Mode } \\
\text { or } \\
\text { Degradation } \\
\text { Type }\end{array}$ & Mechanism(s) & Metrology Method(s) \\
\hline \multirow{3}{*}{$\begin{array}{l}\text { Linear shunt } \\
{[148]}\end{array}$} & Poor junction isolation [148] & \multirow{3}{*}{$\begin{array}{l}\text { Dark lock-in thermography (DLIT) [168] } \\
\text { Light beam-induced current (LBIC) [175] } \\
\text { Scanning electron microscopy (SEM) } \\
\text { Electron beam-induced current (EBIC) [81] } \\
\text { Electroluminescence (EL) imaging [170] } \\
\text { Photoluminescence (PL) imaging [173, 174] }\end{array}$} \\
\hline & $\begin{array}{l}\text { Cracks prior to diffusion } \\
\text { [148] }\end{array}$ & \\
\hline & SiC filaments [151] & \\
\hline $\begin{array}{l}\text { Non-linear } \\
\text { shunt [148] }\end{array}$ & $\begin{array}{l}\text { Metal contacting base via } \\
\text { gaps in emitter doping [148] }\end{array}$ & $\begin{array}{l}\text { DLIT [168] } \\
\text { EL imaging [170] }\end{array}$ \\
\hline
\end{tabular}




\begin{tabular}{|c|c|c|}
\hline & $\begin{array}{l}\text { Recombination } \\
\text { created at scratches on } \\
\text { front surface [148] }\end{array}$ & \multirow{3}{*}{$\begin{array}{l}\text { SEM } \\
\text { EBIC [81] } \\
\text { SE contrast }[82,85,86] \\
\text { Transmission electron microscopy (TEM) } \\
\text { Energy-dispersive x-ray analysis (EDX) }\end{array}$} \\
\hline & $\begin{array}{l}\text { Recombination } \\
\text { crystal defects [148] }\end{array}$ & \\
\hline & $\mathrm{Si}_{3} \mathrm{~N}_{4}$ inclusions [148] & \\
\hline \multirow{3}{*}{$\begin{array}{l}\text { Junction pre- } \\
\text { breakdown } \\
\text { [152] }\end{array}$} & \begin{tabular}{lrr} 
Type I: & \multicolumn{2}{c}{ Surface } \\
contamination & prior & to \\
diffusion [153] & & \\
\end{tabular} & \multirow{3}{*}{$\begin{array}{l}\text { SEM } \\
\text { EDX } \\
\text { Reverse bias EL imaging } \\
\text { DLIT [168] } \\
\text { EBIC [81] } \\
\text { Micro-X-ray fluorescence ( } \mu \text {-XRF) } \\
\text { TEM }\end{array}$} \\
\hline & $\begin{array}{l}\text { Type II: Decoration of } \\
\text { crystallographic defects } \\
\text { with metal impurities [152, } \\
154]\end{array}$ & \\
\hline & $\begin{array}{l}\text { Type III: Dislocations at } \\
\text { etch pits [41, 152] and bulk } \\
\text { defects [50] }\end{array}$ & \\
\hline \multirow{2}{*}{$\begin{array}{l}\text { PID-s } \quad[156, \\
157,159,161]\end{array}$} & $\begin{array}{l}\text { Local inversion layer shunts } \\
\text { from accumulation of metal } \\
\text { ions }[163,164,166]\end{array}$ & \multirow{2}{*}{$\begin{array}{l}\text { DLIT [168] } \\
\text { EL [170] } \\
\text { Secondary ion mass spectroscopy (SIMS) [74] } \\
\text { Time-of-flight SIMS (ToF-SIMS) } \\
\text { SEM } \\
\text { EBIC [81] } \\
\text { TEM } \\
\text { EDX } \\
\text { Scanning TEM (STEM) }\end{array}$} \\
\hline & $\begin{array}{l}\text { Local shunts via } \mathrm{Na} \\
\text { decorated stacking faults } \\
{[165]}\end{array}$ & \\
\hline
\end{tabular}

Table 2. Failure modes, degradation mechanisms and relevant metrology methods related to emitter formation.

\section{Anti-reflection coating and passivation}

\subsection{Background}

Dielectric films are used in c-Si cells to act as ARC and/or passivation layers, most commonly on the front side of the cell. For the standard $n^{+} p$ screen-printed Al-BSF cell design primarily used in production today, a hydrogenated, amorphous silicon nitride $\left(a-\mathrm{SiN}_{\mathrm{x}}: \mathrm{H}\right.$, or $\mathrm{SiN}_{\mathrm{x}}$ for simplicity) is used to both passivate the $n^{+}$emitter and act as an ARC. By depositing $\operatorname{SiN}_{x}$ on the front surface of the cell, surface recombination of minority carriers is reduced by a reduction in the $D_{i t}$, primarily through a reduction in "dangling bonds", and the presence of a positive fixed charge $\left(Q_{f}\right)$ at the semiconductor/dielectric interface that deflects minority carriers from the surface (i.e., field effect passivation) [178]. The emitter saturation current density $\left(J_{0 e}\right)$ is therefore reduced, which significantly impacts the open-circuit voltage $\left(V_{O C}\right)$ of the solar cell. This is shown in Figure 6(a), where the current density-voltage $(J-V)$ characteristics are simulated using the one-diode model with three different saturation current densities $\left(J_{0}\right)$ [179]. An ARC is utilized to limit front surface reflectance $\left(R_{f e}\right)$. By utilizing a non-absorbing thin film with an appropriate refractive index and thickness, a reduction in $R_{f e}$ is achieved. The desired refractive index is dependent on the refractive indices of the Si wafer and the incident medium, 
which is typically $\approx 1.5$ for a solar cell encapsulated with in a PV module. The purpose of controlling the thickness of the film (typically $75 \mathrm{~nm}$ in practice) is to provide destructive interference at one specific wavelength $(\lambda \approx 600 \mathrm{~nm}$ in this case), providing a minimum in the $R_{f e}$ vs. $\lambda$ curve that reduces the total $R_{f e}$ integrated over all wavelengths of interest. Without an ARC, an approximately 4$5 \%$ loss in the short-circuit current density $\left(J_{S C}\right)$ is expected, and without an ARC or texturing, a $20 \%$ loss is expected (calculated using OPAL 2 [180] with complex refractive index data taken from [181]). The impact of this $J_{S C}$ enhancement on the $\mathrm{J}$ - $V$ curve of a simulated c-Si solar cell is shown in Figure 6Error! Reference source not found.(b). Another practical consideration for the $\mathrm{SiN}_{\mathrm{x}}$ film is that the screen-printed $\mathrm{Ag}$ pastes used to contact the emitter must be able to fire through this $\mathrm{SiN}_{\mathrm{x}}$ film.
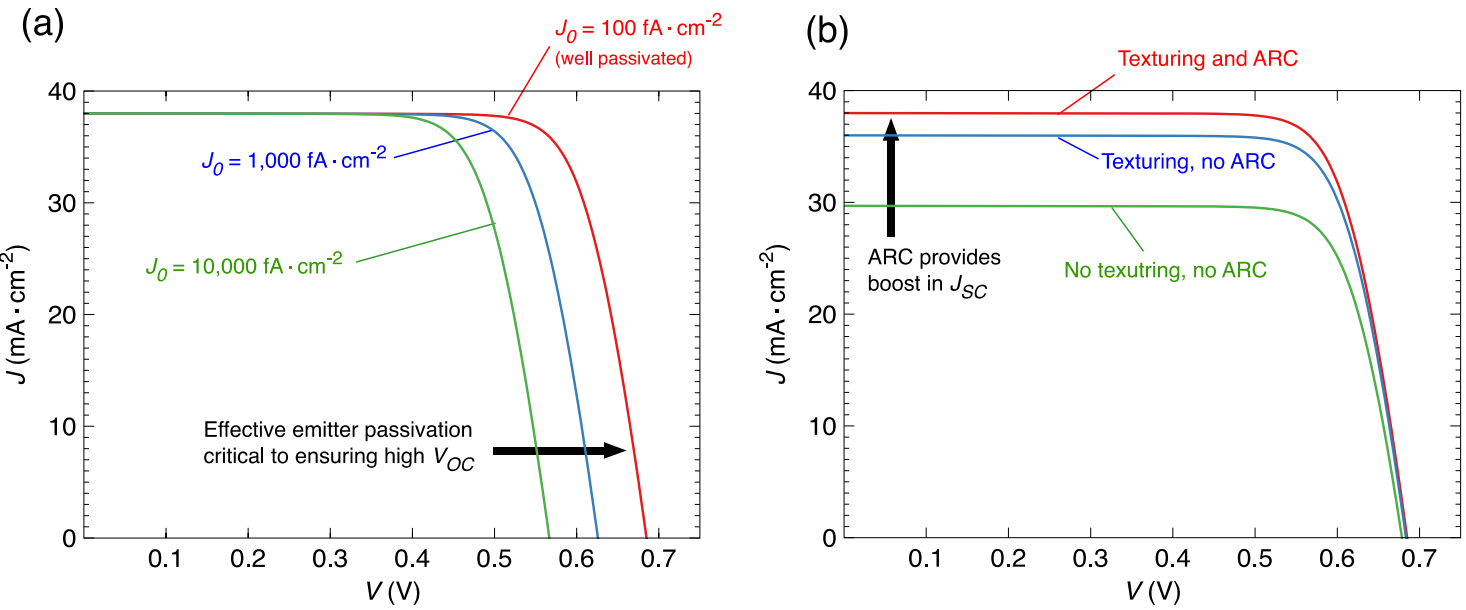

Figure 6. (a) Simulated $J-V$ curves featuring of c-Si cells with three different $J_{0}$ values $\left(J_{0}=100\right.$ $\left.\mathrm{fA} \cdot \mathrm{cm}^{-2} \rightarrow \eta=20.4 \% ; J_{0}=1,000 \mathrm{fA} \cdot \mathrm{cm}^{-2} \rightarrow \eta=18.2 \% ; J_{0}=10,000 \mathrm{fA} \cdot \mathrm{cm}^{-2} \rightarrow \eta=16.1 \%\right)$, indicating the influence of emitter passivation on $V_{O C}$. (b) Simulated $J-V$ curves featuring of $c-S i$ cells for three cases: with texturing and a $75 \mathrm{~nm} \mathrm{SiN}$ ARC ( $\eta=20.4 \%)$; with texturing, but no $\operatorname{ARC}(\eta=19.3 \%)$; and no texturing or ARC $(\eta=16.0 \%)$. Optical simulations were carried using OPAL 2 [180] to determine $J_{S C}$ losses due to $R_{f e}$. These simulations were performed assuming a cell encapsulated in EVA and glass and all assuming $J_{0}=100 \mathrm{fA} \cdot \mathrm{cm}^{-2}$. (Assumed resistance values for both curves: $R_{S}=1.2 \Omega \cdot \mathrm{cm}^{2}, R_{S H}=10,000 \Omega \cdot \mathrm{cm}^{2}$ ).

\section{2. $\underline{A R C}$ and passivation materials}

\subsubsection{Silicon nitride}

$\mathrm{SiN}_{\mathrm{x}}$ will be the primary material of focus in the sections below related to $A R C$ and passivation-related failure modes and degradation mechanisms, since it is the primary material used by industry today. For a detailed review of the use of $\mathrm{SiN}_{\mathrm{x}}$ for surface passivation, see [182]. In the next few sections however, some alternative passivation and ARC materials are briefly covered, along with potential reliability and durability issues associated with those materials.

\subsubsection{Silicon oxide}

There is a long history of using thermally grown $\mathrm{SiO}_{2}$ passivation layers to create high efficiency c-Si solar cells [183]. For $\mathrm{Si}$ wafers with thermal $\mathrm{SiO}_{2}$ 
passivation, it is known that defect generation can occur at the chargepassivated $\mathrm{Si} / \mathrm{SiO}_{2}$ interfaces upon exposure to UV light [184]. Even with encapsulation and $\mathrm{AM} 1.5 \mathrm{G}$ spectrum, photons with sufficient energy to induce these defects have been shown to occur when a positive fixed charge is present, which is the case for a $\mathrm{SiN}_{\mathrm{x}} \mathrm{ARC}$ deposited on top of a thin thermal $\mathrm{SiO}_{2}$ passivation layer [185]. For evaluating defect generation at $\mathrm{Si} / \mathrm{SiO}_{2}$ interfaces, $J_{0}$ can be monitored by periodically using photoconductance measurements following exposure to light of a controlled spectrum [185]. Additionally, damp-heat exposure has also been shown to degrade passivation at the $\mathrm{Si} / \mathrm{SiO}_{2}$ interface [186]. In this work, Mclntosh and Dai explain that various $\mathrm{H}$ species $\left(\mathrm{H}, \mathrm{H}^{+}\right.$and $\mathrm{H}_{2}$ ) can diffuse into the bulk $\mathrm{SiO}_{2}$ film and to the $\mathrm{Si} / \mathrm{SiO}_{2}$ interface which can both passivate and depassivate dangling bonds, create new dangling bonds or create non-dangling bond defects. In this case, $J_{0}$ was again monitored, this time periodically following damp-heat exposure.

\subsubsection{Titanium oxide}

Titanium oxide $\left(\mathrm{TiO}_{2}\right.$ or $\left.\mathrm{TiO}_{\mathrm{x}}\right)$ was previously used in the PV industry as an $A R C$ for many years before getting displaced by $\mathrm{SiN}_{\mathrm{x}}$, despite being a very low cost material. The primary reasons for it being displaced are that as-deposited $\mathrm{TiO}_{\mathrm{x}}$ films provide little surface passivation unless accompanied by some type of oxidation step [187] and a lack of $\mathrm{H}$ prevents sufficient grain boundary passivation. While $\mathrm{TiO}_{\mathrm{x}}$ offers some advantages as an ARC (e.g., low cost [188], high index with less absorption), one concern in using a $\mathrm{SiO}_{2} / \mathrm{TiO}_{\mathrm{x}}$ front side stack is the $\mathrm{TiO}_{x}$ coating's permeability. Talló and Mclntosh investigated the damp-heat stability of $\mathrm{SiO}_{2}$ passivated samples with and without $\mathrm{TiO}_{x}$ coatings and found that $\mathrm{TiO}_{x}$ did not protect the samples from damp-heat degradation, in contrast to $\mathrm{SiN}_{\mathrm{x}}$ which can be made impermeable to water vapor [189].

\subsubsection{Aluminum oxide}

Aluminum oxide $\left(\mathrm{Al}_{2} \mathrm{O}_{3}\right.$ or $\left.\mathrm{AlO}_{\mathrm{x}}\right)$ has received significant interest of late due to the ability of to achieve both sufficiently low interface defect densities $\left(D_{\text {it }}<\right.$ $\left.10^{12} \mathrm{~cm}^{-2}\right)$ and large negative fixed charges $\left(\left|Q_{f}\right|>10^{12} \mathrm{~cm}^{-2}\right)$, providing both chemical and field effect passivation of $p$-type and $p^{+}$surfaces (see [190] and references therein). A number of film deposition methods have been used to deposit $\mathrm{AlO}_{\mathrm{x}}$ at production scale, including spatial atomic layer deposition (ALD) [191, 192], sputtering [193-195], PECVD [196-199] and atmospheric pressure CVD (APCVD) [200-202]. While there doesn't seem to be any clear reliability concerns with this material, it is still a rather new material system for PV and requires further study from a reliability and durability perspective. One potential concern is blistering when used with a capping layer (e.g., $\mathrm{SiN}_{\mathrm{x}}$ ), as is common with rear passivated cell architectures on (e.g., pPERC) [203]. However, this issue can be mitigated by using a post-deposition annealing step [203] or a high deposition temperature during $\mathrm{AlO}_{\mathrm{x}}$ deposition [202].

\subsubsection{Amorphous silicon}

Intrinsic hydrogenated amorphous silicon (a-Si:H) is used as the passivation material in high efficiency silicon heterojunction (SHJ) cells. This technology has 
been successfully commercialized by Sanyo and now Panasonic in the form of the heterojunction with intrinsic thin layer (HIT) cell, wherein Panasonic has achieved efficiencies over $25 \%$ and $V_{O C}$ values greater than $740 \mathrm{mV}$.[204]. While there could very well be reliability-related issues associated with this cell architecture, the literature is quite lacking in this area.

\subsubsection{Hafnium oxide}

Hafnium oxide $\left(\mathrm{HfO}_{x}\right)$, deposited by ALD, has recently been investigated as a surface passivation materials for c-Si solar cell applications [205-207]. Similar to $\mathrm{AlO}_{\mathrm{x}}, \mathrm{HfO}_{\mathrm{x}}$ films deposited on Si possess low $D_{\text {it }}\left(<10^{12} \mathrm{~cm}^{-2}\right)$, excellent field effect passivation, and are transparent for wavelengths of relevance to c-Si solar cells. As with $\mathrm{AlO}_{\mathrm{x}}$, this materials has not been investigated comprehensively in terms of reliability and durability.

\subsection{Failure modes and degradation mechanisms related to $A R C$ and passivation}

\subsubsection{Potential induced degradation}

The origin of PID was previously described in the Emitter Formation section of this paper. Regarding the impact of PID on surface passivation, Swanson et al. proposed a metal-oxide-semiconductor (MOS) model to explain the cause of PID in high efficiency, back contact c-Si cells [208]. It was proposed that module leakage current leaves behind negative fixed charges at the surface of the $\mathrm{SiO}_{2} / \mathrm{SiN}_{\mathrm{x}}$ passivated cells leading to inversion layer formation (shunting) and increased surface recombination (e.g., PID-s). Hacke et al. have also showed PID can lead to electrolytic corrosion [158]. This model has since been applied to standard $n^{+} p$ screen-printed cells [156]. Experimental evidence from several studies has linked properties of the $\mathrm{SiN}_{\mathrm{x}}$ film to PID, including refractive index, film density, film uniformity and thickness, in addition to the module glass (e.g., soda lime glass), encapsulation (e.g., EVA) and system configuration issues (e.g., polarity, grounding) [156, 158, 164]. Pingel et al. showed that higher refractive index films (i.e., Si-rich) were more resilient to PID [156]. Another study suggested PID resistant $\mathrm{SiN}_{\mathrm{x}}$ films with low refractive index can be fabricated if the appropriate process parameters are employed [209]. However, no explanation of the influence of specific deposition conditions on PID resistance was provided.

\subsubsection{Induced mechanical stress}

The deposition of $\mathrm{SiN}_{\mathrm{x}}$ on Si wafers can induce stress, thereby affecting the mechanical properties of wafer and potentially impacting the reliability of the finished cell. By measuring wafer bow before and after deposition, multiple authors have found that the stress induced is dependent on the stoichiometry of the $\mathrm{SiN}_{\mathrm{x}}$ film, with the resulting stress being tensile $[210,211]$ in some cases and compressive in others [212]. Wan et al. show an increase in the calculated stress from $x=0.8$ to $x=1.2$ (where $x$ is the $[\mathrm{N}] /[\mathrm{Si}]$ ratio in the film after growth) with a peak occurring at $\approx 1.2$, followed by a reduction in stress as $x$ increases beyond this point [212]. This suggests that Fourier transform infrared (FTIR) spectroscopy might be a method of indirectly avoiding high stress $\mathrm{SiN}_{\mathrm{x}}$ films by monitoring Si-N, N-H and Si-H bond densities. Because mass film density and 
refractive index are related to the film stoichiometry, it is no surprise that a correlation between stress and both film density and refractive index have also been demonstrated [210]. Refractive index measurements using ellipsometry techniques might therefore also be an indirect method of predicting the induced stress following $\mathrm{SiN}_{\mathrm{x}}$ deposition. In the study by Wan et al., no strong correlation between passivation performance and induced stress was observed [212].

In the literature, there is little data on direct methods of measuring the stress induced by the $\mathrm{SiN}_{\mathrm{x}}$ film for $\mathrm{C}$-Si solar cells, aside from the aforementioned method of measuring the curvature of the wafer before and after deposition. For other applications (e.g., microelectronics, MEMS), researchers have also applied Raman/ $\mu$-Raman spectroscopy [213] and nanoindentation [214]. Others have pointed out the possibility of using FTIR, low energy electron diffraction (LEED), and X-ray diffraction (XRD) [215]. A potential non-contact method of directly measuring residual stress is IR polariscopy [40].

\subsubsection{Blistering}

When large amounts of $\mathrm{H}$ are included in the $\mathrm{SiN}_{\mathrm{x}}$ film, as is the case with multicrystalline cells, blistering can occur [216]. It is unclear if this may or may not impact the reliability of the cell. An ammonia surface treatment before $\mathrm{SiN}_{\mathrm{x}}$ deposition has been shown by Hauser et al. to mitigate this process effect without an additional process step [216]. Blistering can lead to increased surface reflectance, which means reflectance measurements could be one way to detect the problem. Optical and electron microscopy performed off-line can be subsequently used to confirm and image blistering or flaking off of the $\mathrm{SiN}_{\mathrm{x}}$ film.

\subsubsection{Background plating and pinhole formation}

In the case of plated contacts, the formation of pinholes during PECVD $\operatorname{SiN}_{x}$ deposition can lead to background plating (i.e., "ghost-plating") in undesired locations on the wafer [217]. While this has an immediate deleterious effect on cell performance, it could also lead to potential long-term reliability and durability concerns, particularly for cells using Cu-plated contacts. Saint-Cast et al. investigated four different methods of characterizing pinholes [218]: (1) measuring resistivity of the dielectric layer using evaporated Al contacts (qualitative method); (2) by applying wafers to an anisotropic etching step (i.e., $\mathrm{KOH}$ texturing), inverted pyramids are formed at locations with large pinholes $\left(\approx 20 \mu \mathrm{m}^{2}\right)$ that are detectable with an optical microscope, while smaller pinholes can be detected by SEM (this method can only be applied to smooth, untextured surfaces); (3) because electroless $\mathrm{Ni}$ plating results in the formation of $\mathrm{Ni}-\mathrm{Si}$ contact only in locations where the dielectric layer is missing, Ni plating followed by subsequent investigation by SEM can be used to observe pinholes; and (4) by plating samples with both $\mathrm{Ni}$ and, subsequently, $\mathrm{Ag}$, the resulting metal points can be made large enough to view with an optical microscope (even for small pinholes), which allows for faster detection over larger areas. 


\subsection{Metrology techniques relevant to $A R C$ and passivation}

In a manufacturing environment, the quality of the $\mathrm{SiN}_{\mathrm{x}}$ films are commonly measured off-line, although many of the methods used are compatible with noncontact, in-line measurements.

The optical performance of these $\mathrm{SiN}_{\mathrm{x}}$ ARCs is commonly determined by measuring reflectance versus wavelength. However, it should be noted that this method doesn't account for absorption in the $\mathrm{SiN}_{\mathrm{x}}$ layer unless transmission measurements are also performed. Spectroscopic ellipsometry is primarily used to measure the complex refractive index $(n, k)$ of the $\mathrm{SiN}_{\mathrm{x}}$ films. Knowing $n$ and $k$, as well as the ARC thickness, the reflectance and absorption of the ARC can be easily calculated. Chemical composition and bond densities affect the complex refractive index (Si-rich films have a higher index with more loss in the blue region) and can be determined using FTIR.

Passivation performance is normally evaluated by measuring the effective minority carrier lifetime $\left(\tau_{\text {eff }}\right)$ and $J_{0}$ via photoconductance $(P C)$ measurements (e.g., photoconductance decay, quasi-steady-state photoconductance) [219]. Spatially-resolved measurements like PL imaging [220] and $\mu$-PCD lifetime mapping [221] can be used for checking passivation film uniformity and other quick failure analysis. Analysis of the local diode ideality factor via contactless $\mathrm{PC}$ or PL measurements can be used to evaluate recombination processes without the influence of series or shunt resistance [222].

$D_{i t}$ and $Q_{f}$ (magnitude and polarity) of passivating dielectrics can be determined using capacitance-voltage $(C-V)$ profiling, however test structures must be fabricated requiring the deposition of patterned metallization [223]. An alternative method of extracting $D_{i t}$ and $Q_{f}$ not requiring metallization is noncontact Corona-voltage measurements [224]. Second harmonic generation is another potential method of measuring $Q_{f}$, however at this point, it seems to be more of a qualitative method [225].

The amount of $\mathrm{H}$ incorporated in the $\mathrm{SiN}_{\mathrm{x}}$ film is related to grain boundary passivation in multicrystalline wafers, and LBIC has been shown as an effective way to monitor grain boundary passivation in multicrystalline wafers (particularly when coupled to materials characterization techniques) [226]. This is important for cell efficiency, but the relationship between $\mathrm{H}$ content and reliability/durability is still unclear. Some commonly used off-line methods for measuring $\mathrm{H}$ content in $\mathrm{SiN}_{\mathrm{x}}$ and other passivation films include (but are not limited to) elastic recoil detection analysis (ERDA) [227], nuclear reaction analysis (NRA) [228] and SIMS $[186,194]$.

To measure the induced stress of Si wafers, the curvature of the wafer (i.e., wafer bow) is measured before and after $\mathrm{SiN}_{\mathrm{x}}$ deposition [212]. IR polariscopy is a potential non-contact method of measuring, and even mapping, stress before and after $\mathrm{SiN}_{\mathrm{x}}$ deposition [40]. Raman/ $\mu$-Raman spectroscopy [213] and nanoindentation [214] are both potential off-line techniques for measuring stress in wafers.

Optical and electron microscopy can be used to image blistering and pinholes, however, less time consuming methods would likely need to be implemented in a manufacturing environment. 
Various characterization methods have been used to identify PID after exposure to HV bias, including: lock-in-thermography (LIT) and EL for macroscopic spatially resolved analysis and shunt identification; SEM with EBIC for more localized, microscopic analysis; and ToF-SIMS depth profiling of chemical composition $[164,166]$. Additionally, Suns- $V_{O C}$ measurements can be used to monitor both $J_{0}$ [208] and the pseudo fill factor $F F$ without influences from $R_{S}$ [158]. Predictive metrology that can screen for susceptible $\mathrm{SiN}_{\mathrm{x}}$ films on the manufacturing floor is still not available, and it is still unclear at this point whether this is even possible.

Other measurement techniques are highly useful in characterizing relevant failure modes after some samples have undergone some level of accelerated aging testing or specialized test setup. For example, to test for PID, module leakage current measurements can be performed in a salient water bath or by applying a conductive past to the front glass, in addition to testing in an environmental chamber with HV bias [158]. However, these types of tests aren't conducive to integration into manufacturing and therefore fall outside the scope of this paper.

\begin{tabular}{|c|c|c|c|}
\hline $\begin{array}{c}\text { ARC and/or } \\
\text { Passivation } \\
\text { Material }\end{array}$ & $\begin{array}{c}\text { Failure Mode } \\
\text { or } \\
\text { Degradation } \\
\text { Type }\end{array}$ & Mechanism(s) & Metrology Method(s) \\
\hline \multirow{5}{*}{$\operatorname{SiN}_{x}$} & $\begin{array}{l}\text { Electrolytic } \\
\text { corrosion }\end{array}$ & $\begin{array}{l}\text { Potential induced } \\
\text { degradation } \\
\text { corrosion of the } \mathrm{SiN}_{x} \\
\text { ARC [158] }\end{array}$ & \multirow{2}{*}{$\begin{array}{l}\text { Scanning electron microscopy (SEM) } \\
\text { Lock-in-thermography (LIT) } \\
\text { Photoluminescence (PL) imaging } \\
\text { Electroluminescence (EL) imaging } \\
\text { Suns- } V_{O C}[158,208] \\
\text { Electron-beam-induced current (EBIC) } \\
\text { Time-of-flight secondary ion mass } \\
\text { spectroscopy (ToF-SIMS) [164, 166] }\end{array}$} \\
\hline & $\begin{array}{l}\text { PID shunting } \\
\text { (PID-s) }\end{array}$ & $\begin{array}{l}\text { Inversion layer } \\
\text { formation (shunting) }\end{array}$ & \\
\hline & $\begin{array}{l}\text { Crack } \\
\text { formation }\end{array}$ & $\begin{array}{l}\text { Induced tensile [210, } \\
211] \text { or compressive } \\
\text { [212] stress caused by } \\
\mathrm{SiN}_{\mathrm{x}} \text { deposition }\end{array}$ & $\begin{array}{l}\text { Fourier transform infrared (FTIR) } \\
\text { Wafer curvature tests [212] } \\
\text { IR polariscopy [40] } \\
\text { Raman/ } \mu \text {-Raman spectroscopy [213] } \\
\text { Nanoindentation [214] }\end{array}$ \\
\hline & Blistering & $\begin{array}{l}\text { Outgassing in } \mathrm{H} \text {-rich } \\
\mathrm{SiN}_{\mathrm{x}}: \mathrm{H} \text { films [216] }\end{array}$ & $\begin{array}{l}\text { Optical microscopy } \\
\text { SEM } \\
\text { Reflectance measurements } \\
\text { Elastic recoil detection analysis (ERDA) } \\
\text { [227] } \\
\text { Nuclear reaction analysis (NRA) [228] } \\
\text { SIMS [186, 194] }\end{array}$ \\
\hline & $\begin{array}{l}\text { Pinhole } \\
\text { formation }\end{array}$ & $\begin{array}{l}\text { Pinhole formation } \\
\text { during } \mathrm{SiN}_{\mathrm{x}} \text { deposition } \\
\text { resulting in } \\
\text { background plating of } \\
\text { metals (e.g., } \mathrm{Cu} \text { ) [217] }\end{array}$ & $\begin{array}{l}\text { Optical microscopy } \\
\text { SEM } \\
\text { Dielectric resistivity measurements [218] }\end{array}$ \\
\hline Thermal $\mathrm{SiO}_{2}$ & $\begin{array}{l}\text { Defect } \\
\text { generation }\end{array}$ & $\begin{array}{l}\text { UV light induced } \\
\text { defects at the charge- } \\
\text { passivated } \\
\text { interface }[184]\end{array}$ & $\begin{array}{l}\text { Photoconductance decay (PCD) [219] } \\
\text { Quasi-steady-state photoconductance } \\
\text { (QSSPC) [219] } \\
\text { Microwave PCD ( } \mu \text {-PCD) mapping [221] } \\
\text { PL imaging [220] }\end{array}$ \\
\hline
\end{tabular}




\begin{tabular}{|c|c|c|c|}
\hline & $\begin{array}{l}\text { Degradation of } \\
\mathrm{SiO}_{2} \\
\text { passivation }\end{array}$ & $\begin{array}{l}\text { Depassivation of } \\
\text { dangling bonds due to } \\
\text { diffusion of } \mathrm{H} \text { species } \\
\text { during damp-heat } \\
\text { exposure [186] }\end{array}$ & $\begin{array}{l}\text { PCD [219] } \\
\text { QSSPC [219] } \\
\mu-P C D \text { mapping [221] } \\
\text { PL imaging [220] } \\
\text { SIMS [186] }\end{array}$ \\
\hline $\mathrm{TiO}_{2}$ or $\mathrm{TiO}_{x}$ & $\begin{array}{l}\text { Degradation of } \\
\text { intermediate } \\
\mathrm{SiO}_{2} \\
\text { passivation } \\
\text { layer }\end{array}$ & $\begin{array}{l}\mathrm{TiO}_{\mathrm{x}} \text { permeability to } \\
\mathrm{H}_{2} \mathrm{O} \text { is higher than } \\
\mathrm{SiN}_{\mathrm{x}} \text {, leading to } \\
\text { degradation during } \\
\text { damp-heat exposure } \\
{[189]}\end{array}$ & $\begin{array}{l}\text { PCD [219] } \\
\text { QSSPC [219] } \\
\mu-P C D \text { mapping [221] } \\
\text { PL imaging [220] }\end{array}$ \\
\hline $\mathrm{Al}_{2} \mathrm{O}_{3}$ or $\mathrm{AlO}_{\mathrm{x}}$ & Blistering & $\begin{array}{l}\text { Gaseous desorption } \\
\text { from the } \mathrm{AlO}_{\mathrm{x}} \text { layer in } \\
\mathrm{AlO}_{\times} / \mathrm{SiN}_{\mathrm{x}} \text { stack [203] }\end{array}$ & $\begin{array}{l}\text { SEM [203] } \\
\text { Light I-V [203] } \\
\text { LBIC [203] } \\
\text { Series resistance imaging using PL [203] }\end{array}$ \\
\hline
\end{tabular}

Table 3. Failure modes, degradation mechanisms and relevant metrology methods related to ARCs and passivation.

\subsection{Gap Analysis}

To date, there appears to be no definitive ability to predictively determine the susceptibility of a $\mathrm{SiN}_{\mathrm{x}}$ film to PID without the need for destructive testing or accelerated aging. Although some qualitative thinking that higher index films are less susceptible to PID, some groups have indicated that even lower index films can still be rather PID resilient. One challenge is that in addition to the $\mathrm{SiN}_{\mathrm{x}}$ layer many other factors at the cell- (e.g, emitter) and module-level (e.g., encapsulation material, glass) can impact the PID resilience, so decoupling the effects of these factors may not be simple. As alluded to in section 3.5, more fundamental studies on PID would likely benefit the PV community.

There seems to be a lack of understanding as to what level of induced stress due to $\mathrm{SiN}_{\mathrm{x}}$ deposition could lead to cracks or other mechanical failures after prolonged exposure in the field and how this stress compares to that induced during downstream manufacturing processes (e.g., cell metallization, cell interconnection).

Fast, non-destructive methods of detecting blistering and pinholes in $\mathrm{SiN}_{\mathrm{x}}$ and other dielectric materials might be useful to the industry, particularly if new c-Si technologies like rear passivated cells and plated contacts gain higher levels of adoption.

Finally, there is little to no information in the literature regarding potential reliability issues associated with silicon heterojunction based solar cells (e.g., HIT cells).

\section{Metallization}

\subsection{Background}

Good ohmic contact with low interfacial recombination velocity between the Si wafer and metal contacts is required for high efficiency solar cells. The quality of this contact will be influenced by paste content, rheology and wetting behavior. Metallization will occur on both the front and rear of the cell, with different requirements for each contact type. For example, the front of the cell must remain as open to light as possible, restricting the coverage of the metal over the 
surface, while the rear of the cell may be completely covered. Thus, the durability of each contact type must be addressed separately. Although several metallization schemes are available, this review will focus on the most widely used method, namely $\mathrm{Ag}$ thin-front-side fingers and busbars with Al-containing full-surface or grid back contacts.

The function of the front metallization is to conduct electrons from the emitter to the ribbon, requiring low contact losses between the $\mathrm{Si}$ wafer and electronically conductive metal. An increase in contact resistance will lead to a decrease in power output. Therefore, the stability of this contact is of critical importance for fielded units. For example, in the 1990s, the power loss associated with increased series resistance accounted for as much as $0.5 \% / y e a r$ of the 1-2\%/year observed in the field [229]. More recently, average long-term annual power losses have been reported to be between $0.7 \%$ and $5 \%$ per annum, with increased series resistance contribution dominating in those modules with power losses greater than 0.5\% [230-232]. For modules with power losses less than $0.5 \%$, the dominant source of degradation was from $I_{S C}$-related losses.

The impact of contact resistance is observed within the series resistance, which may be the result of various different processes, not all of which are associated with the Ag-Si interface. For example, interconnect failure, poor solder joints, and other connection losses will all contribute to an increased series resistance. The impact of the interconnection, solder joints, and other connection issues will be addressed in a separate paper. The focus of this paper is on the cell-level metallization itself.

\subsubsection{Back contact metallization}

Since shading effects are not applicable for conventional rear contacts, this contact frequently covers the entire rear surface. Typically rear contacts employ both $\mathrm{Al}$ and $\mathrm{Ag}$, so as to reduce costs without compromising conductivity. The most common contact application technique is screen-printing, where a screen is placed over the wafer, and a paste containing Ag, solvents, and lead-borosilicate glass, is deposited onto the wafer via squeegee application through the screen. For conventional cells, the back contacts are formed by printing the Ag-bus bars, followed by coating with an Al-containing paste. Since Al is not solderable, in order to interconnect the cells, "islands" or "stripes" of Ag-containing Al-paste are screen-printed onto the back surface, to which the $\mathrm{Cu}$ ribbon will be soldered in the final cell [233]. The Al phase covers the area of the back side not covered by $\mathrm{Ag}$, with a small overlap between the Ag bus bars and Al. After screen-printing both the Ag and Al pastes, the cell is dried to remove the solvent (a.k.a. "bakeout"). A few designs are in use with the back contact, but they can be broadly classified as either full-surface or local contacts.

Full-surface contacts have the entire rear side contacted with Al, which then forms the BSF, hence the term Al-BSF cell. The BSF serves to reduce rear surface recombination by repelling minority carriers. For cell architectures featuring local contacts, a passivating dielectric layer (e.g., $\mathrm{SiN}_{\mathrm{x}}, \mathrm{SiO}_{2}, \mathrm{AlO}_{\mathrm{x}}$ ) covers the Si wafer at the rear, with local areas of the dielectric removed to allow for point or line contacts to be formed [190]. Not only does the passivation 
increase with the inclusion of the dielectric layer, but the reflection increases as well, further improving cell performance [234]. Although other contacting schemes are available, such as IBC, this paper will primarily focus on the fullsurface Al-BSF contacts, since this is the technology used in high-volume manufacturing today [234].

\subsubsection{Front side metallization}

Front side metallization (a.k.a. "fingers") must be able to interface with two different materials: the $\mathrm{Si}$ wafer and the solder-coated $\mathrm{Cu}$ ribbon. During solar cell operation, electron transfer occurs from the Si wafer to the Ag metal fingers, requiring intimate contact between these two phases. The electrons are conducted along the length of the finger to the busbar, transferred to the $\mathrm{Cu}$ ribbon and carried to the next cell in series.

Ideally, the metal fingers are narrow and tall (i.e., large aspect ratio) so as to minimize the optical shadowing on the Si and maximize cross-sectional area of the finger and resultant finger conductivity. In practice, these fingers tend to be 50-90 $\mu \mathrm{m}$ wide (depending on the number of fingers) and 15-30 $\mu \mathrm{m}$ tall, and are deposited mostly by screen-printing techniques [2, 235]. Other common deposition techniques include laser transfer [236], direct printing [235], and plating [237], but this report will focus on screen-printing. For an optimized system, front side screen-printing results in an unbroken $\mathrm{H}$-pattern of narrow fingers connected by wider busbars. Following front side screen-printing, the solvent is baked out, and finally the cell is fired at elevated temperatures (i.e., $>800^{\circ} \mathrm{C}$ ), forming both front and rear contacts simultaneously. Once again, the bake-out and firing conditions must be optimized for the paste and emitter used by the cell manufacturer.

A key factor for a successful front contact $\mathrm{Si} / \mathrm{Ag}$ interface is the ability of the paste to penetrate the $\mathrm{SiN}_{\mathrm{x}} \mathrm{ARC}$ during firing. In the case of the screen-printed cells, this requires the addition of etchants $\left(\mathrm{Pb}-\mathrm{B}-\mathrm{SiO}_{\mathrm{x}}\right.$ glass) within the paste used during screen-printing, and subsequent firing at elevated temperatures $\left(>800^{\circ} \mathrm{C}\right)$. The paste and firing conditions must be optimized such that the paste will etch through the $\mathrm{SiN}_{\mathrm{x}}$ layer, but not through the emitter. After firing, a thin layer of glass is formed between the wafer and finger, through which the electrons must tunnel before being collected by the $\mathrm{Ag}$ finger [238, 239]. Ag crystallites also form within the emitter, due to diffusion into Si and epitaxial growth, and these crystallites contribute significantly to reducing contact resistance $[238,239]$. The amount of both electrically active and inactive $P$ in the emitter has been shown by SEM imaging and EDX analysis to impact $\mathrm{Ag}$ crystallite formation. Increasing the resistance of the emitter results in an increase in inactive $\mathrm{P}$, which increases the contact resistance of the $\mathrm{Ag}$ finger [240]. In the past, commercially available solar cells utilized emitters with sheet resistances of $40-60 \Omega \cdot \mathrm{cm}^{2}$, allowing contact resistances of about $1 \mathrm{~m} \Omega \cdot \mathrm{cm}^{2}$ [2]. Increasing sheet resistance leads to higher $V_{O C}$ and $J_{S C}$, but could come at the expense of increased series resistance (which reduces the fill factor). However, newer paste formulations that allow for good contact with $>70 \Omega \cdot \mathrm{cm}^{2}$ emitters have recently been demonstrated, allowing current cells to feature higher sheet resistances [108, 109, 128, 241]. 


\subsubsection{Alternative metallization technologies}

Metal wrap through (MWT) cells have a modified structure whereby all contacts are made at the rear side. To accomplish this, laser-drilled holes (i.e., vias) are formed through the wafer, allowing the front metallization to be continuous to the rear side. Isolation of the negative and positive electrodes is required, as is emitter formation along the walls of the vias. However, the observed increase in efficiency could potentially compensate for the added complexity. Related to the MWT approach, emitter wrap through (EWT) has also been explored. In this approach, all metal is removed from the front surface, and the emitter is required to collect and conduct electrons to the metallization on the rear surface. Similar to the MWT, the positive and negative electrodes must be insulated from each other in order to achieve high voltages.

Other technologies for contact formation include Cu-plating, laser-transferred contacts, and print-on-print processes and each process has inherent risks. For example, $\mathrm{Cu}$ diffusion must be reduced for Cu-contacts, through $\mathrm{Ti}_{\text {or }} \mathrm{NiSi}_{\mathrm{x}}$ premetallization. If the pre-metallization layer breaks down over time, Cu can diffuse into the Si wafer, which will significantly reduce the minority carrier lifetime [242]. Furthermore, "ghost plating" may occur, where $\mathrm{Cu}$ is deposited in regions away from the fingers. In a similar fashion, $\mathrm{Na}$ has been observed on the surface of $\mathrm{Ni}$ from laser-transferred contacts. Since $\mathrm{Na}$ has been implicated in PID, its presence within the cell should be limited. Print-on-print contact formation may result in poor alignment between printing, increasing shadowing of the front surface.

\subsection{Failure modes related to metallization}

\subsubsection{Screen-printing irregularities}

The ability of the paste to be deposited cleanly and completely onto the surface of the Si will have an impact on durability, as non-connected regions will result in hot spots. In order to effectively deposit Ag paste, the design of the mesh with respect to the paste must be optimized. Design criteria include but are not limited to the mesh/particle size ratio mesh calendaring, emulsion thickness squeegee hardness, snap-off and squeegee speed, pressure and angle [243]. All these parameters will have an impact on the final performance of the fingers, but they must also be balanced against the ability of the Si wafer to withstand the forces. For example, increasing the pressure during screen-printing will decrease contact resistance [244], but it could increase the risk of wafer cracking, particularly for wafers with high TTV.

\subsubsection{Wafer bow}

For the Al pastes used by industry, the Al acts as a $p$-type dopant, creating a BSF that can reduce the surface recombination velocity at the rear side of the cell [245]. However, by contacting the complete surface, residual stress is introduced to the $\mathrm{Si}$, due to CTE mismatch and cooling after the elevated cofiring temperatures. These stresses will lead to bow and warp of the Si wafer, leading to $\mu$-crack formation, and are exaggerated as the wafers become thinner [246]. Reducing the amount of Al deposited on the back surface will alleviate 
some stresses, but too little Al will lead to electrical connectivity issues [247]. If the residual stress does not result in immediate crack formation after co-firing, subsurface cracks may be formed, and subsequent handling (e.g., soldering) may apply sufficient force to form cracks.

\subsubsection{Micro-crack failure mode}

Si wafers are prone to cracking due to their decreasing thickness and brittle nature. These cracks can occur both during handling of the wafer as well as through their operation in the field. The effects of the $\mu$-cracks are to reduce the active cell area through interruption of the metal fingers [248, 249], not to mention the additional risk of wafer breakage during cell processing. These $\mu$ cracks may also influence the durability of the wafer during handling and loading in the field (through snow and ice).

Wafer fracturing after co-firing has been observed to occur along the rear bus-bar for that area with overlap between the Al and Al/Ag bus-bar [250]. As was stated, in order to make contact with the Al surface, solderable Ag/Al paste is applied in stripes or islands. However, this configuration can lead to a decrease in cell strength. Kohn et al. showed that at the overlap between the Al and $\mathrm{Ag} / \mathrm{Al}$ phases, an increase in stress is present, causing breakage forces to significantly decrease $[251,252]$. This is due to the presence of a crack between the two phases, which results in stress-risers at the Si surface, initiating crack formation and eventual propagation at lower stresses than would typically be required for pristine Si. Ensuring a good interface between the $\mathrm{Al}$ and $\mathrm{Al} / \mathrm{Ag}$ phases would assist in reducing the potential for this failure mechanism.

$\mu$-cracks formed during processing increase the risk of cell breakage downstream, increasing $\mathrm{Si}$ wafer costs due to lost materials and equipment downtime. Trautmann et al. reported that for incoming wafers, the presence of cracks decreased the breakage force by more than half [253]. Although the forces applied during processing are minimal, there can be sufficient force to cause breakage. For example, Wagner et al. demonstrated the impact of screenprinting on wafer breakage [254]. Specifically, in their study they found that screen-printing increased the number of cells with cracks by about $1 \%$, and that this is due to repeat errors (e.g., mesh contamination through too infrequent cleaning).

\subsubsection{Over firing (emitter/junction damage)}

An improved short wavelength quantum efficiency can be achieved through the use of shallow emitters $(>65 \Omega / \square$ emitters. However, this can increase the risk of the paste etching completely through the emitter (i.e., punch through). Manipulation of the emitter profile during diffusion can mitigate this [101, 128]. As mentioned in the emitter section, the trend for monocrystalline silicon cells has been towards lower surface concentration and deeper profiles which reduce emitter recombination losses and maintain good metal contact [100-106, 255].

\subsection{Metrology techniques relevant to metallization}

Corescan is frequently used to determine the emitter contact resistance, through measuring the local voltage difference between an illuminated region 
and the back contact [244]. This requires direct contact to the emitter, thereby damaging the antireflective coating and is not applicable to real-time production rate measurements [256]. However, this tool is very useful for optimizing a process, as it can identify not only emitter/metal contact resistance, but can also assist in identifying $\mu$-cracks, over-firing, contamination, and edge isolation errors [257].

CELLO uses a modulated LBIC with lock-in techniques to determine local series and shunt resistances, diffusion length, and BSF. However, due to limitations on the signal-to-noise ratio due in part to the capacitive nature of the $p-n$ junction and linearity requirements, CELLO is also a time-intensive technique, with full-cell scans requiring hours for completion [256, 258]. Thus, this method is not realistic for line-speed measurements.

Determining contact resistance between the emitter and the metallization has been demonstrated through dark and illuminated LIT [256, 259]. In this metrology technique, the cell is imaged in the IR region ( $>10 \mu \mathrm{m}$ wavelength) while a current is applied. Regions of poor contact will be evident as regions of high series resistance, visible on the cell. Shunts can also be located using thermography. An example of this is in detecting cases of over firing (i.e., emitter punch through), as shown in Figure 7.

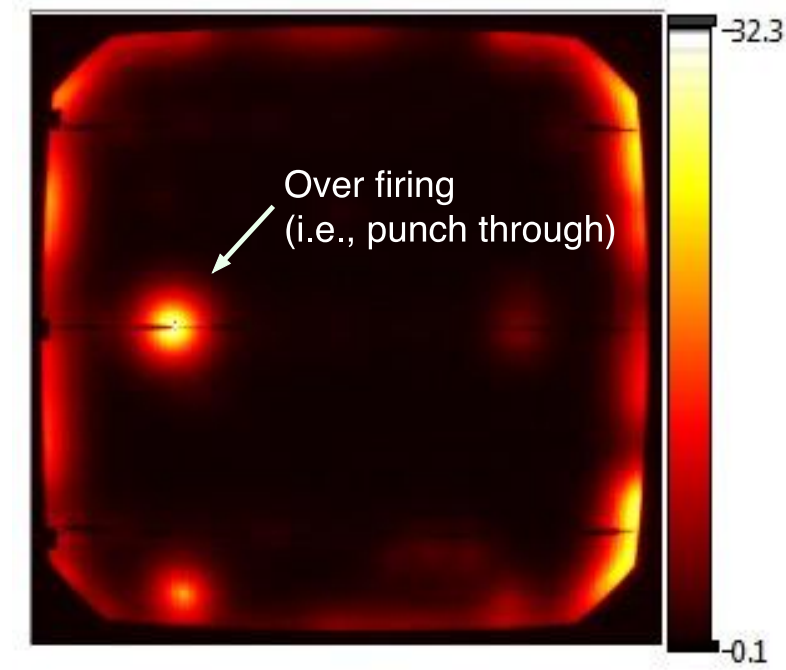

Figure 7. Time-resolved thermography image (Tau Science IRIS-210) highlighting a case of over firing of the emitter.

Ultrasonic methods have been used to examine crack formation within silicon wafers [37]. In this method, the resonance ultrasonic vibrations change as the number and size of cracks increases. Although this technique is not able to provide spatial resolution, it does provide for quick wafer rejection metrics.

Large cracks are easily identified through EL and PL techniques [173, 260, 261]. The requirement of contacts for EL methods limits this technique for use after metallization. However, PL can be applied at the wafer level, and can be a good tool for determining the effect of screen-printing on crack formation. In addition to crack detection, EL and PL techniques have been used to identify series resistances, through modifying the excitation source (either voltage or light 
intensity) [261-263]. Examples of EL images showing grid failure are shown for monocrystalline and multicrystalline $\mathrm{Si}$ in Figure 8(a),(b), and an example of how biased-PL imaging can be used to extract series resistance images for cells is shown in Figure 8(c).

(a)

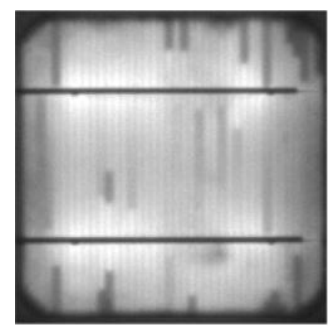

(b)

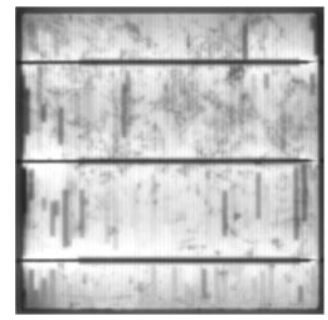

(c)

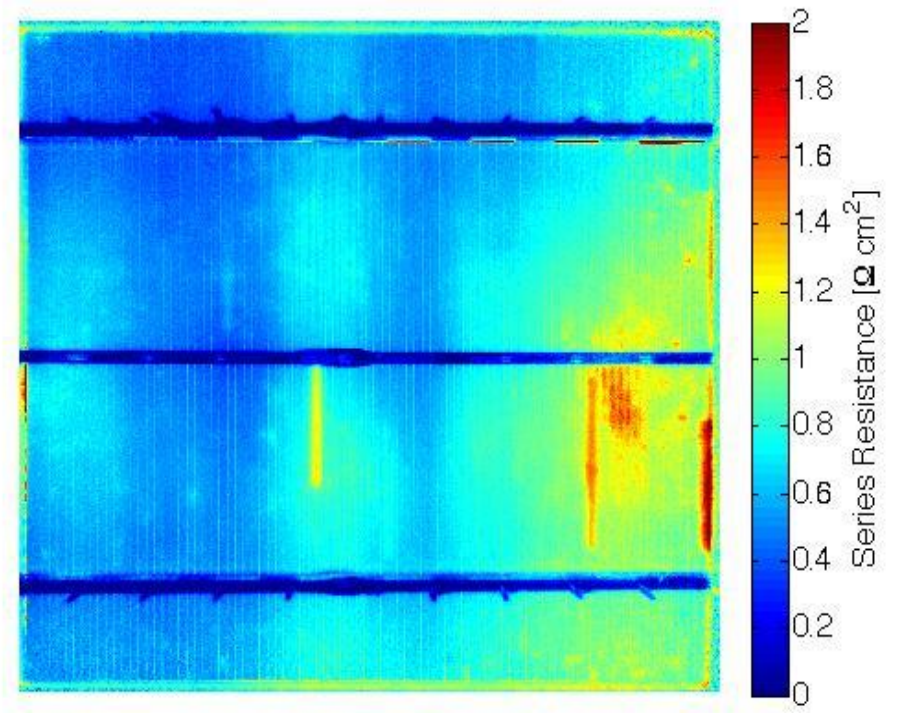

Figure 8. (a) EL image of a monocrystalline Si cell with several gridline failures, represented by the rectangular dark spots. (b) Similar EL image of a multicrystalline Si cell with gridline failures. (c) Series resistance image extracted using biased-PL with a BT Imaging LIS-R1.

One technique that has recently been developed is $x$-ray tomosynthesis, where x-rays are used to probe the internal structure of the solar cell [264]. A benefit of this technique is that a single measurement is able to capture several layers, and discrimination between the layers is possible. Therefore, cavities within the solder on the front side can be separated from voids in the back contact. Also, features within the back contact can be observed, providing a methodology for analysis of field-aged units.

LBIC has been demonstrated to qualitatively probe the variation in rear recombination by using a $980 \mathrm{~nm}$ laser. Lauermann et al. [265] utilized different pastes on passivated rear surfaces and examined how the geometry of the laser fired opening influenced the formation of local back surface fields.

Transmission line method (TLM) is a technique for determining both the resistance of the emitter and the contact resistance. The resistance is measured by determining the voltage difference between fingers separated by varying 
distances. However, this method assumes constant contact resistance among all fingers, requires that no parallel conduction occurs between fingers, and gives information about a very small region of the cell [266]. Generally, a small section of the cell is removed in order to isolate the fingers one from the other, making real-time measurements impossible.

Electron microscopic evaluation (e.g., SEM, TEM) of the samples can identify the glass thickness between the Ag finger and Si wafer, as well as the presence of any voids or gaps [267]. This method requires removal of a section of metalized wafer, subsequent coating to render the sample conductive (if needed), and then placement in an electron beam within a vacuum chamber. As such, sample preparation and testing can be laborious, but information obtained in electron microscopy of $\mathrm{Si}$ wafers and cells can be invaluable in process development.

Scanning spreading resistance microscopy (SSRM) follows an approach similar to AFM, wherein a tip is brought into contact with the surface and a potential is applied between it and the sample. In the case of solar cells, a small section of the cell may be removed, polished, and mounted on a conductive substrate. After applying the polarized tip to the surface, current will flow between the tip and the sample, depending on the local resistance. In this manner, resistance maps may be generated [268]. Since this approach is destructive, it is best suited for off-line process development rather than in-line metrology.

\begin{tabular}{|c|c|c|}
\hline Failure Mode & Mechanism(s) & Metrology Method(s) \\
\hline Hot spot formation & $\begin{array}{l}\text { Front contact screen-printing } \\
\text { irregularities }\end{array}$ & $\begin{array}{l}\text { Corescan [244] } \\
\text { CELLO [256, 258] } \\
\text { Lock-in thermography (LIT) [256, 259] } \\
\text { Electroluminescence (EL) imaging } \\
\text { Photoluminescence (PL) imaging } \\
\text { Scanning electron microscopy (SEM) } \\
\text { Transmission electron microscopy (TEM) } \\
\text { Scanning spreading resistance } \\
\text { microscopy (SSRM) [268] }\end{array}$ \\
\hline \multirow{2}{*}{ Cracking } & $\begin{array}{l}\text { Increased mechanical stress } \\
\text { due to wafer bow induced by } \\
\text { Al rear contact layer }\end{array}$ & \multirow{2}{*}{$\begin{array}{l}\text { Resonance ultrasonic vibrations (RUV) } \\
{[37]} \\
\text { Optical microscopy } \\
\text { Scanning electron microscopy (SEM) } \\
\text { EL imaging } \\
\text { PL imaging }\end{array}$} \\
\hline & Micro-crack formation & \\
\hline
\end{tabular}

Table 4. Failure modes and relevant metrology methods related to cell metallization.

\subsection{Gaps analysis}

There is currently some debate over the durability of $\mathrm{Pb}$-free solder. This may relate to the metallization, since the use of $\mathrm{Pb}$ is to improve the wettability of the solder on the bus-bar surface. Thus, there may be opportunities to modify the metallization such that soldering is facilitated. Additionally, potential reliability issues associated void formation in local Al contacts used in pPERC cells is not 
well understood. A cross-sectional SEM image of this type of void is shown in Figure 9(b).

(a)

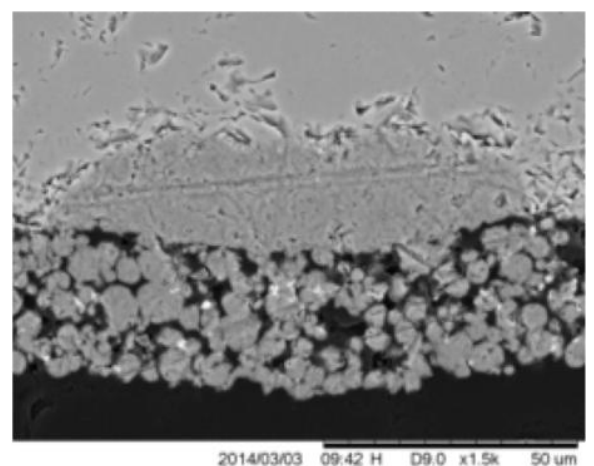

(b)

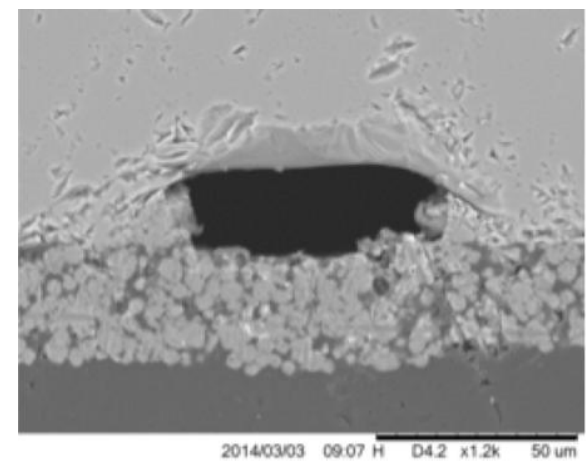

Figure 9. Cross-sectional SEM images of local Al contacts of a pPERC cell with no void (a) and with a void (b).

\section{Summary}

\subsection{Wet chemical processes}

The wet chemical processes that take place after wafer production, including saw damage removal, texturing, edge isolation, and PSG removal can impact the durability and reliability of PV modules. Relevant failure modes that can be induced due to wet chemical processing include the introduction of impurities, etch pits and pre-breakdown, emitter drive-in, melting, crack formation, and scratching. Metrology has focused on characterization of electrical properties, visual observation of damage, mechanical properties, and elemental analysis of the cells. Further research into how high the purity of the chemicals used in manufacturing must be to prevent degradation is needed.

\subsection{Emitter formation}

Emitter formation for Al-BSF solar cells is usually carried out using $\mathrm{POCl}_{3}$ diffusion although alternative approaches like ion implantation are receiving growing attention. Failure modes associated with emitter formation include linear and non-linear shunts, junction pre-breakdown, and potential induced degradation shunting. The characterization of failure modes associated with emitter formation have focused on wafer imaging techniques like DLIT and EL, and micron-level techniques like SIMS, EBIC, and TEM. Shunting and PID mechanisms and the role of emitter formation in such failure modes need further study.

\subsection{Anti-reflection coating and passivation}

Dielectric films perform as ARCs and/or passivation layers in c-Si cells. $\mathrm{SiN}_{x}$ is the primary material used today and the focus of this work, but $\mathrm{SiO}_{2}, \mathrm{TiO}_{2}$, $\mathrm{AlO}_{\mathrm{x}}, \mathrm{a}-\mathrm{Si}: \mathrm{H}$, and $\mathrm{HfO}_{\mathrm{x}}$ are also of interest. Key failure modes associated with $\mathrm{SiN}_{x}$ ARCs include $\mathrm{SiN}_{x}$ corrosion via potential induced degradation, induced mechanical stress, and pinhole formation. Metrology of these failure modes has focused on optical performance, the complex refractive index, chemical composition and bond densities, effective minority carrier lifetime, emitter 
saturation current, and the magnitude and polarity of passivating dielectrics. To improve the ability to relate the metrology of this processing step to cell and module durability it is necessary to develop non-destructive methods to predict PID and identify pinholes in the dielectric materials. It is also necessary to gain understanding of the impacts of stresses imposed by deposition on long-term durability.

\subsection{Metallization}

Metallization is in the form of grids on the front side of the cell and can completely cover the back side of the cell to collect the distributed photogenerated carriers. Failure modes associated with metallization include screen-printing irregularities, wafer bow, $\mu$-cracks, and emitter/junction damage caused by over firing. These failure modes can be characterized by focusing on the contact, series, and shunt resistances, crack formation, and rear recombination velocities. It is necessary to investigate the durability of $\mathrm{Pb}$-free solder.

\section{Conclusion}

In this review paper, Part II of a three-part series on the use of manufacturing metrology to improve PV module reliability and durability across the supply chain, an overview of potential failure modes and degradation mechanisms induced during $\mathrm{c}-\mathrm{Si}$ cell manufacturing is provided. Cell manufacturing processes are grouped into four different areas: (1) wet chemical processes; (2) emitter formation; (3) anti-reflection coating and passivation; and (4) metallization. In each area, an overview of the common processes and materials used by industry is given along with descriptions of known (or potential) reliability issues associated with these manufacturing steps. Additionally, a literature review of measurement techniques aimed at reducing or eliminating the probability of such failures occurring is presented and organized into four tables (one for each of the areas listed above) that connect these measurement and characterization methods to the relevant failure modes and mechanisms.

\section{Acknowledgements}

The authors acknowledge Joel Barnett (Tokyo Electron), Ron Sinton (Sinton Instruments), Fei Yan (Applied Materials), Lynne Dellis (DuPont), Bhushan Sopori (NREL), and Prakash Basnyat (NREL) for their helpful comments.

This material is based upon work supported by the U.S. Department of Energy, Office of Energy Efficiency and Renewable Energy, in the Solar Energy Technologies Program, under Award Number DE-EE0004947.

\section{References}

[1] International Technology Roadmap for Photovoltaic. 5th ed: SEMI; 2014. [2] Neuhaus D-H, Munzer A. Industrial Silicon Wafer Solar Cells. Advances in OptoElectronics. 2007;2007. 
[3] Goodrich AC, Powell DM, James TL, Woodhouse M, Buonassisi T. Assessing the drivers of regional trends in solar photovoltaic manufacturing. Energy \& Environmental Science. 2013;6:2811-21.

[4] Powell DM, Winkler MT, Choi HJ, Simmons CB, Needleman DB, Buonassisi

T. Crystalline silicon photovoltaics: a cost analysis framework for determining technology pathways to reach baseload electricity costs. Energy \& Environmental Science. 2012;5:5874.

[5] Aberle AG, Boreland MB, Hoex B, Mueller T. Industrial Silicon Wafer Solar Cells - Status and Trends. Green. 2012;2:135-48.

[6] De Wolf S, Descoeudres A, Holman ZC, Ballif C. High-efficiency Silicon Heterojunction Solar Cells: A Review. Green. 2012;2:7-24.

[7] Wolden CA, Kurtin J, Baxter JB, Repins I, Shaheen SE, Torvik JT, et al. Photovoltaic manufacturing: Present status, future prospects, and research needs. Journal of Vacuum Science \& Technology A: Vacuum, Surfaces, and Films. 2011;29:030801.

[8] del Cañizo C, del Coso G, Sinke WC. Crystalline silicon solar module technology: Towards the $1 €$ per watt-peak goal. Progress in Photovoltaics: Research and Applications. 2009;17:199-209.

[9] Green MA, Emery K, Hishikawa Y, Warta W, Dunlop ED. Solar cell efficiency tables (Version 45). Progress in Photovoltaics: Research and Applications. 2015;23:1-9.

[10] Kerschaver EV, Beaucarne G. Back-contact solar cells: a review. Progress in Photovoltaics: Research and Applications. 2006;14:107-23.

[11] Swanson RM. A vision for crystalline silicon photovoltaics. Progress in Photovoltaics: Research and Applications. 2006;14:443-53.

[12] Rahman MZ. Advances in surface passivation and emitter optimization techniques of c-Si solar cells. Renewable and Sustainable Energy Reviews. 2014;30:734-42.

[13] Davis KO, Brooker RP, Seigneur HP, Rodgers M, Rudack AC, Schoenfeld WV. Pareto analysis of critical challenges for emerging manufacturing technologies in silicon photovoltaics. Solar Energy. 2014;107:681-91. [14] Coletti G, Gordon I, Schubert MC, Warta W, Johannes Ovrelid E, Jouini A, et al. Challenges for photovoltaic silicon materials. Solar Energy Materials and Solar Cells. 2014;130:629-33.

[15] Goodrich A, Hacke P, Wang Q, Sopori B, Margolis R, James TL, et al. A wafer-based monocrystalline silicon photovoltaics road map: Utilizing known technology improvement opportunities for further reductions in manufacturing costs. Solar Energy Materials and Solar Cells. 2013;114:110-35.

[16] Green MA. The Passivated Emitter and Rear Cell (PERC): From conception to mass production. Solar Energy Materials and Solar Cells. 2015;143:190-7. [17] Koch W, Endrös AL, Franke D, Häßler C, Kalejs JP, Möller HJ. Bulk Crystal Growth and Wafering for PV. In: Luque A, Hegedus S, editors. Handbook of Photovoltaic Science and Engineering. West Sussex, England: John Wiley \& Sons; 2003. p. 205-54. 
[18] Bidiville A, Wasmer K, Michler J, Nasch PM, Van der Meer M, Ballif C. Mechanisms of wafer sawing and impact on wafer properties. Progress in

Photovoltaics: Research and Applications. 2010;18:563-72.

[19] ValTech Corporation.2013.

[20] Moynihan M. An Overview of Wet Chemistry Processing for the Manufacture of Silicon Solar Cells. CircuiTree. 2009;22:16.

[21] Möller HJ. Wafering of silicon crystals. physica status solidi (a). 2006;203:659-69.

[22] Seigneur H, Rudack A, Walters J, Brooker P, Davis KO, Schoenfeld WV, et al. Diamond wire sawing for PV - Short- and long-term challenges. Photovoltaics International. 2015;27:27-39.

[23] Holt A, Thogersen A, Rohr C, Bye J, Helgesen G, Nordseth D, et al. Surface structure of mono-crystalline silicon wafers produced by diamond wire sawing and by standard slurry sawing before and after etching in alkaline solutions. In: 35th IEEE Photovoltaic Specialists Conference; 2010. Honolulu, HI, pp. 0035014.

[24] Wu H, Melkote SN, Danyluk S. Mechanical Strength of Silicon Wafers Cut by Loose Abrasive Slurry and Fixed Abrasive Diamond Wire Sawing. Advanced Engineering Materials. 2012;14:342-8.

[25] Meinel B, Koschwitz T, Acker J. Textural development of SiC and diamond wire sawed sc-silicon wafer. Energy Procedia. 2012;27:330-6.

[26] Teomete E. Roughness damage evolution due to wire saw process. Int $\mathrm{J}$ Precis Eng Manuf. 2011;12:941-7.

[27] Gastinger K, M'Hamdi M, Bergstrøm T, Johnsen L. The importance of temperature control during crystallization and wafering in silicon solar cell production. Photovoltaics International. 2010;7:49-54. [28] Yamada T, Fukunaga M, Ichikawa T, Furuno K, Makino K, Yokoyama A. Prediction of warping in silicon wafer slicing with wire-saw machine. Theoretical and Applied Mechanics Japan. 2002;51:251-8.

[29] Bhagavat S, Kao I. A finite element analysis of temperature variation in silicon wafers during wiresaw slicing. International Journal of Machine Tools and Manufacture. 2008;48:95-106.

[30] Solanki CS. Si Wafer Based Solar Cell Technology. Solar Photovoltaics:

Fundamentals, Technologies and Applications. 2nd ed. Connaught Circus,New

Dehli: PHI Learning Private Limited; 2011. p. 155.

[31] Williams K. Etching. In: Hull R, editor. Properties of Crystalline Silicon. London, UK: INSPEC; 1999. p. 811.

[32] Seidel H, Csepregi L, Heuberger A, Baumgärtel H. Anisotropic Etching of Crystalline Silicon in Alkaline Solutions: I . Orientation Dependence and Behavior of Passivation Layers. Journal of The Electrochemical Society. 1990;137:361226.

[33] Schneider A, Pernau T, Peter K, Fath P. Mechanical Wafer Stability Enhancements and Texturing Effects of Remote Downstream Plasma Etching. In: 3rd World Conference on Photovoltaic Energy Conversion; 2003. Osaka, Japan, pp. 1419-22. 
[34] Chunlan Z, Tao L, Wenjing W, Lei Z, Hailing L, Yehua T, et al. The effect of saw mark on the over-ghosting for acidic textured multicrystalline wafers with silicon nitride anti-reflectance films. In: 37th IEEE Photovoltaic Specialists Conference; 2011. Seattle, WA, pp. 002221-4.

[35] Hahn S, Kugimiya K, Vojtechovsky K, Sifalda M, Yamashita M, Blaustein $\mathrm{PR}$, et al. Characterisation of mirror-polished Si wafers and advanced $\mathrm{Si}$ substrate structures using the magic mirror method. Semiconductor Science and Technology. 1992;7:A80.

[36] Dekkers HFW, De Wolf S, Agostinelli G, Szlufcik J, Pernau T, Amoldbik WM, et al. Investigation on mc-si Bulk Passivation Using Deuterated Silicon-Nitride. In: 3rd World Conference on Photovoltaic Energy Conversion; 2003. Osaka, Japan, pp. 983-6.

[37] Dallas W, Polupan O, Ostapenko S. Resonance ultrasonic vibrations for crack detection in photovoltaic silicon wafers. Meas Sci Technol. 2007;18:852-8. [38] Ostapenko S, Dallas W, Hess D, Polupan O, Wohlgemuth J. Crack Detection and Analyses using Resonance Ultrasonic Vibrations in Crystalline Silicon Wafers. In: 4th World Conference on Photovoltaic Energy Conversion; 2006. Waikoloa, HI, pp. 920-3.

[39] Sopori B, Rupnowski P, Basnyat P, Mehta V. A high throughput, noncontact system for screening silicon wafers predisposed to breakage during solar cell production. In: 37th IEEE Photovoltaic Specialists Conference; 2011. Seattle, WA, pp. 001134-9.

[40] He S, Zheng T, Danyluk S. Analysis and determination of the stress-optic coefficients of thin single crystal silicon samples. Journal of Applied Physics. 2004;96:3103-9.

[41] Bauer J, Wagner JM, Lotnyk A, Blumtritt H, Lim B, Schmidt J, et al. Hot spots in multicrystalline silicon solar cells: avalanche breakdown due to etch pits. physica status solidi (RRL) - Rapid Research Letters. 2009;3:40-2.

[42] Sopori B, Devayajanam S, Shet S, Guhabiswas D, Basnyat P, Moutinho H, et al. Characterizing damage on Si wafer surfaces cut by slurry and diamond wire sawing. In: 39th IEEE Photovoltaic Specialists Conference; 2013. Tampa, FL, pp. 0945-50.

[43] Nievendick J, Zimmer M, Demant M, Krieg A, Rein S, Rentsch J. In-line measurement of "trench structures" caused by the texturization of mc-silicon solar cells. Solar Energy Materials and Solar Cells. 2011;95:3142-7.

[44] Jiang CS, Moutinho HR, Johnston S, Yan Y, Al-Jassim MM, Gorman J, et al. Characterization of laser edge isolation in multicrystalline silicon solar cells. In: 35th IEEE Photovoltaic Specialists Conference; 2010. Honolulu, HI, pp. 0017216.

[45] Fenner DB, Biegelsen DK, Bringans RD. Silicon surface passivation by hydrogen termination: A comparative study of preparation methods. Journal of Applied Physics. 1989;66:419-24.

[46] Popovich VA, Yunus A, Janssen M, Bennett IJ, Richardson IM. Effect of microstructure and processing parameters on mechanical strength of multicrystalline silicon solar cells. In: 35th IEEE Photovoltaic Specialists Conference; 2010. Honolulu, HI, pp. 002222-6. 
[47] Sonner C, Oltersdorf A, Zimmer M, Rentsch J. Influence of Contaminations and Cleaning Sequences on Alkaline Texturisation. In: 26th European

Photovoltaic Solar Energy Conference and Exhibition; 2011. Hamburg, Germany, pp. 1666-70.

[48] Popovich VA, Westra JM, van Swaaij RACMM, Janssen M, Bennett IJ, Richardson IM. Raman spectroscopy characterization of residual stress in multicrystalline silicon solar wafers and solar cells: Relation to microstructure, defects and processing conditions. In: 37th IEEE Photovoltaic Specialists Conference; 2011. Seattle, WA, pp. 001668-73.

[49] Kray D, Hopman S, Spiegel A, Richerzhagen B, Willeke GP. Study on the edge isolation of industrial silicon solar cells with waterjet-guided laser. Solar Energy Materials and Solar Cells. 2007;91:1638-44.

[50] Lausch D, Petter K, Wenckstern Hv, Grundmann M. Correlation of prebreakdown sites and bulk defects in multicrystalline silicon solar cells. physica status solidi (RRL) - Rapid Research Letters. 2009;3:70-2.

[51] Sedao X, Sarnet T, Fares M, Schulz-Ruhtenberg M, Hernàndez JL, Krantz $\mathrm{S}$, et al. High Throughput Laser Junction Isolation for Silicon Solar Cells. In: 25th European Photovoltaic Solar Energy Conference and Exhibition; 2010. Valencia, Spain, pp. 2325-8.

[52] Solanki CS. Si Wafer Based Solar Cell Technology. Solar Photovoltaics : Fundamentals, Technologies and Applications. 2nd ed. Connaught Circus, New Dehli: PHI Learning Private Limited; 2011. p. 155.

[53] Kashkoush I, Chen G, Nemeth D. Characterization of c-Si texturization in wet KOH/IPA and its effect on cell efficiency. In: 26th European Photovoltaic Solar Energy Conference and Exhibition; 2011. Hamburg, Germany, pp. 2020-3. [54] Baker-Finch SC, Mclntosh KR, Terry ML. Isotextured Silicon Solar Cell Analysis and Modeling 1: Optics. IEEE Journal of Photovoltaics. 2012;2:457-64. [55] Baker-Finch SC, McIntosh KR, Terry ML, Yimao W. Isotextured Silicon Solar Cell Analysis and Modeling 2: Recombination and Device Modeling. IEEE Journal of Photovoltaics. 2012;2:465-72.

[56] Lee K-S, Ha M-H, Kim JH, Jeong J-W. Damage-free reactive ion etch for high-efficiency large-area multi-crystalline silicon solar cells. Solar Energy Materials and Solar Cells. 2011;95:66-8.

[57] Sopori B, Rupnowski P, Guhabiswas D, Devayajanam S, Shet S, Khattak $\mathrm{CP}$, et al. A reflectance spectroscopy-based tool for high-speed characterization of silicon wafers and solar cells in commercial production. In: 35th IEEE Photovoltaic Specialists Conference; 2010. Honolulu, HI, pp. 002238-41. [58] Sopori B, Devayajanam S, Rivero R, Rupnowski P. Online monitoring for Si solar cell manufacturing. In: 39th IEEE Photovoltaic Specialists Conference; 2013. Tampa, FL, pp. 0939-44.

[59] Richter PJ, Bottari FJ, Wong DC. PSG trapping of metal contaminants during belt furnace inline phosphorus diffusion in crystalline Si wafers. In: 35th IEEE Photovoltaic Specialists Conference; 2010. Honolulu, HI, pp. 003593-6. [60] Yang C-H. Nano-Crystalline Manipulation to Achieve Laser-based CrackFree Edge Isolation for Silicon-Based Solar Cells. Raleigh, North Carolina: North Carolina State University; 2012. 
[61] Hallam B, Wenham S, Lee H, Lee E, Lee H, Kim J, et al. Effect of edge junction isolation on the performance of laser doped selective emitter solar cells. Solar Energy Materials and Solar Cells. 2011;95:3557-63.

[62] Kyeong D, Gunasekaran M, Kim K, Kim H, Kwon T, Moon I, et al. Laser Edge Isolation for High-efficiency Crystalline Silicon Solar Cells. Journal of the Korean Physical Society. 2009;55:124-8.

[63] Johnson MW, Gildor A. Deposition of contaminants on silicon media during wet processing. In: 37th IEEE Photovoltaic Specialists Conference; 2011.

Seattle, WA, pp. 001079-80.

[64] Johnson MW. Understanding metallic and ionic contamination in photovoltaic wet chemistries from chemical delivery systems. In: 35th IEEE Photovoltaic Specialists Conference; 2010. Honolulu, HI, pp. 003505-9.

[65] Zuschlag A, OhI S, Bernhard J, Morhenn H, Ebser J, Junge J, et al. UXRF investigations on the influence of solar cell processing steps on iron and copper precipitates in multicrystalline silicon. In: 35th IEEE Photovoltaic Specialists Conference; 2010. Honolulu, HI, pp. 000347-51.

[66] Yoon S, Kim J, Choi K. Gettering of metal impurities by using phosphorus diffusion in UMG silicon wafers. Journal of the Korean Physical Society. 2012;60:2079-82.

[67] Fenning DP, Zuschlag AS, Bertoni MI, Lai B, Hahn G, Buonassisi T. Improved iron gettering of contaminated multicrystalline silicon by hightemperature phosphorus diffusion. Journal of Applied Physics. 2013;113:214504. [68] Basore PA, Clugston DA. PC1D version 4 for Windows: from analysis to design. In: 25th IEEE Photovoltaic Specialists Conference; 1996. Washington, DC, pp. 377-81.

[69] Valdes LB. Resistivity Measurements on Germanium for Transistors. Proceedings of the IRE. 1954;42:420-7.

[70] Boussey J. Stripping Hall effect, sheet and spreading resistance techniques for electrical evaluation of implanted silicon layers. Microelectronic Engineering. 1998;40:275-84.

[71] Smits FM. Measurement of Sheet Resistivities with the Four-Point Probe. Bell System Technical Journal. 1958;37:711-8.

[72] Ruland E, Fath P, Pavelka T, Pap A, Peter K, Mizsei J. Comparative study on emitter sheet resistivity measurements for inline quality control. In: 3rd World Conference on Photovoltaic Energy Conversion; 2003. Osaka, Japan, pp. 10857.

[73] Isenberg J, Biro D, Warta W. Fast, contactless and spatially resolved measurement of sheet resistance by an infrared method. Progress in Photovoltaics: Research and Applications. 2004;12:539-52.

[74] Zalm PC. Secondary ion mass spectrometry. Vacuum. 1994;45:753-72. [75] Clarysse T, Vanhaeren D, Hoflijk I, Vandervorst W. Characterization of electrically active dopant profiles with the spreading resistance probe. Materials Science and Engineering: R: Reports. 2004;47:123-206.

[76] Ambridge T, Faktor MM. An automatic carrier concentration profile plotter using an electrochemical technique. J Appl Electrochem. 1975;5:319-28. 
[77] Başaran E. Choice of electrolyte for doping profiling in Si by electrochemical C-V technique. Applied Surface Science. 2001;172:345-50.

[78] Peiner E, Schlachetzki A, Krüger D. Doping Profile Analysis in Si by Electrochemical Capacitance- Voltage Measurements. Journal of The Electrochemical Society. 1995;142:576-80.

[79] De Wolf P, Stephenson R, Trenkler T, Clarysse T, Hantschel T, Vandervorst W. Status and review of two-dimensional carrier and dopant profiling using scanning probe microscopy. Journal of Vacuum Science \&amp; Technology B. 2000;18:361-8.

[80] Duhayon N, Eyben P, Fouchier M, Clarysse T, Vandervorst W, Álvarez D, et al. Assessing the performance of two-dimensional dopant profiling techniques. Journal of Vacuum Science \&amp; Technology B. 2004;22:385-93.

[81] Leamy HJ. Charge collection scanning electron microscopy. Journal of Applied Physics. 1982;53:R51-R80.

[82] Elliott SL, Broom RF, Humphreys CJ. Dopant profiling with the scanning electron microscope-A study of Si. Journal of Applied Physics. 2002;91:911622.

[83] Venables D, Jain H, Collins DC. Secondary electron imaging as a twodimensional dopant profiling technique: Review and update. Journal of Vacuum Science \&amp; Technology B. 1998;16:362-6.

[84] El-Gomati M, Zaggout F, Jayacody H, Tear S, Wilson K. Why is it possible to detect doped regions of semiconductors in low voltage SEM: a review and update. Surface and Interface Analysis. 2005;37:901-11.

[85] Heath JT, Jiang C-S, Al-Jassim MM. Imaging the solar cell P-N junction and depletion region using secondary electron contrast. In: 37th IEEE Photovoltaic Specialists Conference; 2011. Seattle, WA, pp. 001656-61.

[86] Heath JT, Jiang C-S, Al-Jassim MM. Diffused junctions in multicrystalline silicon solar cells studied by complementary scanning probe microscopy and scanning electron microscopy techniques. In: 35th IEEE Photovoltaic Specialists Conference; 2010. Honolulu, HI, pp. 000227-32.

[87] Voyer C, Buettner T, Bock R, Biro D, Preu R. Microscopic homogeneity of emitters formed on textured silicon using in-line diffusion and phosphoric acid as the dopant source. Solar Energy Materials and Solar Cells. 2009;93:932-5. [88] Istratov AA, Buonassisi T, McDonald RJ, Smith AR, Schindler R, Rand JA, et al. Metal content of multicrystalline silicon for solar cells and its impact on minority carrier diffusion length. Journal of Applied Physics. 2003;94:6552-9. [89] Buonassisi T, Istratov AA, Heuer M, Marcus MA, Jonczyk R, Isenberg J, et al. Synchrotron-based investigations of the nature and impact of iron contamination in multicrystalline silicon solar cells. Journal of Applied Physics. 2005;97:074901.

[90] Istratov AA, HiesImair H, Weber ER. Iron contamination in silicon technology. Appl Phys A. 2000;70:489-534.

[91] Myers SM, Seibt M, Schröter W. Mechanisms of transition-metal gettering in silicon. Journal of Applied Physics. 2000;88:3795-819.

[92] Kang JS, Schroder DK. Gettering in silicon. Journal of Applied Physics. 1989;65:2974-85. 
[93] McHugo SA, Hieslmair H, Weber ER. Gettering of metallic impurities in photovoltaic silicon. Appl Phys A. 1997;64:127-37.

[94] Schröter W, Kühnapfel R. Model describing phosphorus diffusion gettering of transition elements in silicon. Applied Physics Letters. 1990;56:2207-9.

[95] Schröter W, Kveder V, Seibt M, Sattler A, Spiecker E. Mechanisms and computer modelling of transition element gettering in silicon. Solar Energy Materials and Solar Cells. 2002;72:299-313.

[96] Cuevas A, Stocks M, Armand S, Stuckings M, Blakers A, Ferrazza F. High minority carrier lifetime in phosphorus-gettered multicrystalline silicon. Applied Physics Letters. 1997;70:1017-9.

[97] Macdonald D, Cuevas A, Kinomura A, Nakano Y. Phosphorus gettering in multicrystalline silicon studied by neutron activation analysis. In: 29th IEEE Photovoltaic Specialists Conference; 2002. New Orleans, LA, pp. 285-8. [98] Talvitie H, Vähänissi V, Haarahiltunen A, Yli-Koski M, Savin H. Phosphorus and boron diffusion gettering of iron in monocrystalline silicon. Journal of Applied Physics. 2011;109:093505.

[99] Bentzen A, Holt A, Kopecek R, Stokkan G, Christensen JS, Svensson BG. Gettering of transition metal impurities during phosphorus emitter diffusion in multicrystalline silicon solar cell processing. Journal of Applied Physics. 2006;99:093509.

[100] Komatsu Y, Koorn M, Vlooswijk AHG, Venema PR, Stassen AF. Efficiency Improvement by Deeper Emitter with Lower Sheet Resistance for Uniform Emitters. Energy Procedia. 2011;8:515-20.

[101] Komatsu Y, Stassen AF, Venema P, Vlooswijk AHG, Meyer C, Koorn M. Sophistication of doping profile manipulation - emitter performance improvement without additional process step. In: 25th European Photovoltaic Solar Energy Conference and Exhibition; 2010. Valencia, Spain, pp. 1924-9.

[102] Safiei A, Windgassen H, Wolter K, Kurz H. Emitter Profile Tailoring to Contact Homogeneous High Sheet Resistance Emitter. Energy Procedia. 2012;27:432-7.

[103] Ebong A, Cooper IB, Rounsaville BC, Zimbardi F, Upadhyaya A, Rohatgi A, et al. Formation of high quality screen-printed contacts to homogeneous high sheet resistance emitters (HHSE). In: 37th IEEE Photovoltaic Specialists Conference; 2011. Seattle, WA, pp. 002157-60.

[104] Cooper I, Tate K, Carroll A, Mikeska K, Reedy R, Rohatgi A. High efficiency achieved on POCL3 emitter Si solar cells with low saturation current density while reducing Ag consumption by 40-60\%. In: 27th European Photovoltaic Solar Energy Conference and Exhibition; 2012. Frankfurt am Main, Germany, pp. 6147.

[105] Scardera G, Meisel A, Mikeska K, Carroll A, Burrows M, Poplavskyy D, et al. High Efficiency Phosphorus Emitters for Industrial Solar Cells: Comparing Advanced Homogeneous Emitter Cells and Selective Emitters using Silicon Ink Technology. In: 27th European Photovoltaic Solar Energy Conference and Exhibition; 2012. Frankfurt am Main, Germany, pp. 923-5. 
[106] Dastgheib-Shirazi A, Steyer M, Micard G, Wagner H, Altermatt P, Hahn G. Effects of process conditions for the $n+-$-emitter formation in crystalline silicon. In: 38th IEEE Photovoltaic Specialists Conference; 2012. Austin, TX, pp. 001584-9. [107] Dastgheib-Shirazi A, Steyer M, Micard G, Wagner H, Altermatt PP, Hahn G. Relationships between Diffusion Parameters and Phosphorus Precipitation during the POCl3 Diffusion Process. Energy Procedia. 2013;38:254-62. [108] Mikeska K, Li Z, VerNooy PD, Liang L, Carroll AF, Chou J, et al. New thick film paste flux for contacting silicon solar cells. In: 26th European Photovoltaic Solar Energy Conference and Exhibition; 2011. Hamburg, Germany, pp. 502-4. [109] Mikeska KR, Carroll AF, Hanna LG, Lewittes ME, Li Z, Liang L, et al. Thick film pastes for contacting homogeneous lightly doped n-type emitters enabling high blue light response. In: 27th European Photovoltaic Solar Energy Conference and Exhibition; 2012. Frankfurt am Main, Germany, pp. 1717-21. [110] Burrows MZ, Meisel A, Balakrishnan D, Tran A, Inns D, Kim E, et al. Frontside Ag contacts enabling superior recombination and fine-line performance. In: 39th IEEE Photovoltaic Specialists Conference; 2013. Tampa, FL, pp. 2171-5. [111] Bentzen A, Schubert G, Christensen JS, Svensson BG, Holt A. Influence of temperature during phosphorus emitter diffusion from a spray-on source in multicrystalline silicon solar cell processing. Progress in Photovoltaics: Research and Applications. 2007;15:281-9.

[112] Voyer C, Biro D, Buettner T, Preu R. Mechanisms involved in the formation of phosphosilicate glass by dehydration of sprayed phosphoric acid in an in-line diffusion furnace. In: 22nd European Photovoltaic Solar Energy Conference and Exhibition; 2007. Milan, Italy.

[113] Hartiti B, Slaoui A, Muller JC, Stuck R, Siffert P. Phosphorus diffusion into silicon from a spin- on source using rapid thermal processing. Journal of Applied Physics. 1992;71:5474-8.

[114] Doshi P, Mejia J, Tate K, Rohatgi A. Integration of screen-printing and rapid thermal processing technologies for silicon solar cell fabrication. IEEE Electron Device Letters. 1996;17:404-6.

[115] Biro D, Preu R, Schultz O, Peters S, Huljic DM, Zickermann D, et al. Advanced diffusion system for low contamination in-line rapid thermal processing of silicon solar cells. Solar Energy Materials and Solar Cells. 2002;74:35-41.

[116] Gangopadhyay U, Park S, Kim K, Park J, Kim D, Yi J. Large area monocrystalline silicon solar cell using SOD. In: 3rd World Conference on Photovoltaic Energy Conversion; 2003. Osaka, Japan, pp. 1431-4.

[117] Liu Z, Takato H, Togashi C, Sakata I. Oxygen-atmosphere heat treatment in spin-on doping process for improving the performance of crystalline silicon solar cells. Applied Physics Letters. 2010;96:153503.

[118] Bentzen A. Phosphorus Diffusion and Gettering in Silicon Solar Cells. Oslo, Norway: University of Oslo; 2006.

[119] Hoarfrost ML, Takei K, Ho V, Heitsch A, Trefonas P, Javey A, et al. SpinOn Organic Polymer Dopants for Silicon. The Journal of Physical Chemistry Letters. 2013;4:3741-6. 
[120] Debarge L, Schott M, Muller JC, Monna R. Selective emitter formation with a single screen-printed p-doped paste deposition using out-diffusion in an RTPstep. Solar Energy Materials and Solar Cells. 2002;74:71-5.

[121] Sangwook P, Cho E, Kim D. Toward a High Efficiency Siliocn Solar CellsSimplified Cell Processing using Paste Contained Phosphorous Compounds. In: 4th World Conference on Photovoltaic Energy Conversion; 2006. Waikoloa, $\mathrm{HI}$, pp. 1231-3.

[122] Bueno G, Freire I, Varner K, Pérez L, Lago R, Jimeno J, et al.

Simultaneous diffusion of screen printed boron and phosphorus paste for bifacial silicon solar cells. In: 20th European Photovoltaic Solar Energy Conference and Exhibition; 2005. Munich, Germany, pp. 1458-61.

[123] Salami J, Pham T, Khadilkar C, McViker K, Shaikh A. Characterization of screen printed phosphorus diffusion paste for Silicon solar cells. In: Technical Digest of the International PVSEC-14; 2004. Bangkok, Thailand.

[124] Edwards M, Bocking J, Cotter JE, Bennett N. Screen-print selective diffusions for high-efficiency industrial silicon solar cells. Progress in Photovoltaics: Research and Applications. 2008;16:31-45.

[125] Vallejo B, González-Mañas M, Caballero MA. X-ray topography study of monocrystalline silicon wafers diffused with phosphorus by different methods. Appl Phys A. 2013;113:531-6.

[126] Benick J, Rentsch J, Schetter C, Voyer C, Biro D, Preu R. PECVD PSG as a dopant source for industrial solar cells. In: 21st European Photovoltaic Solar Energy Conference and Exhibition; 2006. Dresden, Germany, pp. 1012-5. [127] Sivoththaman S, Laureys W, De Schepper P, Nijs J, Mertens R. Selective emitters in Si by single step rapid thermal diffusion for photovoltaic devices. IEEE Electron Device Letters. 2000;21:274-6.

[128] Davis KO, Jiang KY, Demberger C, Zunft H, Haverkamp H, Habermann D, et al. Improved control of the phosphorous surface concentration during in-line diffusion of c-Si solar cells by APCVD. Phys Status Solidi-R. 2013;7:319-21. [129] HiesImair H, Mandrell L, Sullivan J, Chun M, Zhuo L, Zhu R, et al. High Productivity Ion Implantation for 19\% Efficient Industrial Silicon Solar Cells. In: 27th European Photovoltaic Solar Energy Conference and Exhibition; 2012.

Frankfurt am Main, Germany, pp. 1901-5.

[130] Jaeger RC. Introduction to Microelectronic Fabrication: Volume 5 of Modular Series on Solid State Devices: Addison-Wesley Publishing Company, Inc.; 1988.

[131] Chun M, Mandrell L, Stavrides A, Sullivan J, Latchford I, Adibi B.

Comparison of Post-Implant Annealing Behavior between Continuous Flux Ion Implantation and Pulsed Ion Implantation for Solid Phase Expitaxial Re-Growth Applications. In: 27th European Photovoltaic Solar Energy Conference and Exhibition; 2012. Frankfurt am Main, Germany, pp. 1950-3.

[132] Westbrook RD, Wood RF, Jellison GE. Glow- discharge- implanted, thermally annealed, oxide- passivated silicon solar cells of $19 \%$ efficiency. Applied Physics Letters. 1987;50:469-71.

[133] Spitzer MB, Tobin SP, Keavney CJ. High-efficiency ion-implanted silicon solar cells. IEEE Transactions on Electron Devices. 1984;31:546-50. 
[134] Dubé CE, Tsefrekas B, Buzby D, Tavares R, Zhang W, Gupta A, et al. High efficiency selective emitter cells using patterned ion implantation. Energy Procedia. 2011;8:706-11.

[135] Rohatgi A, Meier DL, McPherson B, Ok Y-W, Upadhyaya AD, Lai J-H, et al. High-Throughput Ion-Implantation for Low-Cost High-Efficiency Silicon Solar Cells. Energy Procedia. 2012;15:10-9.

[136] Applied Materials Solion XP Ion Implanter.2013.

[137] Wang X-S, Li Y-M, Zhang L-J. Over 19\% CE c- Si cells enabled by ion implantation. In: 27th European Photovoltaic Solar Energy Conference and Exhibition; 2012. Frankfurt am Main, Germany, pp. 1558-62.

[138] Han W, Shan W, Jiang Q, Li Y, Qiu Z, Li J, et al. Mass Production Implementation of Solion Ion Implantation Technology. In: 27th European Photovoltaic Solar Energy Conference and Exhibition; 2012. Frankfurt am Main, Germany, pp. 1498-502.

[139] Jeon M, Lee J, Kim S, Lee W, Cho E. Ion implanted crystalline silicon solar cells with blanket and selective emitter. Materials Science and Engineering: B. 2011;176:1285-90.

[140] Jian W, Yunyu L, Xusheng W, Lingjun Z. Application of ion Implantation Emitter in PERC Solar Cells. IEEE Journal of Photovoltaics. 2014;4:52-7.

[141] Dullweber T, Hesse R, Bhosle V, Dubé C. Ion-implanted PERC Solar Cells with Al2O3/SiNx Rear Passivation. Energy Procedia. 2013;38:430-5.

[142] Benick J, Müller R, Bateman N, Hermle M, Glunz S. Fully implanted n-type PERT solar cells. In: 27th European Photovoltaic Solar Energy Conference and Exhibition; 2012. Frankfurt am Main, Germany, pp. 676-9.

[143] Yuguo T, Young-Woo O, Zimbardi F, Upadhyaya AD, Jiun-Hong L, Ning S, et al. Fully Ion-Implanted and Screen-Printed 20.2\% Efficient Front Junction Silicon Cells on $239 \mathrm{~cm} 2 \mathrm{n}$-Type CZ Substrate. IEEE Journal of Photovoltaics. 2014;4:58-63.

[144] Boscke TS, Kania D, Schollhorn C, Stichtenoth D, Helbig A, Sadler P, et al. Fully Ion Implanted and Coactivated Industrial n-Type Cells With 20.5\% Efficiency. IEEE Journal of Photovoltaics. 2014;4:48-51.

[145] Su S-P, Huang Y-H, Kang C-M, Chen SHT, Cheng L-W. The investigation of implanted boron emitter for $n$-type bifacial silicon solar cells. In: 39th IEEE Photovoltaic Specialists Conference; 2013. Tampa, FL, pp. 1242-5.

[146] Bateman N, Sullivan P, Reichel C, Benick J, Hermle M. High quality ion implanted boron emitters in an interdigitated back contact solar cell with $20 \%$ efficiency. Energy Procedia. 2011;8:509-14.

[147] Romer U, Peibst R, Ohrdes T, Larionova Y, Harder NP, Brendel R, et al. Counterdoping with patterned ion implantation. In: 39th IEEE Photovoltaic Specialists Conference; 2013. Tampa, FL, pp. 1280-4.

[148] Breitenstein O, Rakotoniaina JP, Al Rifai MH, Werner M. Shunt types in crystalline silicon solar cells. Progress in Photovoltaics: Research and Applications. 2004;12:529-38.

[149] Breitenstein O, Bauer J, Wagner JM, Lotnyk A. Imaging physical parameters of pre-breakdown Sites by lock-in thermography techniques. Progress in Photovoltaics: Research and Applications. 2008;16:679-85. 
[150] Herrmann W, Wiesner W, Vaassen W. Hot spot investigations on PV modules-new concepts for a test standard and consequences for module design with respect to bypass diodes. In: 26th IEEE Photovoltaic Specialists Conference; 1997. Anaheim, CA, pp. 1129-32.

[151] Breitenstein O, Bauer J, Rakotoniaina JP. Material-induced shunts in multicrystalline silicon solar cells. Semiconductors. 2007;41:440-3.

[152] Kwapil W, Kasemann M, Gundel P, Schubert M, Warta W, Breitenstein O, et al. Physical mechanisms of breakdown in multicrystalline silicon solar cells. In: 24th European Photovoltaic Solar Energy Conference and Exhibition; 2009. Hamburg, Germany, pp. 896-900.

[153] Lausch D, Petter K, Bakowskie R, Czekalla C, Lenzner J, von Wenckstern $\mathrm{H}$, et al. Identification of pre-breakdown mechanism of silicon solar cells at low reverse voltages. Applied Physics Letters. 2010;97:073506.

[154] Kwapil W, Gundel P, Schubert MC, Heinz FD, Warta W, Weber ER, et al. Observation of metal precipitates at prebreakdown sites in multicrystalline silicon solar cells. Applied Physics Letters. 2009;95:232113.

[155] Breitenstein O, Bauer J, Trupke T, Bardos RA. On the detection of shunts in silicon solar cells by photo- and electroluminescence imaging. Progress in Photovoltaics: Research and Applications. 2008;16:325-30.

[156] Pingel S, Frank O, Winkler M, Daryan S, Geipel T, Hoehne H, et al. Potential Induced Degradation of Solar Cells and Panels. In: 35th IEEE Photovoltaic Specialists Conference; 2010. Seattle, WA, pp. 002817-22. [157] del Cueto JA, McMahon TJ. Analysis of leakage currents in photovoltaic modules under high-voltage bias in the field. Progress in Photovoltaics: Research and Applications. 2002;10:15-28.

[158] Hacke P, Terwilliger K, Smith R, Glick S, Pankow J, Kempe M, et al. System voltage potential-induced degradation mechanisms in PV modules and methods for test. In: 37th IEEE Photovoltaic Specialists Conference; 2011. Seattle, WA, pp. 000814-20.

[159] Schutze M, Junghanel M, Koentopp MB, Cwikla S, Friedrich S, Muller JW, et al. Laboratory study of potential induced degradation of silicon photovoltaic modules. In: 37th IEEE Photovoltaic Specialists Conference; 2011. Seattle, WA, pp. 000821-6.

[160] Koch S, Seidel C, Grunow P, Krauter S, Schoppa M. Polarization effects and tests for crystalline silicon cells. In: 26th European Photovoltaic Solar Energy Conference and Exhibition; 2011. Hamburg, Germany, pp. 1726-31.

[161] Hacke P, Kempe M, Terwilliger K, Glick S, Call N, Johnston S, et al. Characterization of multicrystalline silicon modules with system bias voltage applied in damp heat. In: 25th European Photovoltaic Solar Energy Conference and Exhibition; 2010. Valencia, Spain, pp. 3760-5.

[162] Nagel H, Metz A, Wangemann K. Crystalline Si solar cells and modules featuring excellent stability against potential-induced degradation. In: 26th European Photovoltaic Solar Energy Conference and Exhibition; 2011. Hamburg, Germany, pp. 3107-12.

[163] Raykov A. Towards a Root Cause Model for Potential-Induced Degradation in Crystalline Silicon Photovoltaic Cells and Modules. In: 28th European 
Photovoltaic Solar Energy Conference and Exhibition; 2013. Paris, France, pp. 2998-3002.

[164] Naumann V, Hagendorf C, Grosser S, Werner M, Bagdahn J. Micro Structural Root Cause Analysis of Potential Induced Degradation in c-Si Solar Cells. Energy Procedia. 2012;27:1-6.

[165] Naumann V, Lausch D, Hähnel A, Bauer J, Breitenstein O, Graff A, et al. Explanation of potential-induced degradation of the shunting type by $\mathrm{Na}$ decoration of stacking faults in Si solar cells. Solar Energy Materials and Solar Cells. 2014;120:383-9.

[166] Bauer J, Naumann V, Großer S, Hagendorf C, Schütze M, Breitenstein O. On the mechanism of potential-induced degradation in crystalline silicon solar cells. physica status solidi (RRL) - Rapid Research Letters. 2012;6:331-3. [167] Naumann V, Lausch D, Graff A, Werner M, Swatek S, Bauer J, et al. The role of stacking faults for the formation of shunts during potential-induced degradation of crystalline Si solar cells. physica status solidi (RRL) - Rapid Research Letters. 2013;7:315-8.

[168] Breitenstein O, Rakotoniaina JP, Rifai MHA. Quantitative evaluation of shunts in solar cells by lock-in thermography. Progress in Photovoltaics: Research and Applications. 2003;11:515-26.

[169] Kasemann M, Walter B, Warta W. Reliable hot-spot classification in $10 \mathrm{~ms}$ using ultra-fast lock-in thermography. Progress in Photovoltaics: Research and Applications. 2009;17:441-50.

[170] Fuyuki T, Kondo H, Yamazaki T, Takahashi Y, Uraoka Y. Photographic surveying of minority carrier diffusion length in polycrystalline silicon solar cells by electroluminescence. Applied Physics Letters. 2005;86:262108.

[171] Würfel P, Trupke T, Puzzer T, Schäffer E, Warta W, Glunz SW. Diffusion lengths of silicon solar cells from luminescence images. Journal of Applied Physics. 2007;101:123110.

[172] Trupke T, Bardos RA. Photoluminescence: a surprisingly sensitive lifetime technique. In: 31st IEEE Photovoltaic Specialists Conference; 2005. Orlando, FL, pp. 903-6.

[173] Trupke T, Bardos RA, Schubert MC, Warta W. Photoluminescence imaging of silicon wafers. Applied Physics Letters. 2006;89:044107.

[174] Augarten Y, Trupke T, Lenio M, Bauer J, Weber JW, Juhl M, et al. Calculation of quantitative shunt values using photoluminescence imaging.

Progress in Photovoltaics: Research and Applications. 2013;21:933-41. [175] Marek J. Light- beam- induced current characterization of grain boundaries. Journal of Applied Physics. 1984;55:318-26.

[176] Donolato C. Theory of beam induced current characterization of grain boundaries in polycrystalline solar cells. Journal of Applied Physics.

1983;54:1314-22.

[177] Schneller E, Shiradkar NS, Dhere NG. Performance variation of commercially available modules after six months of outdoor system voltage stress testing. In: 40th IEEE Photovoltaic Specialists Conference; 2014. Denver, CO, pp. 3216-9. 
[178] Aberle AG. Surface Passivation of Crystalline Silicon Solar Cells: A Review. Progress in Photovoltaics: Research and Applications. 2000;8:473-87.

[179] McIntosh KR. Lumps, Humps and Bumps: Three detrimental effects in the current-voltage curve of a silicon solar cell: University of New South Wales;

2001.

[180] McIntosh KR, Baker-Finch SC. OPAL 2: Rapid optical simulation of silicon solar cells. In: 38th IEEE Photovoltaic Specialists Conference; 2012. Austin, TX, pp. 265-71.

[181] Duttagupta S, Ma F, Hoex B, Mueller T, Aberle AG. Optimised Antireflection Coatings using Silicon Nitride on Textured Silicon Surfaces based on Measurements and Multidimensional Modelling. Energy Procedia.

2012;15:78-83.

[182] Aberle AG. Overview on SiN surface passivation of crystalline silicon solar cells. Solar Energy Materials and Solar Cells. 2001;65:239-48.

[183] Green MA, Zhao J, Wang A, Wenham SR. Very high efficiency silicon solar cells-science and technology. IEEE Transactions on Electron Devices.

1999;46:1940-7.

[184] Kooi E. Effects of ionizing irradiations on the properties of oxide covered silicon surfaces. Philips Research Reports. 1965;20:595-619.

[185] Black LE, McIntosh KR. Defect Generation at Charge-Passivated Si-SiO2 Interfaces by Ultraviolet Light. IEEE Transactions on Electron Devices.

2010;57:1996-2004.

[186] McIntosh KR, Dai X. Damp-heat degradation and repair of oxide-passivated silicon. physica status solidi (a). 2011;208:1931-6.

[187] Richards BS, Cotter JE, Honsberg CB. Enhancing the surface passivation of TiO2 coated silicon wafers. Applied Physics Letters. 2002;80:1123-5.

[188] Richards BS. Single-material TiO2 double-layer antireflection coatings.

Solar Energy Materials and Solar Cells. 2003;79:369-90.

[189] Talló MC, Mclntosh KR. Permeability of TiO2 Anti-Reflection Coatings to

Damp Heat. In: 24th European Photovoltaic Solar Energy Conference and

Exhibition; 2009. Hamburg, Germany, pp. 2037-40.

[190] Dingemans G, Kessels E. Status and prospects of Al2O3-based surface passivation schemes for silicon solar cells. J Vac Sci Technol A.

2012;30:040802.

[191] Poodt P, Lankhorst A, Roozeboom F, Spee K, Maas D, Vermeer A. Highspeed spatial atomic-layer deposition of aluminum oxide layers for solar cell passivation. Advanced Materials. 2010;22:3564-7.

[192] Vermang B, Rothschild A, Racz A, John J, Poortmans J, Mertens R, et al. Spatially separated atomic layer deposition of $\mathrm{Al} 2 \mathrm{O} 3$, a new option for highthroughput Si solar cell passivation. Progress in Photovoltaics: Research and Applications. 2011;19:733-9.

[193] Li T-T, Cuevas A. Effective surface passivation of crystalline silicon by rf sputtered aluminum oxide. physica status solidi (RRL) - Rapid Research Letters. 2009;3:160-2. 
[194] Li T-TA, Cuevas A. Role of hydrogen in the surface passivation of crystalline silicon by sputtered aluminum oxide. Progress in Photovoltaics: Research and Applications. 2011;19:320-5.

[195] Li T-TA, Ruffell S, Tucci M, Mansoulié Y, Samundsett C, De lullis S, et al. Influence of oxygen on the sputtering of aluminum oxide for the surface passivation of crystalline silicon. Solar Energy Materials and Solar Cells. 2011;95:69-72.

[196] Miyajima S, Irikawa J, Yamada A, Konagai M. High Quality Aluminum Oxide Passivation Layer for Crystalline Silicon Solar Cells Deposited by ParallelPlate Plasma-Enhanced Chemical Vapor Deposition. Applied Physics Express. 2010;3:012301.

[197] Saint-Cast P, Benick J, Kania D, Weiss L, Hofmann M, Rentsch J, et al. High-efficiency c-Si solar cells passivated with ALD and PECVD aluminum oxide. IEEE Electron Devices Letters. 2012;31:695-7.

[198] Saint-Cast P, Kania D, Heller R, Kuehnhold S, Hofmann M, Rentsch J, et al. High-temperature stability of c-Si surface passivation by thick PECVD Al2O3 with and without hydrogenated capping layers. Applied Surface Science. 2012;258:8371-6.

[199] Saint-Cast P, Kania D, Hofmann M, Benick J, Rentsch J, Preu R. Very low surface recombination velocity on $\mathrm{p}$-type $\mathrm{c}$-Si by high-rate plasma-deposited aluminum oxide. Applied Physics Letters. 2009;95:151502.

[200] Black LE, Allen T, Cuevas A, McIntosh KR, Veith B, Schmidt J. Thermal stability of silicon surface passivation by APCVD Al2O3. Solar Energy Materials and Solar Cells. 2013;120:339-45.

[201] Black LE, McIntosh KR. Surface passivation of c-Si by atmospheric pressure chemical vapor deposition of Al2O3. Applied Physics Letters. 2012;100:202107.

[202] Davis KO, Jiang K, Wilson M, Demberger C, Zunft H, Haverkamp H, et al. Influence of precursor gas ratio and firing on silicon surface passivation by APCVD aluminium oxide. physica status solidi (RRL) - Rapid Research Letters. 2013;7:942-5.

[203] Vermang B, Goverde H, Uruena A, Lorenz A, Cornagliotti E, Rothschild A, et al. Blistering in ALD Al2O3 passivation layers as rear contacting for local Al BSF Si solar cells. Solar Energy Materials and Solar Cells. 2012;101:204-9. [204] Masuko K, Shigematsu M, Hashiguchi T, Fujishima D, Kai M, Yoshimura N, et al. Achievement of More Than 25\% Conversion Efficiency With Crystalline Silicon Heterojunction Solar Cell. IEEE Journal of Photovoltaics. 2014;4:1433-5. [205] Lin F, Hoex B, Koh YH, Lin J, Aberle AG. Low-Temperature Surface Passivation of Moderately Doped Crystalline Silicon by Atomic-Layer-Deposited Hafnium Oxide Films. ECS Journal of Solid State Science and Technology. 2012;2:N11-N4.

[206] Wang J, Mottaghian SS, Baroughi MF. Passivation Properties of AtomicLayer-Deposited Hafnium and Aluminum Oxides on Si Surfaces. IEEE Transactions on Electron Devices. 2012;59:342-8. 
[207] Lin F, Hoex B, Koh YH, Lin JJ, Aberle AG. Low-temperature Surface Passivation of Moderately Doped Crystalline Silicon by Atomic-layer-deposited Hafnium Oxide Films. Energy Procedia. 2012;15:84-90.

[208] Swanson R, Cudzinovic M, DeCeuster D, Desai V, Jürgens J, Kaminar N, et al. The surface polarization effect in high-efficiency silicon solar cells. In: 15th International Photovoltaic Science and Engineering Conference; 2005. Shanghai, China.

[209] Koch S, Nieschalk D, Berghold J, Wendlandt S, Krauter S, Grunow P. Potential Induced Degradation effects on crystalline silicon cells with various antireflective coatings. In: 27th European Photovoltaic Solar Energy Conference and Exhibition; 2012. Frankfurt am Main, Germany, pp. 1985-90.

[210] Sinha AK, Levinstein HJ, Smith TE, Quintana G, Haszko SE. Reactive Plasma Deposited Si-N Films for MOS-LSI Passivation. Journal of the Electrochemical Society. 1978;125:601-8.

[211] van Erven AJM, Bosch RCM, Bijker MD. Textured silicon surface passivation by high-rate expanding thermal plasma deposited SiN and thermal $\mathrm{SiO} 2 / \mathrm{SiN}$ stacks for crystalline silicon solar cells. Progress in Photovoltaics: Research and Applications. 2008;16:615-27. [212] Wan Y, Mclntosh KR, Thomson AF. Characterization of stress in amorphous silicon nitride and implications to c-Si surface passivation. In: 38th IEEE Photovoltaic Specialists Conference; 2012. Austin, TX, pp. 001139-43. [213] De Wolf I, Maes HE, Jones SK. Stress measurements in silicon devices through Raman spectroscopy: Bridging the gap between theory and experiment. Journal of Applied Physics. 1996;79:7148-56.

[214] Hong S, Weihs TP, Bravman JC, Nix WD. Measuring stiffnesses and residual stresses of silicon nitride thin films. JEM. 1990;19:903-9.

[215] Srikar VT, Spearing SM. A critical review of microscale mechanical testing methods used in the design of microelectromechanical systems. Experimental Mechanics. 2003;43:238-47.

[216] Hauser A, Spiegel M, Fath P, Bucher E. Influence of an ammonia activation prior to the PECVD SiN deposition on the solar cell performance. Solar Energy Materials and Solar Cells. 2003;75:357-62.

[217] Zhou S, Zhou C, Wang W, Tang Y, Chen J, Yan B, et al. Experimental study on the elimination of over-plating problems in industrial manufacturing of large-area acidic-textured laser-doped multi-crystalline solar cells. Solar Energy Materials and Solar Cells. 2013;108:44-9.

[218] Saint-Cast P, Tanay F, Alemán M, Reichel C, Bartsch J, Hofmann M, et al. Relevant pinhole characterisation methods for dielectric layers for silicon solar cells. In: 24th European Photovoltaic Solar Energy Conference and Exhibition; 2009. Hamburg, Germany, pp. 2084-7.

[219] Sinton RA, Cuevas A. Contactless determination of current-voltage characteristics and minority carrier lifetimes in semiconductors from quasisteady-state photoconductance data. Applied Physics Letters. 1996;69:2510-2. [220] Giesecke JA, Kasemann M, Schubert MC, Würfel P, Warta W. Separation of local bulk and surface recombination in crystalline silicon from luminescence 
reabsorption. Progress in Photovoltaics: Research and Applications. 2010;18:109.

[221] Wilson M, Edelman P, Lagowski J, Olibet S, Mihailetchi V. Improved QSS$\mu P C D$ measurement with quality of decay control: Correlation with steady-state carrier lifetime. Solar Energy Materials and Solar Cells. 2012;106:66-70.

[222] Hameiri Z, McIntosh K, Xu G. Evaluation of recombination processes using the local ideality factor of carrier lifetime measurements. Solar Energy Materials and Solar Cells. 2013;117:251-8.

[223] Loozen X, O'Sullivan BJ, Rothschild A, Vermang B, John J, Gordon I. On the choice of the test structure for the electrical characterization of dielectrics for silicon solar cells. physica status solidi (RRL) - Rapid Research Letters. 2010;4:362-4.

[224] Wilson M, Marinskiy D, Byelyayev A, D'Amico J, Findlay A, Jastrzebski L, et al. The Present Status and Recent Advancements in Corona-Kelvin Non-Contact Electrical Metrology of Dielectrics for IC-Manufacturing. ECS Transactions. 2006;3:3-24.

[225] Dingemans G, van de Sanden MCM, Kessels WMM. Influence of the Deposition Temperature on the c-Si Surface Passivation by Al2O3 Films Synthesized by ALD and PECVD. Electrochemical and Solid-State Letters. 2010;13:H76-H9.

[226] Bertoni MI, Hudelson S, Newman BK, Fenning DP, Dekkers HFW, Cornagliotti E, et al. Influence of defect type on hydrogen passivation efficacy in multicrystalline silicon solar cells. Progress in Photovoltaics: Research and Applications. 2011;19:187-91.

[227] Cohen DD, Siegele R, Chandra T, lonescu M, Richards B, Mclntosh K, et al. Hydrogen Measurements in $\mathrm{SiNx}: \mathrm{H} / \mathrm{Si}$ thin films by ERDA. Materials science forum. 2007;539:3551-6.

[228] Lanford WA, Rand MJ. The hydrogen content of plasma-deposited silicon nitride. Journal of Applied Physics. 1978;49:2473-7.

[229] King DL, Quintana MA, Kratochvil JA, Ellibee DE, Hansen BR. Photovoltaic module performance and durability following long-term field exposure. Progress in Photovoltaics: Research and Applications. 2000;8:241-56. [230] Ndiaye A, Charki A, Kobi A, Kébé CMF, Ndiaye PA, Sambou V. Degradations of silicon photovoltaic modules: A literature review. Solar Energy. 2013;96:140-51.

[231] Jordan DC, Kurtz SR. Photovoltaic Degradation Rates—an Analytical Review. Progress in Photovoltaics: Research and Applications. 2013;21:12-29. [232] Smith R, Jordan D, Kurtz S. Outdoor PV Module Degradation of CurrentVoltage Parameters. In: World Renewable Energy Forum 2012; 2012. Denver, Colorado.

[233] Serenelli L, Izzi M, De luliis S, Tucci M. Contact resistance determination of silver screen printable paste for back solderable contact on p-type c-Si solar cells. In: 26th European Photovoltaic Solar Energy Conference and Exhibition; 2011. Hamburg, Germany, pp. 1478-81. 
[234] Gatz S, Hannebauer H, Hesse R, Werner F, Schmidt A, Dullweber T, et al. $19.4 \%$-efficient large-area fully screen-printed silicon solar cells. physica status solidi (RRL) - Rapid Research Letters. 2011;5:147-9.

[235] Chen X, Church K, Yang H, Cooper IB, Rohatgi A. High Aspect Ratio Fine Gridline for Frontside Metallization of Industrial Silicon Solar Cells by Direct Printing. In: 26th European Photovoltaic Solar Energy Conference and Exhibition; 2011. Hamburg, Germany, pp. 1094-8.

[236] Hoffmann E, Roder TC, Conrad B, Kohler JR, Werner JH. Two Step Process for Optimized Laser Transferred Contacts. In: 26th European Photovoltaic Solar Energy Conference and Exhibition; 2011. Hamburg, Germany, pp. 1640-3.

[237] Mette A, Schetter C, Wissen D, Lust S, Glunz SW, Willeke G. Increasing the efficiency of screen-printed silicon solar cells by light-induced silver plating. In: 4th World Conference on Photovoltaic Energy Conversion; 2006. Waikoloa, Hawaii, pp. 1056-9.

[238] Ballif C, Huljic DM, Willeke G, Hessler-Wyser A. Silver thick-film contacts on highly doped $n$-type silicon emitters: Structural and electronic properties of the interface. Applied Physics Letters. 2003;82:1878-80.

[239] Lin C-H, Tsai S-Y, Hsu S-P, Hsieh M-H. Investigation of Ag-bulk/glassyphase/Si heterostructures of printed Ag contacts on crystalline Si solar cells.

Solar Energy Materials and Solar Cells. 2008;92:1011-5.

[240] Kulushich G, Zapf-Gottwick R, Nguyen VX, Werner JH. Role of phosphorus in contact formation on silicon solar cells. Phys Status Solidi-R. 2012;6:370-2. [241] Hilali MM, Rohatgi A. Development of screen-printed silicon solar cells with high fill factors on $100 \mathrm{ohm} / \mathrm{sq}$ emitters. IEEE Transactions on Electron Devices. 2004;51:948-55.

[242] Savin H, Yli-Koski M, Haarahiltunen A. Role of copper in light induced minority-carrier lifetime degradation of silicon. Applied Physics Letters.

2009;95:152111.

[243] Vazquez C, Laudisio G, Anderson R, Clark DA, Caballero LJ, Vazquez MA, et al. Improvement of Metallization Process in a Commercial Cz-Si Solar Cell. In: 26th European Photovoltaic Solar Energy Conference and Exhibition; 2011. Hamburg, Germany, pp. 1787-90.

[244] van der Heide ASH, Bultman JH, Hoornstra J, Schönecker A. Error diagnosis and optimisation of $\mathrm{C}-\mathrm{Si}$ solar cell processing using contact resistances determined with the Corescanner. Solar Energy Materials and Solar Cells. 2002;74:43-50.

[245] Kaminski A, Vandelle B, Fave A, Boyeaux JP, Nam LQ, Monna R, et al. Aluminium BSF in silicon solar cells. Solar Energy Materials and Solar Cells. 2002;72:373-9.

[246] Schneider A, Gerhards C, Fath P, Bucher E, Young RJS, Raby JA, et al. Bow reducing factors for thin screenprinted mc-Si solar cells with AI BSF. In: 29th IEEE Photovoltaic Specialists Conference; 2002. New Orleans, LA, pp. 336-9. [247] Popovich VA, Janssen M, Richardson IM, van Amstel T, Bennett IJ. Microstructure and Mechanical Properties of Aluminum Back Contact Layers. In: 
24th European Photovoltaic Solar Energy Conference and Exhibition; 2009. Hamburg, Germany, pp. 1453-8.

[248] Koentges M, Kunze I, Kajari-Schroeder S, Breitenmoser X, Bjorneklett B. Quantifying the risk of power loss in PV modules due to micro cracks. In: 25th European Photovoltaic Solar Energy Conference and Exhibition; 2010. Valencia, Spain, pp. 3745-52.

[249] Koentges M, Kunze I, Kajari-Schroeder S, Breitenmoser X, Bjorneklett B. Origin and consequences of (micro)-cracks in crystalline silicon solar modules. In: PV Module Reliability Workshop; 2011. Golden, Colorado. [250] Kohn C, Hug M, Kuebler R, Krappitz M, Kleer G. Increase of the Strength of Screen Printed Silicon Solar Cells by Post Treatments. In: 25th European Photovoltaic Solar Energy Converence and Exhibition; 2010. Valencia, Spain. [251] Kohn C, Kuebler R, Krappitz M, Kleer G, Reis I, Retzlaff M, et al. Influence of the metallization process on the strength of silicon solar cells. In: 24th European Photovoltaic Solar Energy Conference and Exhibition; 2009. Hamburg, Germany, pp. 1419-23.

[252] Moyer J, Zhang W, Kurtz E, Tavares R, Buzby D, Kleinbach S. The Role of Silver Contact Paste on Reliable Connectivity Systems. In: 25th European Photovoltaic Solar Energy Converence and Exhibition; 2010. Valencia, Spain, pp. 2624-30.

[253] Trautmann M, Mangold K, Hemsendorf M, Berge C, Probst C, Rueland E. Inline microcrack detection and mechanical stability of silicon wafers. In: 25th European Photovoltaic Solar Energy Conference and Exhibition; 2010. Valencia, Spain, pp. 2618-21.

[254] Wagner T, Schutz M, Ammon M. A new method for reliable crack detection in wafers and cells. In: 26th European Photovoltaic Solar Energy Conference and Exhibition; 2011. Hamburg, Germany, pp. 2078-81.

[255] Dastgheib-Shirazi A, Steyer M, Micard G, Wagner H, Altermatt PP, Hahn G. Relationships between Diffusion Parameters and Phosphorus Precipitation during the POCl3 Diffusion Process. Energy Procedia. 2013;38:254-62. [256] Breitenstein O, Rakotoniaina JP. Electrothermal simulation of a defect in a solar cell. Journal of Applied Physics. 2005;97:074905.

[257] Van der Heide ASH. Apparatus for localizing production errors in a photovoltaic element.2004.

[258] Carstensen J, Popkirov G, Bahr J, Föll H. CELLO: an advanced LBIC measurement technique for solar cell local characterization. Solar Energy Materials and Solar Cells. 2003;76:599-611.

[259] Isenberg J, Warta W. Realistic evaluation of power losses in solar cells by using thermographic methods. Journal of Applied Physics. 2004;95:5200-9. [260] Gabor AMR, M.; Montminy, S.; Alegria, L.; Bordonaro, C.; Woods, J.; Felton, L. Soldering Induced Damage to Thin Solar Cells and Detection of Cracked Cells in Modules. In: 21st European Photovoltaic Solar Energy Conference and Exhibition; 2006. Dresden, Germany.

[261] Trupke T, Pink E, Bardos RA, Abbott MD. Spatially resolved series resistance of silicon solar cells obtained from luminescence imaging. Applied Physics Letters. 2007;90:093506. 
[262] Hinken D, Ramspeck K, Bothe K, Fischer B, Brendel R. Series resistance imaging of solar cells by voltage dependent electroluminescence. Applied Physics Letters. 2007;91:182104.

[263] Kampwerth H, Trupke T, Weber JW, Augarten Y. Advanced luminescence based effective series resistance imaging of silicon solar cells. Applied Physics Letters. 2008;93:202102.

[264] Voland V, Hoyer U, Auer R, Salamon M, Uhlmann N, Brabec CJ. Defect recognition in crystalline silicon solar cells by X-ray tomosynthesis with layer resolution. Progress in Photovoltaics: Research and Applications. 2015;23:12430.

[265] Lauermann T, Annika Z, Scholz S, Hahn G, Terheiden B. The influence of contact geometry and sub-contact passivation on the performance of screenprinted Al2O3 passivated solar cells. In: 26th European Photovoltaic Solar Energy Conference and Exhibition; 2011. Hamburg, Germany, pp. 1137-43. [266] Reeves GK, Harrison HB. Obtaining the specific contact resistance from transmission line model measurements. IEEE Electron Device Letters. 1982;3:111-3.

[267] Li ZG, Liang L, Cheng LK. Electron microscopy study of front-side Ag contact in crystalline Si solar cells. Journal of Applied Physics. 2009;105:066102. [268] Uruena A, John J, Eyben P, Vanhaeren D, Werner T, Hantschel T, et al. Studying local aluminum back surface fields (AI-BSF) contacts through scanning spreading resistance microscopy (SSRM). In: 26th European Photovoltaic Solar Energy Conference and Exhibition; 2011. Hamburg, Germany, pp. 1530-3. 